Acta Crystallographica Section A

Foundations of

Crystallography

ISSN 0108-7673

\section{International Union of Crystallography Twenty-First General Assembly and International Congress of Crystallography, Osaka, Japan, 23-31 August 2008}

\section{Introduction and Opening Ceremony}

By invitation of the Science Council of Japan and the Japanese National Committee for Crystallography, the Twenty-First General Assembly and International Congress of Crystallography were held at the Osaka International Convention Centre, Osaka, Japan, 23-31 August 2008.

The meetings were attended by 2477 participants and 140 accompanying persons from 66 countries and territories.

The General Assembly and Congress were opened on the evening of 23 August at the Convention Centre. Welcoming Addresses were made by Professor T. Tsukihara (Chair of the Local Organizing Committee), Professor Y. Ohashi (President of the IUCr), Professor N. Doi (Vice-President of the Science Council of Japan), Professor R. Kuroda who read a Congratulatory Address by the Prime Minister of Japan (Y. Fukuda) and Mr T. Hashimoto (Governor of Osaka Prefecture). Professor B. R. Henry [Vice-President of ICSU (International Council for Science)] made a presentation describing the role of Union members in implementing the ICSU Strategic Plan. There followed a musical interlude. The Ewald Prize was then accepted by Dr D. Sayre, who presented the Ewald Award Lecture, introduced by Dr J. P. Glusker. The evening ended with a Welcoming Reception. The Opening Ceremony was preceded by the 60th Anniversary Ceremony of the IUCr, which was introduced by Professor Y. Ohashi (President of the IUCr). Professor H. Schenk described the Commemorative Special Issue of Section A of Acta Crystallographica, Professor W. L. Duax described the Commemorative Photographic Exhibition, Professor S. Sasaki (Chair of the National Committee for Crystallography of the Science Council of Japan) congratulated the IUCr on its anniversary and Professor A. Takenaka (President of the Crystallographic Society of Japan) presented gifts to the Past Presidents of the IUCr and to IUCr officers. Professor E. N. Baker then presented the Anniversary Lecture: 'Crystallography and the World Around Us', introduced by Professor I. Torriani (IUCr Vice-President).

\section{Twenty-First International Congress}

\subsection{Scientific programme}

Two Plenary Lectures, 36 Keynote Lectures, 98 Microsymposia, Open Commission Meetings and poster sessions were held. The abstracts in the published book of Collected Abstracts were prepared from electronic submissions and were also provided on a CD-ROM.

\subsection{Exhibitions}

A commercial exhibition comprising 58 companies and booksellers was organized.

\subsection{Social events}

Evening entertainments included the Awaji Puppet Theatre with Introductory Lecture, sessions on (1) Music, (2) the Future of Female Crystallographers and (3) Art and Crystallography, a banquet and a Closing Ceremony. Various excursions were also arranged.

\section{Minutes of the Twenty-First General Assembly}

These Minutes have been prepared by M. H. Dacombe, Executive Secretary, under the authority of S. Lidin, General Secretary and Treasurer of the IUCr and Secretary of the General Assembly.

\subsection{Introduction and list of delegates}

Sessions of the General Assembly were held on the evenings of Sunday 24 August, Monday 25 August and Thursday 28 August. It was not found necessary to meet on Friday 29 August, as originally planned. The following attendance list gives the names of official delegates appointed by the Adhering Bodies and the alternates who substituted at one or more sessions. Dates of attendance are given in parentheses for those who were not present at every session. The names are listed by the countries to which the respective Adhering Bodies belong, and the number of votes of the Adhering Body is given in parentheses after the name of the country. The names of the Chairs of the delegations are given in bold where they are known; those of alternates are marked by an asterisk. The Category of Adherence for India was increased to 3 at the first session. There were no delegates from Chile, Greece, Slovenia and Venezuela.

Argentina (1): R. Baggio

Australia (3): J. M. Guss, J. Martin, S. W. Wilkins

Austria (1): F. Belaj

Belgium (2): L. Van Meervelt, J. Wouters

Brazil (1): M. Fantini

Canada (3): L. T. J. Delbaere, J. Schrag, P. Whitfield

China, People's Republic (4): E. Brostromer* (24 and 25 August),

L.-F. Li, Z. Liu* (25 August), S.-X. Lu (28 August), X.-D. Su,

N. Yang (24 and 28 August)

China, The Academy of Sciences Located in Taipei (2): S. L. Chang, C. Hsiao

Croatia (1): B. Grzeta

Czech/Slovak Republics (2): R. Kuzel, P. Mikulik

Denmark (1): G. R. Andersen

Egypt (1): K. El Sayed

Finland (1): K. J. Hämäläinen

France (4): J. Cherfils, J.-C. Daran, J.-L. Hodeau, O. Perez

Germany (4): K. Diederichs, W. Neumann, U. Pietsch, M. Weiss

Hungary (1): G. Faigel

India (3): K. Byrappa, P. Chakrabarti, A. Nangia

Israel (1): N. Adir 
Italy (3): C. Mealli, R. Oberti, R. Spagna

Japan (4): Y. Amemiya, S. Sasaski, Y. Sugawara, S. Wakatsuki

Korea (1): H. M. Park* (28 August), S. W. Suh (24 and 25 August)

Mexico (1): L. Bucio

The Netherlands (2): R. de Gelder, A. L. Spek

New Zealand (1): J. Simpson

Norway (1): C. H. Görbitz

Poland (1): A. Pietraszko (24 and 28 August), M. Wołcyrz (25 August)

Portugal (1): M. Duarte (24 August), J. Ferreira da Silva* (28 August)

Regional Committee: Algeria/Latvia/Morocco/Tunisia/Turkey/

Ukraine (1): A. Thalal

Regional Committee: Bangladesh/Malaysia/Singapore/Thailand/ Vietnam (1): T. White

Russia (5): M. Antipin, A. Avilov, I. Bashkin, E. Boldyreva, N. Bolotina

Serbia (1): P. Vuli

Slovenia (1): I. Leban (24 and 25 August)

South Africa (2): S. E. Bourne, D. G. Billing

Spain (3): S. García-Granda, E. Gutiérrez-Puebla, F. J. Lahoz

Sweden (2): E. Sauer-Eriksson (25 and 28 August)

Switzerland (2): M. Schiltz, W. Steurer

UK (5): A. J. Blake, H. R. Powell, P. R. Raithby, G. M. Rosair, C. C. Wilson.

USA (5): J. A. Kaduk, J. Flippen-Anderson, K. A. Kantardjieff, B. H. Toby, V. Young

Present as members of the Executive Committee: Y. Ohashi (President), I. Torriani (Vice-President), S. Lidin (General Secretary and Treasurer), W. L. Duax (Immediate Past President), P. Colman, G. R. Desiraju, C. J. Gilmore, G. Heger, C. Lecomte, D. Viterbo (Ordinary Members). M. H. Dacombe was in attendance as Executive Secretary.

\subsection{First Session, Sunday 24 August 2008, 7:05 p.m.}

(1) Introductory remarks by the President

Professor Y. Ohashi welcomed the delegates and observers, including Professor B. R. Henry representing the International Council for Science (ICSU).

(2) Procedural matters

In order to verify the list of voting delegates, the President requested the General Secretary to read this list, and asked delegates to indicate their presence when their names were called. (This procedure was repeated at the beginning of each session of the General Assembly.)

Two delegates, one from Finland and one from Taipei, were appointed to act as tellers when votes had to be counted during the Assembly.

(3) Approval of Agenda

The Agenda and Appendices to the Agenda had been distributed to Secretaries of National Committees in May 2008. The Agenda were approved.

(4) Amendments to Statutes and By-Laws affecting adherence to the Union

The President reported that there were no proposals.

(5) Applications for membership of the Union

Applications for membership of the IUCr had been received from the Regional Committee of Crystallographers from Algeria, Latvia, Morocco, Tunisia, Turkey and Ukraine (Category I) and the Regional Committee of Crystallographers from Bangladesh, Malaysia, Singapore, Thailand and Vietnam (Category I). The Executive Committee recommended to the General Assembly that these be accepted. The applications were accepted by the General Assembly and the delegates took their seats.

(6) Withdrawal of Adhering Bodies

The President reported that the Adhering Body for Venezuela was more than four years in arrears and its membership had been suspended automatically in accordance with Statute 9.6. The General Assembly confirmed the withdrawal of the Adhering Body for Venezuela.

(7) Changes in names of Adhering Bodies

The change in name of the Adhering Body of Korea (to the Korean Crystallographic Association) was accepted by the General Assembly.

(8) Changes in Category of Adherence of Adhering Bodies

The change in Category of Adherence of the Adhering Body for India (the Indian National Science Academy) from Category II to Category III was approved by the General Assembly.

(9) Approval of Minutes of Twentieth General Assembly

The Minutes, which were contained in the published Report of the Twentieth General Assembly and International Congress of Crystallography [Acta Cryst. (2006), A62, 465-526], were approved and two copies were signed by the President and the General Secretary, in accordance with By-Law 1.13. There were no matters arising from the Minutes.

(10) Amendments to Statutes and By-Laws not affecting adherence to the Union

The United States National Committee for Crystallography had proposed changes to the Statutes and By-Laws. Dr J. A. Kaduk outlined the case for making the changes, which were intended to ensure maximum diversity in the membership of the Executive Committee and to emphasize the role of the General Assembly as the forum at which crystallographers directed the work of the Union. The President referred to the circular he had sent to the National Committees in which he had addressed the proposed changes. The General Secretary then reported on the votes of the Executive Committee when they had considered each proposal.

The first proposal was that the Executive Committee should contain one representative from each of the Regional Associates. Professor J. M. Guss commented that the make-up of the three Regional Associates was different with a mixture of membership categories (for example, AsCA had only countries as members). Professor J. R. Helliwell supported the principle of greater connectivity between the IUCr and the Regional Associates but thought that a first step could be to strengthen the links that already existed through the IUCr Representatives to the Regional Associates. These Representatives generally attended the council meetings of the Regional Associates. The first proposal was not approved by the General Assembly.

The second proposal was intended to emphasize that it was the right of any crystallographer to speak at the General Assembly, and not a privilege granted by the Chair (though it was up to the Chair to manage the discussion). [At present, interested persons (not the delegates) may participate in discussions at a General Assembly only if specifically invited or permitted to do so by the Chair.] Professor $\mathrm{H}$. Schenk commented that he could recall no occasion when a crystallographer had been denied the opportunity to contribute to discussions at a General Assembly. The proposal was not approved by the General Assembly.

The third proposal was that at least two nominees should be presented to the General Assembly for consideration as candidates for election of officers of the Union. The proposal was not approved by the General Assembly. 


\section{(11) Report of Executive Committee}

The Report of the Executive Committee on the activities of the IUCr since the Twentieth General Assembly had been submitted to the National Committees and the Commissions in May 2008, in accordance with Statute 6.8, and follows these Minutes as Appendix A1. The President particularly thanked the Science Council of Japan and the Japanese National Committee for Crystallography for the invitation to hold the present Congress in Osaka, and Professor Y. Fujii (Chair of the International Programme Committee) and Professors T. Tsukihara and Y. Kai (Chair and Secretary of the Local Organizing Committee) for their hard work. The Report was accepted without discussion.

\section{(12) Financial Report}

A Financial Report, covering the calendar years 2005, 2006 and 2007, had been prepared by the Treasurer and had been submitted to the National Committees and the Commissions in May 2008. The Report follows these Minutes as Appendix A2.

The Treasurer reported the composition of the Finance Committee and noted the sad loss of Dr S. G. Fleet who had been the IUCr investment adviser for many years. The Union operated in three currencies: member subscriptions were largely paid in CHF, twothirds of the investments, income and most expenses were in GBP, and one-third of the investments and some expenses were in USD.

The Union had operated with a profit in 2007, following small deficits in 2005 and 2006. The intention was to make a small profit so that the services provided to crystallographers could be maintained and developed.

The main activity of the Union was the production of its journals and books. Fewer journal pages had been published in 2007 because a new shorter format of papers for Acta Crystallographica Section E had been introduced. The distinction between Section $\mathrm{C}$ and Section $\mathrm{E}$ was now much clearer. The price per page had decreased over the triennium. International Tables had become available online in 2007.

The Treasurer reported that the investments had become less exposed to market fluctuations over the triennium with the present split $53 \%$ equities $/ 47 \%$ bonds and cash. This compared with a split of $81 \%$ equities $/ 19 \%$ bonds and cash in 2002 . As the Union was operating with a small profit there was no need to cash investments during the present market downturn, so losses 'on paper' would not be realized.

The Treasurer forecast that the coming triennium would see an increase in online-only pages, especially following the successful launch of Section E as an open-access-only journal. The future of the other journals will need to be considered carefully.

Finally, the Treasurer noted that the IUCr had received the prestigious ALPSP (Association of Learned and Professional Society Publishers) Award for Publishing Innovation for Data Exchange, Quality Assurance and Integrated Data Publication (CIF and checkCIF).

The continued success of the publishing operation was due to the dedicated work of the competent and productive staff.

The General Assembly thanked the Treasurer for his report with applause.

The President thanked the Finance Committee for its work.

(13) Ewald Prize

Details of the Prize, awarded to Dr D. Sayre at the Opening Ceremony, and the citation are given in Appendix A3.

The Selection Committee was thanked for its work.

(14) Commission on Journals

The Report of the Commission on Journals had been distributed to the National Committees and the Commissions in May 2008 and is reprinted in Appendix A4.
The Chair (G. Kostorz) highlighted the fact that there were more than 150 Co-editors who deserved the thanks of the crystallographic community. The President noted that the journals were in a very healthy state when many other journals published elsewhere were suffering and thanked the Commission.

The General Assembly accepted the Report with applause.

(15) Commission on International Tables

The Report by the Chair of the Commission on International Tables had been distributed to the National Committees and the Commissions in May 2008 and is reprinted in Appendix A4.

The Chair (Professor H. Fuess) particularly thanked Professor Th. Hahn for his work on International Tables over many years. Additionally, Professor U. Shmueli had recently completed his work as Editor of the third edition of Volume B and had now retired. Both Editors were thanked with applause by the General Assembly.

The President noted that there were now eight Volumes in the Series and thanked the Commission for its work.

The Report was accepted with applause.

(16) Committee on Electronic Publishing, Dissemination and Storage of Information

The Report of the Committee on Electronic Publishing, Dissemination and Storage of Information had been distributed to the National Committees and the Commissions in May 2008 and is reprinted in Appendix A5.

The President noted that the Chair had retired at the Florence Congress and that so far it had not proved possible to find a replacement.

(17) Committee for the Maintenance of the CIF Standard (COMCIFS)

The Report of the Chair of the Committee for the Maintenance of the CIF Standard (COMCIFS) had been distributed to the National Committees and the Commissions in May 2008 and is reprinted in Appendix A6.

The President thanked the Chair for his great contribution to the IUCr.

(18) Committee on Crystallographic Databases

The Report of the Chair of the Committee on Crystallographic Databases had been distributed to the National Committees and the Commissions in May 2008 and is reprinted in Appendix A7.

(19) IUCr Newsletter

The Report of the Editors of the IUCr Newsletter had been distributed to the National Committees and the Commissions in May 2008 and is reprinted in Appendix A8.

J. L. Flippen-Anderson (an Editor of the Newsletter) particularly thanked Patti Coley for her work on producing the Newsletter.

The President thanked the Editors for their work.

(20) IUCr/Oxford University Press Book Series

The Report of the Chair had been distributed to the National Committees and the Commissions in May 2008 and is reprinted in Appendix A9.

The Chair (H. Schenk) noted that seven proposals were under consideration.

(21) Non-publishing Commissions

The reports of the Commissions on their activities since the Twentieth General Assembly had been distributed to the National Committees and the Commissions in May 2008. The reports are reprinted in Appendix A4.

The President reported that the Executive Committee had held indepth discussions with the Chairs.

The reports were taken as read, but the Chair of each Commission, or his or her alternate, accepted the invitation of the President to 
say a few words about future developments and to answer any questions.

The President thanked all the Chairs for their work.

The General Assembly accepted all the reports that had been received on the activities of the non-publishing Commissions.

The President then adjourned the session at 8:45 p.m.

\subsection{Second Session, Monday 25 August 2008, 7:05 p.m.}

\section{(22) Proposal for new Commission}

The President reported that a formal proposal had been received to establish a Commission on Crystallography in Art and Cultural Heritage. The Executive Committee had considered the terms of reference and proposed membership and recommended that the Commission should be established.

Professor E. Dooryhée presented the proposal to establish the Commission.

The General Assembly approved the formation of a Commission on Crystallography in Art and Cultural Heritage.

(23) Review of existing Commissions

The President reported that the Executive Committee was considering a proposal to change the name of one of the Commissions and this item would be returned to later (see Minute 31).

(24) Determination of number of elected members of each Commission

In accordance with Statute 5.10( $d)$, the Assembly had to determine the number of persons to be elected on the Commissions until the Twenty-Second General Assembly; these numbers did not include Chairs, Co-editors or ex officio members. The numbers of elected members approved by the General Assembly (Chairs not included) are set out below:

\section{Commission on Journals}

2. Commission on International Tables

3. Commission on Aperiodic Crystals

4. Commission on Biological Macromolecules

5. Commission on Charge, Spin and Momentum Densities

6. Commission on Crystal Growth and Characterization of Materials

7. Commission on Crystallographic Computing

8. Commission on Crystallographic Nomenclature

9. Commission on Crystallographic Teaching

10. Commission on Crystallography in Art and Cultural Heritage

11. Commission on Electron Crystallography

12. Commission on High Pressure

13. Commission on Inorganic and Mineral Structures

14. Commission on Mathematical and Theoretical Crystallography

15. Commission on Neutron Scattering

16. Commission on Powder Diffraction

17. Commission on Small-Angle Scattering

18. Commission on Structural Chemistry

19. Commission on Synchrotron Radiation

20. Commission on XAFS

(25) Reports of Representatives on Regional and Scientific Associates

In accordance with Statute 8.5, the reports of the Representatives on Regional and Scientific Associates had been circulated with the
Agenda papers in May 2008. These reports are reprinted as Appendix A11.

J. A. Kaduk reported that the 2007 Public Report of the ICDD was available on the ICDD web site.

H. Dabkowska noted that collaboration with the IOCG was good. All the reports were accepted.

(26) Reports of Representatives on bodies not belonging to the Union

In accordance with Statute 8.5, the reports of the Representatives had been circulated with the Agenda papers in May 2008. These reports are reprinted as Appendix A12.

W. L. Duax apologized that his report as IUCr Representative to ICSU had not been submitted. He had attended ICSU's 28th General Assembly in Suzhou, People's Republic of China, in 2005 and reported on the work of the IUCr and its Regional Associates.

B. McMahon reported that interactions with CODATA were very beneficial for the IUCr and that working relations with the ICSTI Representative were good.

H. Dabkowska reported that she had attended COSPAR's meeting in Montreal in June 2008. Interactions were not strong but it was good to maintain contact for possible developments in the future.

J. R. Helliwell agreed that interactions with the CODATA Representative were beneficial. The linking of information with the primary data had been important, as reflected in the winning of the ALPSP Award.

All the reports were accepted.

(27) Sponsorship of meetings: Sub-committee on the Union Calendar

The Report of the Chair had been distributed to the National Committees and the Commissions in May 2008 and is reprinted in Appendix A10.

The Chair (D. Viterbo) noted that during the last triennium 65 applications for support had been received and only four had been rejected. He thanked the members of the Committee for their work. He also reported that the scope of the Committee was being extended so that more local meetings in developing countries could be supported. Such meetings would not need to be international in character and need not be conducted in the English language. Greater use of the Visiting Professorship Scheme would also be encouraged.

The Committee was thanked with applause for its hard work and major contribution to the community.

(28) Confirmation of date and place of Twenty-Second General Assembly

The invitation from the Spanish Committee for Crystallography on behalf of the Subdirección General de Programas y Organismos Internacionales, Ministerio Educación y Ciencia to hold the Congress and General Assembly in Madrid, Spain, 22-29 August 2011, which had been preliminarily accepted in 2005, was formally accepted.

(29) Preliminary consideration of date and place of Twenty-Third General Assembly

In accordance with By-Law 1.3, the General Assembly could give preliminary consideration to the place of the next but one General Assembly, namely the Twenty-Third General Assembly to be held in 2014. The President announced that invitations had been received from the National Research Council of Canada to hold the Congress in Montreal, Canada, from the Regional Committee of the Czech and Slovak Crystallographic Association to hold the Congress in Prague, Czech Republic, and from the Indian National Science Academy and the Indian Crystallographic Association to hold the Congress in Hyderabad, India. He reported that the Executive Committee had considered the applications and found them to be in order. L. T. J. 
Delbaere presented the formal invitation for Canada, R. Kuzel presented the formal invitation for the Czech and Slovak Republics and A. Nangia presented the formal invitation for India. A decision on which invitation to accept was delayed until the next session to give the delegates time to consider the choice [see Minute (35)].

The President adjourned the session at 9:15 p.m.

\subsection{Third Session, Thursday 28 August 2008, 7:05 p.m.}

(30) Confirmation of appointments of Editors of publications of the Union

In accordance with Statute 7.1, the initial appointments and the reappointments of the Editors of the publications of the IUCr were made by the Executive Committee and were subject to confirmation by the General Assembly.

The Assembly unanimously confirmed the following appointments and reappointments for the period of three years:

Editor-in-Chief of IUCr journals: G. Kostorz (Switzerland)

Editor of Section A of Acta Crystallographica: D. Schwarzenbach (Switzerland)

Editor of Section B of Acta Crystallographica: C. P. Brock (USA)

Editor of Section $C$ of Acta Crystallographica: A. Linden (Switzerland)

Editors of Section D of Acta Crystallographica: E. N. Baker (New Zealand) and Z. Dauter (USA)

Editors of Section E of Acta Crystallographica: W. T. A. Harrison

(UK), J. Simpson (New Zealand) and M. Weil (Austria)

Editors of Section F of Acta Crystallographica: H. M. Einspahr (USA) and M. S. Weiss (Germany)

Editor of Journal of Applied Crystallography: A. Pyzalla (Germany)

Editors of Journal of Synchrotron Radiation: G. Ice (USA), А. Kvick (Sweden) and T. Ohta (Japan)

General Editor of International Tables and Editor of Volume C:

H. Fuess (Germany)

Editor of Volume A: M. Aroyo (Spain)

Editor of Volume B (Third Edition): U. Shmueli (Israel) [Editor of

Fourth Edition to be appointed]

Editor of Volume D: A. Authier (France)

Editors of Volume E: V. Kopský (Czech Republic) and D. B. Litvin (USA)

Editors of Volume F: M. G. Rossmann (USA), E. Arnold (USA) and D. M. Himmel (USA)

Editors of Volume G: S. R. Hall (Australia) and B. McMahon (UK)

Editors of Volume A1: H. Wondratschek (Germany) and U. Müller (Germany)

(31) Review of existing Commissions (continued)

The President reported that the Executive Committee and the Commission on Electron Diffraction proposed that the Commission should be renamed Commission on Electron Crystallography better to reflect its scope.

The General Assembly approved the change of name to Commission on Electron Crystallography.

(32) Determination of general policy and timetable for period to Twenty-Second General Assembly

There were no comments on this item.

(33) Preliminary consideration of activities for period 2011-2014

There were no comments on this item.
(34) Budget estimates for period to Twenty-Second General Assembly: determination of unit contribution

These budget estimates had been distributed with the Agenda papers and are printed as Appendix A13 to these Minutes.

The General Assembly accepted the budget estimates and approved the recommendation of the Executive Committee to continue the unit contribution unchanged, at CHF 1000, for the years 2009, 2010 and 2011.

(35) Preliminary consideration of date and place of Twenty-Third General Assembly (continued)

The General Assembly gave preliminary acceptance to the invitation to hold the Twenty-Third General Assembly in 2014 in Canada.

The President, as Chair of the General Assembly, ruled that the actual votes cast should remain secret.

(36) Election of Chairs and members of Commissions

The nominations made by the Executive Committee for the Chairs and members of Commissions, after consultation with the Commissions through their Chairs, had been notified to delegates.

Since no other nominations had been made by the delegates, the persons recommended by the Executive Committee were considered elected.

The current full memberships of all the Commissions, including the ex officio members, together with the addresses of the Chairs, are given as Appendix C.

(37) Election of Representatives on bodies not belonging to the Union and on Regional and Scientific Associates

The nominations made by the Executive Committee for those Representatives to be elected by the General Assembly had been notified to delegates. As no other nominations were made, these persons were considered elected.

The names and addresses of the Representatives of the Union, including those appointed ex officio, are given in Appendix C.

(38) Election of Officers of the Union

The nominations made by the Executive Committee for Officers of the Union had been included in the Agenda papers distributed in May 2008. C. J. Gilmore (UK) and S. Larsen (France) were nominated for President, P. Colman (Australia) for Vice-President and S. Lidin (Sweden) for General Secretary and Treasurer. Nine nominations were made for the three six-year vacancies for Ordinary Members: E. Boldyreva (Russia), C. W. Carter (USA), V. Cody (USA), L. T. J. Delbaere (Canada), K. El Sayed (Egypt), C. Lecomte (France), J. M. Perez-Mato (Spain), Xiao-Dong Su (People's Republic of China) and Yu Wang (Taipei). The same nine nominations were made for the one or two possible three-year vacancies for an Ordinary Member. As there was only one candidate for VicePresident and one candidate for General Secretary and Treasurer these candidates were considered elected. The General Assembly decided that sufficient biographic data for the nominees for President had been provided and that there was no need for the two candidates to make presentations. Elections for the President, three Ordinary Members for the normal six-year term and one vacancy for a threeyear term (to complete the term of P. Colman following his election as Vice-President) were held by secret ballot. The following nominees were elected:

President

S. Larsen (France)

Vice-President

P. Colman (Australia)

General Secretary and Treasurer

S. Lidin (Sweden)

Ordinary Members (six years)

E. Boldyreva (Russia) 


\author{
L. T. J. Delbaere (Canada) \\ J. M. Perez-Mato (Spain) \\ Ordinary Member (three years) \\ C. Lecomte (France)
}

The President congratulated the new members of the Executive Committee and individually thanked those who would be retiring.

The newly elected President thanked the General Assembly for the opportunity to work for the Union.

(39) Any other business

As there was no other business and therefore no need for the final session of the General Assembly that had been scheduled for Friday 29 August, the President declared the Twenty-First General Assembly closed at 10:00 p.m.

\section{Closing Ceremony, Saturday 30 August 2008}

Y. Kai (Secretary of the Local Organizing Committee) presented a mini-review of the Congress. Poster Prizes were presented by Y. Fujii (Chair of the International Programme Committee).

Y. Ohashi, the present President, on behalf of the IUCr and the attendees congratulated the organizers for making the Congress such a success and thanked the members of the International Programme Committee and staff for such a successful Congress. I. Torriani, the present Vice-President, and S. Lidin on behalf of the Executive Committee and the attendees thanked the Local Organizing Committee for a well organized Congress. Y. Ohashi thanked the Executive Committee and Chester staff and introduced S. Larsen, the newly elected President. She thanked the hosts for their hospitality and a well run Congress with an excellent programme. She commented that it had also been a good opportunity to learn about Japan and its culture. She thanked the retiring members of the Executive Committee and introduced the new members. She was looking forward to the next 60 years and the launch of the IUCr's new web site was a good start. The Twenty-First General Assembly and Congress was then declared closed.

\section{APPENDIX $A$ \\ Appendices to the Agenda of the Twenty-First General Assembly}

\section{A1. Report of the Executive Committee}

A1.1. Executive Committee and Finance Committee meetings. The Executive Committee met in Florence in August 2005 before and during the General Assembly, in Leuven, Belgium, in August 2006 at the time of the Twenty-Third European Crystallographic Meeting and in Salt Lake City, USA, in July 2007 at the time of the American Crystallographic Association Meeting. The Finance Committee met in March 2005, August 2005, March 2006, August 2006, March 2007 and July 2007, to prepare its advice and recommendations on finances, establishment and staff matters.

The most important items of business dealt with by the Executive Committee during the triennium at these meetings, and in postal and e-mail ballots between meetings, were:

(1) editorial policy, pricing policy and subscription rates, consideration of appointment of new Editors for Acta Cryst. Sections C, E and $\mathrm{F}$ and Journal of Applied Crystallography, approval of appointments of Co-editors, electronic publishing, archival policy, Special
Issues, education papers, language improvement of submitted papers, open access, and other matters concerning the IUCr journals;

(2) approval of launch of Acta Cryst. Section E as a fully openaccess journal;

(3) review of contract with Wiley-Blackwell (formerly BlackwellMunksgaard);

(4) approval of audited accounts;

(5) amendments to Statutes and By-Laws;

(6) review of proposed revision to ICSU dues structure;

(7) General Fund estimates and level of unit contribution, status of membership subscriptions;

(8) Joint National or Regional Committees for Crystallography;

(9) investment policy;

(10) funding and uses of Publications and Journals Development Fund, Research and Education Fund and President's Fund;

(11) closure of Book Fund and establishment of General Assembly and Congress Fund;

(12) revision of guidelines for the Sub-committee on the Union Calendar, sponsorship and financial support for meetings, young scientists' support, revision of internal guidelines;

(13) Journal Grants Fund;

(14) cooperation with databases, open-access databases, policy concerning availability of deposited CIFs;

(15) progress with Volumes A, A1, B, C, D, E, F and G of International Tables and development of associated software, appointment of new Editor for Volume A, consideration of suggestions for new volumes, development work to make International Tables available online;

(16) review of contract with Springer (formerly Kluwer);

(17) IUCr Newsletter, World Directory of Crystallographers;

(18) promotional activities, 60th anniversary of the IUCr;

(19) appointment of the Selection Committee for eighth Ewald Prize;

(20) sponsorship of other prizes;

(21) discussion of arrangements for Osaka Congress;

(22) approval of membership of Programme Committee for Osaka Congress;

(23) level of financial support for Osaka Congress;

(24) nominations and election procedures for Officers of the IUCr and for Chairs and members of Commissions, proposals from National Committees for these positions.

Other items dealt with in this way were:

(25) implementation of the Crystallographic Information File (CIF) for Acta Crystallographica and other uses of CIF, work of Committee for the Maintenance of the CIF Standard (COMCIFS), provision of checking services to other publishers, chemical information, support for mmCIF project and CIF handling software;

(26) approval of publications, jointly with Oxford University Press, in the IUCr/OUP Book Series;

(27) crystallography in Africa;

(28) Visiting Professorship scheme;

(29) review of activities of Commissions;

(30) proposal for new Commission;

(31) review of activities of Regional Associates;

(32) review of the reports of IUCr Representatives on other bodies;

(33) relations with other Scientific Unions;

(34) review of reports of the Committee on Crystallographic Databases.

Items concerning the Chester office were:

(35) staffing requirements in the IUCr office in Chester; 
(36) adoption of new pension scheme;

(37) risk analysis;

(38) upgrading office technology in the IUCr office in Chester, provision of internet services.

A1.2. Publications. The subscription prices of Acta Crystallographica, the Journal of Applied Crystallography and the Journal of Synchrotron Radiation were increased each year during the triennium.

The total annual number of pages published in 2005, 2006 and 2007 are shown in Table 1.

In 2005, Acta Cryst. Section D contained the Proceedings of ICCBM-10, Beijing, People's Republic of China, and the Proceedings of the 2005 CCP4 Study Weekend on Data Collection and Analysis. In 2006, Acta Cryst. Section D contained the Proceedings of the 2006 CCP4 Study Weekend on Crystallography of Complexes and papers presented at a SPINE (Structural Proteomics in Europe) meeting. In 2007, Acta Cryst. Section D contained the Proceedings of the 2007 CCP4 Study Weekend on Molecular Replacement and $J A C$ contained papers presented at SAS 2006, Kyoto, Japan. Various themed issues were also published during the triennium.

All the IUCr journals are available electronically through the Crystallography Journals Online service, including all back issues of the journals from 1948, and also through Blackwell Synergy.

The IUCr has two fully electronic journals available online only (Acta Crystallographica Section E: Structure Reports Online launched in 2001 and Acta Crystallographica Section F: Structural Biology and Crystallization Communications launched in 2005). From 1 January 2008 Section E has been a fully open-access journal. Section F is available free of charge to subscribers to Section D.

The IUCr home page on the web (http://www.iucr.org/) contains information in the following categories: The Union and its Components (including information on Adhering Bodies, Commissions, Regional Associates, Annual Reports, Congress Reports etc.); Journals, International Tables and Other Publications (including information on the titles, synopses, structural schemes and contents of the IUCr journals); and Services (including the World Database of Crystallographers and Crystallography News Online). The number of requests per day is typically of the order of 250000 from about 57500 unique hosts.

Full details on the publication of volumes of International Tables for Crystallography are given in the Triennial Report of this Commission (Appendix A4.2 to the Agenda).

The World Database of Crystallographers continues to undergo major development to provide increased functionality and to allow online amendments and additions to be made by individual crystallographers.

The IUCr Newsletter is distributed free of charge to 587 libraries and 17000 crystallographers and other interested individuals in 39 countries. J. L. Flippen-Anderson and W. L. Duax are the Editors with the editorial office at the Hauptman-Woodward Medical Research Institute at Buffalo, New York, USA, which also handles the distribution. A report on the $I U C r$ Newsletter is given in Appendix A8 to the Agenda.

The IUCr/Oxford University Press Book Series continues to be successful. Details are given in Appendix A9 to the Agenda.

A1.3. Sponsorship of meetings. The Sub-committee on the Union Calendar considers and advises the Executive Committee on requests for IUCr sponsorship and financial support of meetings. The Chair of the Sub-committee has been D. Viterbo in this triennium. A list of IUCr-sponsored meetings is given in Appendix A10 to the Agenda.
Table 1

Total annual number of pages published in IUCr journals.

\begin{tabular}{lrrr}
\hline & 2005 & 2006 & 2007 \\
\hline Acta Crystallographica Section A & 622 & 528 & 510 \\
Acta Crystallographica Section B & 730 & 1138 & 940 \\
Acta Crystallographica Section C & 1412 & 1450 & 1510 \\
Acta Crystallographica Section D & 1681 & 1571 & 1283 \\
Acta Crystallographica Section E & 7439 & 9843 & 8375 \\
Acta Crystallographica Section F & 1102 & 1300 & 1090 \\
Journal of Applied Crystallography & 1045 & 928 & 1895 \\
Journal of Synchrotron Radiation & 838 & $\underline{496}$ & 535 \\
\cline { 2 - 3 } & $\underline{14869}$ & $\underline{17254}$ & $\underline{16138}$ \\
\hline
\end{tabular}

Applications for sponsorship are considered if they are submitted at least nine months in advance of the date of the meeting. Applications will be considered by the Committee four times a year at the end of March, June, September and December. Applications for sponsorship should be timed accordingly. For example, for a meeting to be held in June an application should be submitted by September of the previous year at the latest.

Requests from satellite meetings must be submitted, and possible financial support requested, through the organizing committee of the main meeting.

Meetings (other than satellite meetings) scheduled to be held within two months before or after an IUCr Congress will not be considered for sponsorship. For any meetings scheduled to be held between two and three months before or after a Congress, the application for sponsorship requires the approval of the Chair of the Congress Programme Committee. Meetings (other than satellite meetings) scheduled to be held, in the respective region, within 15 days before or after a meeting of a Regional Associate (American Crystallographic Association, Asian Crystallographic Association, European Crystallographic Association) will not be considered for sponsorship. For any meetings scheduled to be held between 15 days and one month before or after a meeting of a Regional Associate, the application for sponsorship requires the approval of the Chair of the Regional Associate Programme Committee.

Active crystallographers should be involved in the organization of the conference and one or more sessions should deal with specific crystallographic topics. This does not automatically include any session on condensed matter physics, materials science or symmetry not related to crystallography. According to these criteria, all meetings organized by IUCr Commissions automatically qualify.

The IUCr continues to support and uphold ICSU's policy of non-discrimination and adheres to its decisions and procedures concerning free circulation of scientists. Organizers of any meeting seeking IUCr sponsorship and support must assure the Subcommittee on the Union Calendar that the authorities of the country in which the meeting is to take place guarantee free entrance of bona fide scientists from all countries.

General financial support can be given to all meetings except those that form part of a continuing series. However, this restriction does not apply to schools or to meetings regularly organized by IUCr Commissions.

Explicit support from the relevant IUCr Commission(s) is strongly recommended for any meeting.

Travel support for young scientists is available for all meetings (including schools). This money should not be used for waiver of registration fees. 
Table 2

Balance Sheet, Fund Accounts (Swiss Francs)

\begin{tabular}{|c|c|c|c|}
\hline & $\begin{array}{l}31 \text { December } \\
2004\end{array}$ & $\begin{array}{l}\text { Fluctuations } \\
\text { in rates of } \\
\text { exchange }\end{array}$ & $\begin{array}{l}31 \text { December } \\
2007\end{array}$ \\
\hline General Fund & 350512 & 140931 & 247595 \\
\hline President's Fund & 90155 & -1138 & 91583 \\
\hline Acta Crystallographica & 972497 & -55585 & 1486166 \\
\hline Journal of Applied Crystallography & 437378 & -10515 & 809248 \\
\hline Journal of Synchrotron Radiation & 74420 & -1005 & 62407 \\
\hline International Tables & 107795 & 3311 & -201479 \\
\hline Book Fund & -61288 & 36 & \\
\hline \multicolumn{4}{|l|}{ Publications and Journals } \\
\hline Development Fund & 759117 & -11056 & 901099 \\
\hline Research and Education Fund & 903618 & -12227 & 984254 \\
\hline Ewald Fund & 499285 & -6562 & 529974 \\
\hline Newsletter Fund & 118335 & -833 & 74015 \\
\hline \multicolumn{4}{|l|}{ General Assembly and } \\
\hline Congress Fund & & -407 & 34468 \\
\hline Total accumulated balance & 4251824 & 44950 & 5019330 \\
\hline Excluding exchange rates & 4550478 & & 5263361 \\
\hline
\end{tabular}

Table 3

Balance sheet, Assets (Swiss Francs).

\begin{tabular}{|c|c|c|c|c|}
\hline \multirow[b]{2}{*}{ Fixed assets } & \multicolumn{2}{|c|}{31 December 2004} & \multicolumn{2}{|c|}{31 December 2007} \\
\hline & & & & \\
\hline Tangible fixed assets & & 34536 & & 45456 \\
\hline \multicolumn{5}{|l|}{ Current assets } \\
\hline Stock & & 330864 & & 200701 \\
\hline \multicolumn{5}{|l|}{ Cash at banks and in hand } \\
\hline Current accounts & 3620 & & 28811 & \\
\hline Deposit and savings accounts & 78571 & & 637242 & \\
\hline Cash with Union officials & 17812 & 100003 & 17161 & 683214 \\
\hline Investments at market value & & 3642040 & & 3663796 \\
\hline $\begin{array}{l}\text { Debtors, accrued income } \\
\text { and payments in advance }\end{array}$ & & 450032 & & 878821 \\
\hline Subscriptions due & & 27485 & & 39000 \\
\hline Total current assets & & 4550424 & & 5465532 \\
\hline Deduct Creditors and accrued charges & & -333136 & & -491658 \\
\hline Net current assets & & 4217288 & & 4973874 \\
\hline Total assets & & 4251824 & & 5019330 \\
\hline
\end{tabular}

Consideration should be given as to whether the proposed meeting is appropriate in subject, form and timing with respect to other related meetings.

Except in special cases, IUCr funds should not be used to sponsor more than one event per year in the same location.

A1.4. Commissions of the IUCr. Each Commission Chair is required to provide a written triennial report to the General Assembly. These reports are included as Appendices to the Agenda. Financial assistance has again been offered to the Commission Chairs, to enable them to attend the General Assembly for the presentation and discussion of their reports and to meet the Executive Committee prior to the General Assembly.

A1.5. Regional Associates, Scientific Associates, and other bodies. The reports of the Representatives on these bodies are given as separate Appendices to the Agenda.

A1.6. IUCr staff. There have been some staff changes during the triennium. The present members of staff in the IUCr offices in Chester are: M. H. Dacombe (Executive Secretary), M. J. Robinson
(Administrative Assistant to the Executive Secretary), P. R. Strickland (Managing Editor), B. McMahon (Research and Development Officer), C. A. Moore (Editorial Systems Developer), A. S. Berry, G. F. Holmes, L. E. Jones, J. K. Bradshaw, S. Conway, A. Weight and N. J. Ashcroft (Technical Editors), S. Froggatt, S. Glynn, L. Stephenson and A. Hill (Assistant Technical Editors), M. A. Hoyland, D. Holden and D. Hoare (Systems Developers), L. Rathbone (Journals Production Assistant), C. Cook and C. Pear (Administrative Assistants) and A. J. Sharpe (Promotions Officer).

A1.7. Acknowledgements. On behalf of the IUCr, the Executive Committee wishes to express its deep gratitude to the Science Council of Japan and the Japanese National Committee for Crystallography for the invitation to hold the Twenty-First General Assembly and International Congress of Crystallography in Osaka. It particularly wishes to thank the Chair of the Programme Committee, Y. Fujii, and the Chair and Secretary of the Organizing Committee, T. Tsukihara and Y. Kai, respectively.

Finally, the Executive Committee wishes to thank all crystallographers who have assisted in the work of the IUCr in so many ways. This cooperation between crystallographers of different nationalities constitutes a most valuable aspect of the IUCr's activities.

\section{A2. Financial Report}

The accounts of the IUCr for the calendar years 2005 and 2006 have already been published [Acta Cryst. (2007), A63, 204-228; (2007), A63, 484-508]. The accounts for 2007 have been audited and will be published in due course in Acta Crystallographica Section A. Extracts from the full financial statements for the three years 2005, 2006 and 2007 are summarized in Tables 2-4. All amounts are expressed in Swiss Francs. The notations used in this report for the various currencies of the IUCr's activities are CHF $=$ Swiss Franc, GBP $=$ Pound Sterling, USD = US Dollar.

A2.1. General financial development. Table 2 shows a comparison of the fund accounts at the beginning and the end of the triennium. The total assets have increased by CHF 767506 from CHF 4251824 to CHF 5019 330, or $18 \%$, over the triennium. These figures include the fluctuations in exchange rates. If the exchange-rate fluctuations are disregarded, the total assets increased by CHF 712883 from CHF 4550478 to CHF 5263 361, or 16\%, over the triennium.

Table 3 shows the distribution of the assets. The great majority of the amounts under debtors and creditors have been settled since year end.

The total holding of investments at 31 December 2007 is CHF 3663796 at market value, as shown in Table 3, of which $35 \%$ is held by Merrill Lynch and $65 \%$ by Close Brothers. The IUCr bank accounts and short-term deposits are held with the Union Bank of Switzerland, the National Westminster Bank and Merrill Lynch, involving the currencies CHF, GBP and USD.

As an association incorporated in Switzerland, the IUCr is exempt from Swiss Federal and Geneva Cantonal Tax. Under the terms of the United Kingdom/Switzerland Double Taxation Agreement dated 8 December 1977, investment income arising within the UK under present circumstances is not subject to United Kingdom tax. Investment income received from other countries with which Switzerland has a Double Taxation Agreement is also exempt from tax. In October 1985, a recognition of tax-exempt status in the USA was received from the Internal Revenue Service, Department of the US Treasury.

Income and expenditure account. In order to present an overall picture of the state of the Union's affairs an income and expenditure 
Table 4

Income and expenditure.

2005

Income

Membership subscriptions

Sales

Journals, back numbers and single issues

Books

Open Access grant

Investment income

Income from investments

Bank interest

Profit on sale of investments

Other income

Royalties and copyright fees

Advertising income

STAR/CIF income

Total income

\section{Expenditure}

Journals

Publication costs

Editorial expenses

Technical editing

Subscription administration

Books

Publication costs

Editorial expenses

Technical editing

Newsletter

Publication costs

Editorial expenses

President's Fund, other grants and young scientists support

General Assembly costs

Ewald Prize

Committee meetings and expenses

Publications and journals development

General

Electronic publishing/editorial meetings

STAR/CIF

Promotion

Subscriptions paid

Visiting Professorships

Administration expenses

General Secretary and Treasurer, including honorarium 11377

$\begin{array}{ll}\text { Audit and accountancy charges } & 72169\end{array}$

Legal and professional fees $\quad 14549$

Travelling expenses 21811

Bank charges

Executive Secretary's office

Salaries and expenses

Travel expenses of IUCr Representatives on other bodies

Sponsorship of meetings

President's secretary

IUCr/FIZ Agreement

Bad debts

Depreciation
878389
363937
1507842
54303
37316
100350
142682
93268
123573

2423

358564

2459

$-17282$

6780

$-17061$

23894
850828
387435

72475

14942

886

022

248670
4908352

4908352

2804471

Income

Total expenditure

Excess/deficit of income over expenditure

Movement in market value of investments

Profit/loss on exchange rate fluctuations

Accumulated balance at 1 January

Accumulated balance at 31 December
2006

153000

19594

4266721
112602
85922
146333
18263
10270
12139
238659
-

960362

340726

1528058

59946

29733

25441

273038

280348

125424

132427

216841

113172

76189

40110

123345

801856
7382
1750

122329

2007

53000

152000

$\begin{array}{rrr} & 4881772 & \\ 4465245 & 396541 & \\ & 46684 & 5324997 \\ & 129916 & \\ & 34966 & \\ 174866 & 106728 & 271610 \\ & & \\ & 10206 & \\ 250798 & 264486 & 312683 \\ 5043909 & 37991 & 6061290\end{array}$

993593

372273

1764307

$2889092 \quad 62992$

3193165

58657

103317

205628

367602

159019

126809

285828

235986

150185

3892

83605

118966

636639

2292
37350

174884

65188

658734

16790

26100

851165

196392

898016

11609

1165

559

10216

84971

16741

18584

2307

132819

9829

83333

17807

8012

2389

121370

348306

8829

5148

$-19030$

357354

$\begin{array}{r}7601 \\ \hline\end{array}$

381062

231
29867

$-19147$

4000

396013

47774

28207

5760493

300797

$-142019$

$-244032$

5104584

5019330 account for the triennium is included as Table 4. This shows that following a period when the Union was operating at a loss owing to the investment in developing Crystallography Journals Online and International Tables Online, it is now operating with a small surplus of income over expenditure. The Union is predicted to continue to operate with a small surplus in the coming triennium.

A2.2. General Fund. This fund carries the income and expenditure related to the IUCr's administration and its regular scientific activities, other than publications. Table 5 shows a comparison of the budget and accounts for the triennium. The income has two main sources, the subscriptions from Adhering Bodies and the interest income from investments and bank accounts. The subscriptions from Adhering Bodies are based on the unit contribution, which was CHF 1000 for 2005, 2006 and 2007. The yield from investments is $8 \%$ higher than the budgeted amount by CHF 35 290. It should be noted that the investments are held primarily for long-term gain and now that the Union is operating with a surplus there should be no need to realize any of the investments to any significant extent. The proportion of the investments held as bonds and cash is about $40 \%$.

The administration expenses for the journals are calculated as $45 \%$ of the general administration costs of the IUCr, including the work of the Executive Secretary and his office and of the General Secretary 
international union of crystallography

Table 5

General Fund. Comparison of budget and accounts for the years 2005-2007 inclusive (Swiss Francs).

\begin{tabular}{|c|c|c|c|c|c|c|}
\hline & Budget & & Accounts & & Difference & \\
\hline \multicolumn{7}{|l|}{ Income } \\
\hline Subscriptions from Adhering Bodies & 465000 & & 458000 & & -7000 & \\
\hline $\begin{array}{l}\text { Yield from investments and bank accounts } \\
\text { (including profit/loss on disposal of investments) }\end{array}$ & 450000 & 915000 & 485290 & 943290 & 35290 & 28290 \\
\hline \multicolumn{7}{|l|}{ Expenditure } \\
\hline Administration (net) & 1011000 & & 1364867 & & 353867 & \\
\hline Subscriptions to ICSU/ICSU bodies & 33000 & & 28299 & & -4701 & \\
\hline Unfavourable variant from budget & & & & & & -238693 \\
\hline Estimated profit or deficit & & -518000 & & & & -518000 \\
\hline Deficit of income over expenditure & & & & -756693 & & -756693 \\
\hline
\end{tabular}

and Treasurer. The Executive Committee met annually, while the Finance Committee held two meetings in each of 2005, 2006 and 2007. The cost of these meetings varies depending on the location and the circumstances. These costs are included in the expenses of administrative meetings, together with the costs of the IUCr representatives on other bodies. The expenses of scientific meetings include the travel grants and other expenses for the Florence Congress in 2005, the cost of the 2007 meeting of the Programme Committee for the Osaka Congress, the expenses of the non-publishing Commissions, financial support to meetings and schools, and the IUCr/FIZ Agreement (which generated income in each year of the triennium). Proportions of the Research and Development and Promotion costs are charged to the General Fund. The financial support for young scientists attending meetings and schools is charged to the Research and Education Fund.

The unfavourable deviation from budget of CHF 238693 is almost entirely accounted for by the expenditure, which was $19 \%$ higher than predicted. This is largely attributed to the decision to assign development costs associated with the World Database of Crystallographers to the General Fund, following the closure of the Book Fund during the triennium (see below).

A2.3. President's Fund. This Fund is intended mainly for use in emergencies and under special or difficult circumstances, to help crystallographers from countries with currency problems to take part in the activities of the IUCr (especially in connection with the triennial Congresses).

A2.4. Journals Funds. The total number of pages printed for Acta, $J A C$ and $J S R$ were 14 869, 17254 and 16138 in 2005, 2006 and 2007, respectively. The Finance Committee and the Executive Committee have monitored the financial development for all journals very closely. The total number of subscriptions (including full and reduced-rate) decreased by about $5 \%$ p.a. over the triennium. The Crystallography Journals Online service has been available throughout the triennium and has been a great success. It is accessed by more than 57500 unique hosts and receives on average about 250000 requests per day. The online-only Acta Section E Structure Reports Online has been fully open access since the beginning of 2008. The online-only Acta Section F Structural Biology and Crystallization Communications was launched at the beginning of 2005 and is accessible free of charge to subscribers to Acta D. For further details see the Triennial Report by the Chair of the Commission on Journals (Appendix A4.1 to the Agenda).

A2.5. International Tables. The eight-volume International Tables series was completed in 2005 with the publication of Volume G,
Definition and Exchange of Crystallographic Data. International Tables Online was launched in 2007. For further details see the Triennial Report by the Chair of the Commission on International Tables (Appendix A4.2 to the Agenda).

A2.6. Book Fund. This Fund was closed during the triennium, the income and expenses involved with this low-turnover fund, mainly involving the IUCr/OUP Book Series and the World Database of Crystallographers, being transferred to the General Fund.

A2.7. Publications and Journals Development Fund. This Fund was established in 1984 and has been built up through transfers from other funds. In order to build up the fund further and in a systematic way, with the goal to make it self-supporting, in 1989 the Executive Committee decided to increase its balance by crediting it with interest currently calculated as $2.5 \%$ of the balance of the fund. During the triennium the major expenses have been related to the purchase of computer hardware and software, programming and development, promotion, Special Issue costs and projects related to the development of CIF-related products to facilitate deposition of data in crystallographic databases and submission to IUCr journals. It remains the policy of the Executive Committee to support and encourage the IUCr's highly qualified staff by supplying them with the best equipment. Also charged to this Fund are costs of maintaining Crystallography News Online, the crystallographic neXus project (for making CD-ROMs containing a wealth of crystallographic software, extracts of web sites etc. available free of charge to those in developing countries who do not have ready access to the web) and support for the Journal Grants Fund. As the programming and development activities underpin much of the Union's activity, in 1997 the Executive Committee decided that the associated costs should be assigned to the Journals Funds, the International Tables Fund and the General Fund. In 2001 this principle was extended to the promotion expenses.

A2.8. Research and Education Fund. The fund was also established in 1984 and, like the Publication and Journals Development Fund, has been built up through transfers from other funds. This fund is currently increased by $2.5 \%$ p.a., taken from the interest income. CHF 427420 was given as young scientists' support during the triennium. Other expenditure involved the Visiting Professorship Programme and a project to support a $\mathrm{PhD}$ student as part of the Crystallography in Africa initiative.

A2.9. Ewald Fund. The interest on the capital is intended to cover the costs of the Prize. It is calculated as $2.5 \%$ of the balance in the fund, and is taken from the total annual interest income received from the IUCr's investments, in the same way as for the interest 
credited to the Publications and Journals Development Fund and to the Research and Education Fund. The balance of the interest from the investments is credited to the General Fund. An additional CHF 40000 has been transferred to the fund during the triennium.

A2.10. Newsletter Fund. The fund was established in 1994 following the successful launch of the IUCr Newsletter in 1993. The IUCr Newsletter is currently distributed free of charge to 587 libraries and 17000 crystallographers and other interested individuals in 39 countries. The costs to the IUCr were CHF 28273 in 2005, CHF 82404 in 2006 and CHF 77810 in 2007.

A2.11. General Assembly and Congress Fund. The fund was established in 2007 so that the costs associated with the General Assembly and Congress could be spread over the triennium.

\section{A3. Ewald Prize}

The establishment of the Ewald Prize, for outstanding contributions to the science of crystallography, was announced in February 1986 and was given wide publicity. The name of the Prize was chosen with the kind consent of the late Paul Peter Ewald, to recognize Professor Ewald's significant contributions to the foundations of crystallography and to the founding of the International Union of Crystallography, especially his services as the President of the Provisional International Crystallographic Committee from 1946 to 1948, as the first Editor of the IUCr's publication Acta Crystallographica from 1948 to 1959, and as the President of the IUCr from 1960 to 1963.

Shortly after the death of Professor Ewald in 1985, his family informed the President that Professor Ewald had wished to make a bequest to the IUCr. After consulting Mrs Ewald, this generous bequest, together with a donation from the Ewald family and a donation from the IUCr, was used as starting capital for the Ewald Prize. The interest from this capital and further donations from the IUCr are used to finance the Prize.

The Prize consists of a medal, a certificate and an award of USD 30000 . It is presented once every three years during the triennial International Congresses of Crystallography. The first Prize was presented during the Perth Congress, being awarded jointly to J. M. Cowley and A. F. Moodie. The second Prize was presented during the Bordeaux Congress to B. K. Vainshtein. The third Prize was presented during the Beijing Congress to N. Kato. The fourth Prize was presented during the Seattle Congress to M. G. Rossmann. The fifth Prize was presented during the Glasgow Congress to G. N. Ramachandran. The sixth Prize was presented during the Geneva Congress to M. M. Woolfson.The seventh Prize was presented during the Florence Congress to P. Coppens. In January 2008, it was announced that the eighth Ewald Prize had been awarded to Dr D. Sayre for the unique breadth of his contributions to crystallography, which range from seminal contributions to the solving of the phase problem to the complex physics of imaging generic objects by X-ray diffraction and microscopy, and for never losing touch with the physical reality of the processes involved.

The presentation of the Ewald Prize was made during the Congress Opening Ceremony.

\section{A4. Reports of Commissions of the Union}

\section{A4.1. Commission on Journals}

A4.1.1. Overview. The end of the triennium marks 60 years of publication of IUCr journals, and a Special Issue to highlight this event was prepared for publication in Acta Cryst. Section A in January 2008. The continued success of the journals is based on many outstanding contributions of numerous members of the large, but highly interactive community of crystallographers as authors, referees, Editors and Co-editors. This is complemented by the excellent work of a competent and dedicated technical staff at Chester, who are continuously providing not only the necessary support, but also new ideas and initiatives for improvements and innovative ventures. Currently, about 150 Section Editors or Coeditors and the full-time equivalent of 12 technical editors work for the journals. The number of expert referees can only be guessed, and their confidential work deserves highest appreciation.

The last triennium has seen a major increase in the number of pages published in IUCr journals, up from 31521 in the previous triennium to 48261 . This increase has largely been driven by the expansion of Acta Cryst. Section E and the launch of Acta Cryst. Section F. This increase in the number of pages has been accompanied by a reduction in publication times; online submission is now almost exclusively used and this has helped to keep publication times low across the journals.

The citation impact of IUCr journals continued to be high, with the journals occupying two or three of the top five ranking positions in crystallography. The highest impact factors recorded during the triennium were 5.4 for Acta Cryst. Section B and 5.25 for J. Appl. Cryst.

The overall withdrawal plus rejection rate for the journals was $21 \%$ in 2007, down compared with 2006 (23\%) and 2005 (25\%). This is broadly in line with the rates for the previous triennium.

Ethics in science publication and open access have been topics of general concern during the triennium. All submissions to Acta Cryst. Sections $\mathrm{C}$ and $\mathrm{E}$ are now routinely checked for duplication against the crystallographic databases, and the journals also took part in a plagiarism pilot run by CrossRef. The hybrid open-access option introduced for authors in 2004 has become increasingly popular, and at the end of the triennium Acta Cryst. Section E was made into a full open-access journal. This change is intended to place Acta Cryst. Section $\mathrm{E}$ on a sustainable footing.

Acta Cryst. Section F, launched as the IUCr's first online-only biological journal in 2005, has established itself during the triennium as a home for the rapid publication of structure and crystallization communications on biological macromolecules. The journal has an average time from submission to publication, including peer review, of 2.3 months. In 2005-2007 the journal has published 938 papers and 3492 pages.

Finally, let me especially thank the following retiring Section and Main Editors for their major commitment to serving the IUCr journals, namely G. Ferguson (Section Editor of Acta Cryst. Section C), W. Clegg and D. G. Watson (Section Editors of Acta Cryst. Section E), J. M. Guss (Section Editor of Acta Cryst. Section F), and D. M. Mills (a Main Editor of J. Synchrotron Rad.). Their successors will be formally appointed at the Osaka General Assembly.

\section{G. Kostorz, Editor-in-Chief and Chair of Commission}

A4.1.2. Acta Crystallographica Section A. Statistics for Section A are shown in Table 6 .

Pages for science comprise only Research Papers, Short Communications and Letters to the Editor; publication time applies to research papers; the origin of articles binned for Europe, Asia+Australia and the Americas comprises Research Papers and Short Communications counted as integral or half-integral numbers.

In the triennium, Section A published 18 issues, 6 per year. Comparison with the previous period 2002-2004 shows its yearly volume to have slimmed down considerably by about 100 pages and 
Table 6

Statistics for Section A.

\begin{tabular}{|c|c|c|c|c|c|c|c|c|c|}
\hline Year & $\begin{array}{l}\text { Total } \\
\text { pages }\end{array}$ & $\begin{array}{l}\text { Pages for } \\
\text { science }\end{array}$ & $\begin{array}{l}\text { No. of } \\
\text { Research } \\
\text { Papers }\end{array}$ & $\begin{array}{l}\text { No. of } \\
\text { Short } \\
\text { Communications }\end{array}$ & $\begin{array}{l}\text { Average } \\
\text { length of } \\
\text { Research } \\
\text { Papers }\end{array}$ & $\begin{array}{l}\text { Publication } \\
\text { time } \\
\text { (months) }\end{array}$ & $\begin{array}{l}\text { Europe } \\
(\%)\end{array}$ & $\begin{array}{l}\text { Asia } \\
(\%)\end{array}$ & $\begin{array}{l}\text { Americas } \\
(\%)\end{array}$ \\
\hline 2005 & 622 & 531 & 55 & 5 & 9.2 & 5.1 & 60 & 17 & 23 \\
\hline 2005 & 498 & 498 & \multicolumn{7}{|c|}{ Supplement, Abstracts of the IUCr Florence Congress } \\
\hline 2006 & 528 & 447 & 43 & 5 & 10.1 & 5.0 & 61 & 12 & 27 \\
\hline 2006 & 311 & 311 & \multicolumn{7}{|c|}{ Supplement, Abstracts of ECM-23 Leuven, Belgium } \\
\hline 2007 & 510 & 440 & 47 & 3 & 9.1 & 5.3 & 57 & 24 & 19 \\
\hline 2007 & 293 & 293 & \multicolumn{7}{|c|}{ Supplement, Abstracts of ECM-24, Marrakech, Morocco } \\
\hline
\end{tabular}

the index dropped to 1.9 before rebounding to 2.2 in 2006. As the impact factor rose and then declined so did the rate of submission of manuscripts.

The increased submission rate proved, however, to have disadvantages: a greater fraction of submitted manuscripts was unsuitable enough that the rejection and withdrawal rates went up markedly.

The strength of Section B is in the quality and durability of the articles it publishes rather than in their immediate impact. All those connected with the journal are very

10 research papers. The average length of research papers, however, increased by about 1 page. The two slimmest issues comprised only 3 and 4 research papers. The drop is due to a smaller number of submissions, the rejection and withdrawal rates being on average the same as previously (38, 31 and $32 \%, 2005-2007)$. The geographical origins of the papers continue to show a European preponderance including central and eastern Europe. Nearly all authors use the electronic submission procedure.

A number of Special Issues have been published. The January 2005 issue was devoted to 'Phase Transitions I' (Guest Editor D. Pandey, 121 pp.). The Proceedings of the 2005 MaThCryst Summer School on Mathematical Crystallography held in Nancy, France, appeared in March 2006 (Guest Editor M. Nespolo, 99 pp.). The anniversary issue '60 Years of Acta Crystallographica and the IUCr' appeared in January 2008 (Guest Editor H. Schenk, 272 pp.). A second issue entitled 'Phase Transitions II' was commissioned in 2005 and is still in the pipeline (Guest Editor D. Pandey). Lead Articles and Topical Reviews have been published on: Time-Resolved X-ray Diffraction by P. Coppens (2005), 'Forbidden' Resonant Reflections by V. E. Dmitrienko (2005), and Diffraction with a Coherent X-ray Beam by F. Livet (2007). One Lead Article has been commissioned for 2008; others are in discussion.

Section A covers a broad interdisciplinary spectrum of the exact sciences. It has retained its international rating over the past nine years with impact factors oscillating between 1.42 and 1.83 (2007: 1.68). Typical crystallographic topics such as methods of crystal structure determination, charge densities, diffuse scattering and electron crystallography are gradually shifting from theory to applications. Section A becomes increasingly mathematical and difficult to read for many chemical crystallographers. This, and the closing down of crystallography laboratories, may account for the reduced volume of Section A. Section A is competing with physics rather than with chemistry journals. I thank the Chester editorial office, the Co-editors and the referees for their indispensable and efficient collaboration.

\section{Schwarzenbach, Editor}

A4.1.3. Acta Crystallographica Section B. During the triennium 2005-2007 Section B continued to publish six issues per year. In that period there were 87, 127 and 110 articles printed on 730, 1138 and 940 pages. The values for 2005 were low, at least for recent years, while the values for 2006 were near record highs. Papers came from 47 different countries. While nearly all papers were written in English, one was written in German.

The trends in numbers of articles and pages almost certainly reflect the trends in the widely publicized impact factor. That index rose from its historical range of 1.7-2.0 to 3.6 in 2003 and 5.4 in 2004 as a result of citations to papers in the 2002 Special Issue on databases. In 2005 , when the citations of the 2002 papers were no longer counted, pleased with the quality of the papers being published. In November 2006 we were happily surprised by an e-mail from Sidney Abrahams, long-time Editor-in-Chief of the IUCr journals, who wrote:

'I would also like to register my deep satisfaction with the most recent issue of Acta Section B. It has taken about a quarter century of steady progress to have reached this moment but the contents of this issue (even more than most) exactly mirror the kinds of connection between structure and the larger aspects of the physical and chemical sciences that I had hoped for in proposing to split the old Acta Section B into two parts.'

The average length of a full paper in Section B has remained near nine pages for years, but the amount of information included in each paper continues to rise. Several papers reporting structures of more than 15 different compounds have appeared. Multi-temperature studies, for example of phase transitions, have included refinements at a large number of temperatures. Studies of single-crystal photochemical reactions have included full refinements for many different degrees of conversion of reactants to products.

The average complexity of structures being analysed also continues to rise. Section B includes many papers reporting structures of incommensurately (and commensurately) modulated materials. A new development is the use of superspace notation to identify relationships among families of modulated structures. The journal has also recently published several methodological papers that we expect will be well cited for many years.

A comparison of the statistics for the years 2002-2007 suggests that the proportion of papers discussing inorganic structures (i.e. those with primarily ionic or network bonding) is rising while the proportion of articles focusing on molecular structures is falling. The ratio seems to have changed from roughly 1:2 to near 1:1 over the last six years, although it must be noted that the ratio is somewhat variable. The trend, if it is real, may reflect the application to inorganic and network compounds of the new and sophisticated methods for studying polycrystalline and modulated materials. When these methods are more often applied to molecular compounds the balance of inorganic and molecular papers could easily change again.

The average time from submission to publication remains at about six months. It seems that that length of time is necessary if thoughtful reviews and careful revisions are desired. The quality of the refereeing is outstanding.

The journal continues to be very attractive. Jill Bradshaw does a marvellous job with layout so that the figures are the right size and the pages balanced. We also thank the authors who have been good about using colour when it really enhances a figure and agreeing to printing in greyscale otherwise. It is a pleasure to leaf through each issue.

The electronic links between the office in Chester and the Coeditors work so well that we take easy communication and sharing of 
files for granted. We are all very indebted to the Chester staff who keep improving the system and who answer our many requests for information and advice so promptly and helpfully.

During this triennium a number of Co-editors have retired, or soon will retire, from the Editorial Board. They include L. A. Aslanov, A. J. Blake, L. Brammer, G. R. Desiraju, P. G. Jones, F. Krebs Larsen, C. Lecomte, L. B. McCusker, L. R. Nassimbeni, W. C. Stallings and M. R. Taylor. It has been a privilege and a pleasure to work with them.

\section{P. Brock, Editor}

A4.1.4. Acta Crystallographica Section C. Section C continues to invite high-quality detailed studies of novel and challenging crystal and molecular structures of interest in the fields of chemistry, biochemistry, mineralogy, pharmacology, physics and materials science. The unique checking, editing and publishing facilities of the journal ensure the highest standards of structural reliability and presentation, while providing for reports on studies involving special techniques or difficult crystalline materials. Publication times are now steady with the majority of technically correct and well written papers appearing online (http://journals.iucr.org/c) within one to two months of submission. In 2005 Section C published 437 papers (41 inorganic, 134 metal-organic, 262 organic) in a total of 1412 pages. In 2006 Section C published 444 papers (38 inorganic, 182 metal-organic, 224 organic) in a total of 1450 pages. In 2007 Section C published 447 papers (44 inorganic, 191 metal-organic and 212 organic) in a total of 1510 pages.

Some changes have been made to the Notes for Authors in the last three years in an attempt to improve the quality of initial submissions. Following discussions with the Commission on Journals and the Executive Committee, it is now a requirement that the submitting author provides in the _publ_contact_letter section of the CIF a brief statement of what is new, novel or interesting about the structure(s) in the submitted CIF that merits publication in the printed form in Section C; the potential impact of the work must now also be mentioned in the Abstract. The withdrawal/rejection rates for Section $\mathrm{C}$ were $58 \%$ in $2005,50 \%$ in 2006 and $52 \%$ in 2007 . The principal reasons for the significant withdrawal/rejection rates were either that the text in the Comment section of the CIF was deemed not to provide the 'significant added value to the numerical data freely available in the CIF' as detailed in Notes for Authors, or that the text in the Comment section was very poorly crafted. In the past it would appear that authors have often tried for a Section $\mathrm{C}$ publication but were willing to resubmit revised versions to Section $\mathrm{E}$ when it was pointed out that the submitted material was not adequate for a Section $C$ publication. It remains to be seen what effect the new (January 2008) charging policy for Section E will have on Section C submissions.

It is always a pleasure to thank the many Co-editors and referees, and the Chester staff for their superb work in the preparation of Section C; their fine efforts are much appreciated.

\section{G. Ferguson, Editor}

A4.1.5. Acta Crystallographica Section D. Section D was founded in 1993 to capture developments in the rapidly expanding field of biological crystallography. These included major advances in methods, and with them an exponential increase in the numbers of structures being determined by X-ray crystallography. They also brought a growing awareness of the power of crystallography to illuminate biology and of its value to applications such as drug discovery. This growth has continued to the point where there are now more than 40000 crystal structures in the Protein Data Bank, compared with $\sim 1500$ in 1993 . The past 6-8 years have also seen the impact of structural-genomics initiatives, in which large numbers of protein structures have been determined, often before any functional characterization, using increasingly automated methods. These automated methods, which apply to protein crystallization, data collection, structure solution and refinement, have spread into all applications of biological crystallography.

With such major changes in biological crystallography, Section D has also changed, and will continue to do so. The greatest change in the past three years has come with the launch in 2005 of our sister journal, Acta Cryst. Section F. With this change, Section D no longer publishes crystallization papers or routine structure reports. Our stated focus is on methods in biological crystallography and on structural papers that bring new insights to the biology, chemistry or structure of the macromolecules involved. An important aim is to enhance the impact of the journal, and thus to place it at the forefront of its field.

Over the past triennium, Section $\mathrm{D}$ has continued to attract important methodological papers, and it remains pre-eminent in the publication of new methods in biological crystallography. Many of these are captured in the very popular CCP4 study weekend series, which has a different methodological theme each year; it is now published as a Special Issue at the start of every year. We are greatly indebted to the Guest Editors who put these issues together: in 2006, G. Evans and M. Walsh on Data Collection and Analysis and in 2007, T. Skarzynski and A. McCoy on The Crystallography of Complexes. Other Special Issues have also focused on methods: the Proceedings of the 10th International Conference on the Crystallization of Biological Molecules, edited by J. Ng and M. Bartlam in 2005; the 'Get Phases' Workshop on Phasing Methods for High-Throughput Protein Structure Determination, edited by Xiao-Dong Su and T. Terwilliger; and a Special Issue dedicated to the achievements of the SPINE (Structural Proteomics in Europe) consortium, edited by J. M. Guss. The methods papers from Special Issues traditionally are the most widely cited of all Section D publications.

Section D also attracts a steady flow of good-quality structural papers, at a rate of about $6-10$ such publications per month. It is still the case, however, that we struggle to attract structural papers of the highest impact, or papers that report truly novel and important protein structures. This reflects the intense competition posed by biological journals and is the result of several factors: the target readership of such papers is in biology; many of the biological journals have higher impact factors; and more biological journals now publish structural papers. This situation is not likely to change until the impact factor of Section D increases from its present value of 1.7. Present trends suggest, however, that the impact factor is set to rise significantly as crystallization papers from 2004 fall out of the calculation and some highly cited recent papers are included.

At the same time, Section D has a highly strategic position in the field of biological crystallography, which brings with it new roles and opportunities. As automation increases and more researchers enter the field without formal training in crystallography, the need increases for discussions on crystallographic methods and related issues. Recent retractions of structural papers published in highprofile journals emphasize the point. During 2007, a number of papers were published in Section D that discussed crystallographic practice and policy, and we see a vital educational role emerging, which might be facilitated by a Talking Point section in the journal.

In terms of its technical quality, the journal looks superb, and the production quality is outstanding. The electronic submission system continues to work very well, although we have noticed an increasing 
international union of crystallography

difficulty in finding suitable and willing referees. This is a problem that is common to other journals, and which can place a heavy burden on Co-editors and on those referees who are still willing to assist. We need to think about new approaches. Publication times are good, at an average of $\sim 4.5$ months for full articles. The size of the journal was steady at $\sim 1600$ pages over 2005 and 2006 , but declined to $\sim 1300$ in 2007 , concurrent with a slight rise in rejection rates, to about $16 \%$ in 2007 , from about $5 \%$ in the previous triennium.

Finally we thank the many people who contribute to the success of the journal: our authors and readers; the reviewers whose efforts are critical for maintaining quality; our Co-editors who give their time and wisdom in shepherding papers through to acceptance; Louise Jones and Simon Glynn for their efforts at Chester in maintaining superb production quality; and Peter Strickland, as Managing Editor, and Gernot Kostorz, Editor-in-Chief, for their guidance and management.

\section{E. N. Baker and Z. Dauter, Editors}

A4.1.6. Acta Crystallographica Section E. The years 2005-2007 have seen major developments in the production of our journal. The operational statistics are summarized In Table 7.

Over these three years the distribution of papers by country has remained approximately constant. In $200749 \%$ of papers had the main correspondence author in the People's Republic of China, $8 \%$ in India, $6 \%$ in the USA, $5 \%$ in Germany, $4 \%$ in the UK, $3 \%$ in Malaysia, $3 \%$ in Turkey and smaller percentages in other countries; in total, authors from 75 countries published in Section E during 2007.

Significant developments in 2005. For authors, the most important development was the introduction of a new system for the submission, handling and tracking of papers. This new procedure was developed and tested in 2005 for introduction in 2006. It was designed to be easier to use at all stages, for authors, for Co-editors, and for the editorial-office staff. The submission of a new paper now involves uploading all relevant files in a single operation, the online selection of a Co-editor, and the author's declaration regarding copyright and ethical issues. Any CIF generating a level A alert will not pass the submission stage unless an author response to such alerts is included; this response is assessed by the Co-editor as part of the review process. Revisions to submitted papers are also made through the web interface, at the Co-editor's invitation, and the status of the paper can be checked at any time. The introduction of this new system was a major development task for the Chester staff, and a very welcome step forward in streamlining our operations.

In order to apply some restraint to the journal's growth and in response to a decision of the IUCr Executive Committee to limit the number of published pages, there was now a limit of 400 words in the Comment section; papers longer than this, which must be justified in the submission process as a response to a level A alert, were accepted only at the discretion of the Co-editors and Section Editors, and such exceptions were intended to be rare.

Significant developments in 2006. A new tool was provided by the technical staff in Chester, viz publCIF. This provides facilities for the composition and checking of papers and has proved very popular with authors and Co-editors alike. It can be downloaded from http:// journals.iucr.org/e/services/authorservices.html and installed under Windows, Linux and Mac OS.

By 2006, the journal was financially unsustainable in the view of the IUCr Finance and Executive Committees, because it generated very little direct income (most of its readers had free or very low cost access to it as a result of subscribing to Section C or via consortial arrangements) and its production costs had been steadily climbing
Table 7

Statistics for Section E.

\begin{tabular}{llll}
\hline & 2005 & 2006 & 2007 \\
\hline Number of papers published & 2887 & 3991 & 5181 \\
Number of pages & 7439 & 9483 & 8375 \\
Average number of pages per paper & 2.6 & 2.5 & 1.6 \\
Average publication time in months & 0.8 & 0.9 & 0.8 \\
Percentage of inorganic papers & 3 & 4 & 3 \\
Percentage of metal-organic papers & 29 & 33 & 36 \\
Percentage of organic papers & 68 & 63 & 61 \\
Number of papers rejected & 342 & 566 & 644 \\
Number of papers withdrawn & 256 & 325 & 430 \\
Impact factor & 0.491 & 0.581 & 0.567 \\
Number of Co-editors & 48 & 48 & 56 \\
\hline
\end{tabular}

with its popularity. Also, the submission of papers continued to increase without any sign of abating, making life very difficult for the editorial staff, the Section Editors and existing Co-editors; we could not just keep appointing more Co-editors and allow the journal to grow without limit.

The Finance Committee asked those responsible for the journal production to examine the possibility of making the journal completely open access, which would mean free access without any subscription or reader's fee, with the production costs being met by a charge to authors. In practice, this was likely to be the only possible way forward in financial terms; there appeared to be no viable alternatives if the journal was to continue operation. In this case, it was important to make the open-access charge as low as possible. This meant reducing the production costs as much as we could. To satisfy these linked demands, we developed a new format for the pdf version of the published articles, so that many fewer of the submitted results would appear in this format, the bulk of the material being available through a new pdf supplement to the article, as well as via the archived CIF, structure factors etc. The pdf version of the article consists of the title, authors, key indicators, an Abstract (longer than most of the existing ones, but with a length limit), a new 'Related literature' section, Experimental data sections (Crystal data, Data collection and Refinement), very brief table(s) if any at all, a chemical scheme, acknowledgements and references. A small working party reviewed the items that appear in the Experimental data sections, and some of these were removed, not only in Section E papers, but also in Sections B and C for consistency; they are, however, in the pdf supplement and the CIF, together with many other items that have never appeared in the 'old-style' paper, and are therefore fully available to readers. The Experimental text sections and Comment are still provided by authors for the pdf supplement and the CIF; it does not need as much editorial attention or any time-consuming typesetting. Figures are also available through the pdf supplement of the paper. We stress that each publication consists of the complete package supplied by authors - CIF, structure factors, graphics and any other submitted supplementary files - together with the generated paper and supplement, and this still represents a richer collection of material than is provided by publishers of other journals.

Much time and effort of the editorial staff in Chester, together with the Section Editors, was taken up in the final months of 2006 in developing and testing the new procedures, to be introduced early in 2007. Changes included revision of the Notes for Authors, updating of CIF templates and examples, and new Notes for Co-editors, in addition to the web interfaces seen by authors and Co-editors and the very considerable programming effort that lies behind these.

Significant developments in 2007. The new short format developed in 2006 became operational in March 2007. A major result has been a significant easing of the workload on our Co-editors. 
The Executive Committee decided to move the journal's operation and distribution from a subscription basis to an open-access model the first journal of the IUCr to take this step. The new system came into force in December 2007. The intention was to keep the openaccess fee, charged to most authors, as low as possible. This has been achieved successfully, with a standard fee of only USD 150, when the open-access charges of most scientific journals for full research papers are in the thousands of dollars. The resulting combination of free access to the journal for all readers, a low charge to authors, a range of generous discounts from the standard fee and waivers for authors from some countries, and the high quality of the complete publication package provided by the journal is proving very attractive, and the drying up of submissions predicted by some observers following this major change has not occurred: over 100 papers were submitted in the first three weeks of 2008, equivalent to an annual rate approaching half of that reached in 2006 when there were no charges to authors and the journal was using the previous longer format.

We would like to express our sincere appreciation of the efforts of our Co-editors over these three years.

Finally, we again thank the editorial staff in the Chester office for all their help and dedication. In particular, we are indebted to Gillian Holmes, Sean Conway, Sarah Froggatt and Lisa Stephenson who look after Section E on a daily basis, and to Simon Westrip, Mike Hoyland, David Hoare and David Holden who have been particularly involved in the development of new procedures under the direction of Peter Strickland. We are also grateful to those Section C Co-editors who helped us cope with the huge load of submissions prior to the introduction of open access - a staggering 785 and 1066 papers were submitted in the months of October and November, respectively.

\section{G. Watson and W. Clegg, Editors}

A4.1.7. Acta Crystallographica Section F. Section F was launched as the IUCr's first online-only biological journal in 2005. Over the past three years the journal has established itself as a home for the rapid publication of structure and crystallization communications on biological macromolecules, with an average time from submission to publication, including peer review, of 2.3 months. In 2005-2007 the journal has published 938 papers and 3492 pages.

In order to facilitate rapid publication, the journal has developed a streamlined route from database deposition to publication. New tools to help authors prepare their articles include an online facility to create experimental tables from mmCIF files for inclusion in manuscripts. Multimedia submissions are encouraged by the journal and a $\mathrm{Jmol}$ toolkit is in development to allow authors to prepare interactive figures easily and integrate these into their submission to the journal.

The Editors are aware of the importance of maintaining scientific standards in the journal and a list of data items recommended for inclusion in articles has been produced, including a list of standards for NMR studies.

The journal remains a high-quality publication and has been included in Medline and other abstracting and indexing services. Its first impact factor is eagerly awaited in 2008.

\section{H. M. Einspahr and J. M. Guss, Editors}

A4.1.8. Journal of Applied Crystallography. JAC published 1045 pages in 2005, 928 pages in 2006 and 1895 pages in 2007 (including 705 electronic only pages of Conference Proceedings of the 13th International Conference on Small-Angle Scattering held in Kyoto, Japan, in 2006). The increase in the number of pages is due to an increase in the number of articles and, to a lesser extent, to the increased length of individual articles.

There was a small decrease of the average publication time (from 6.7 to 6.4 months) owing to small reductions of editing and review times. Manuscripts are now almost exclusively submitted and reviewed electronically. The average combined rejection and withdrawal rate was $27 \%$. The impact factor continues at a high level, peaking at 5.2 .

The last triennium has seen the retirement of G. Kostorz as Editor after eight years of service and the appointment of A. R. Pyzalla as new Editor in mid-2007. Professor Kostorz's great service to the journal and also that of D. Ohlendorf, who will retire as a Co-editor this year, is highly appreciated.

\section{A. Pyzalla, Editor}

A4.1.9. Journal of Synchrotron Radiation. During the period 20052007, a total of 289 articles comprising 1869 pages were published, an increase on the previous triennium. This increase reflects the journal policy of including Special Issues focused on a particular topic, providing informative summaries of important developments in the field to the synchrotron-radiation community. In total, eight such Special Issues have been published over the last three years, with further ones planned for the future.

The impact factor has risen to 2.4 over the same period; we hope that this trend continues during the upcoming years. The average publication time during this period has been reduced, falling from 6.5 months in 2004 to 5.0 months in 2007.

In the next triennium, we expect the interest in this field will continue to grow as new facilities for the generation of radiation, including free electron lasers (FELs), become operational. We fully expect that $J S R$ will remain the pre-eminent journal dedicated to reporting scientific and instrument advancements, regardless of the source technology, in the years to come.

\section{Å. Kvick, D. M. Mills and T. Ohta, Editors}

A4.2. Commission on International Tables. The publication of the eighth volume of International Tables for Crystallography (Volume G, Definition and Exchange of Crystallographic Data, edited by S. R. Hall and B. McMahon) in 2005 marked the completion of the full series of volumes as first planned by the Commission in the 1990s. Corrected reprints of the fifth editions of Volume A and the Brief Teaching Edition of Volume A were also published during 2005.

Work on International Tables then continued with the emphasis placed on making all eight volumes available online as full-text html and pdfs. The many features that would be available in the online version were demonstrated during the Open Commission Meeting at the Florence Congress in 2005. By 2006, all eight volumes were available on the IUCr's International Tables Online web site at http:// it.iucr.org. In 2007, Springer started to sell access to pdfs of the chapters in the volumes on SpringerLink and to the full version available on the IUCr's own web site. Reviews of International Tables Online have been very favourable and access has been bought by a large number of consortia and institutions across the world so far. The print volumes have also continued to sell well.

Revisions of several of the volumes and the further development of International Tables Online are planned. Th. Hahn retired as Editor of Volume A in 2007. All members of the Commission would like to express their deep gratitude to him for the extraordinary amount of time and work he has devoted to International Tables over the last 45 years. He has been succeeded as Editor of Volume A by M. I. Aroyo, 
who will work on the preparation of the sixth edition of Volume A. Work on the third edition of Volume B has progressed well and the volume is expected to go to press during summer 2008. The volume will include a new chapter on modern extensions of the Ewald method for Coulomb interactions in crystals and three new sections on electron diffraction and electron microscopy in structure determination, three-dimensional reconstruction, and single-particle reconstruction. Chapters on methods of structure determination have been extensively revised and many other chapters have been revised and updated. The second edition of Volume A1 is expected to go to press in 2009. It will include two new chapters: one describing how to create trees of group-subgroup relations and one on the Bilbao Crystallographic Server. Two new sections to the tables and graphs that extend the treatment of the supergroups of space groups and a new section on supergroups are also planned. The presentation of the subgroup data for isomorphic subgroups in the tables will be homogenized. D. M. Himmel has joined E. Arnold and M. G. Rossmann as Editors for the second edition of Volume F, which is now in an advanced stage of planning. Most of the existing chapters will be updated and many new chapters will be commissioned. The second edition is expected to be published in 2010. H. Fuess continues to plan the fourth edition of Volume C. A publication date is not yet known. In addition, significant enhancements to International Tables Online are planned, including the addition of a symmetry database that will provide far more symmetry information to the user than is contained in the printed volumes.

Further information about the volumes can be found at the home page of the Commission, http://www.iucr.org/resources/commissions/ international-tables.

\section{H. Fuess, Chair}

A4.3. Commission on Aperiodic Crystals. The Commission, including three new members, was re-appointed by the General Assembly during the Florence Congress. Official meetings of the Commission took place during the Florence Congress and, again, during Aperiodic 2006 in Zao, Japan, September 2006. Commission members and consultants have also kept in regular contact via e-mail as well as at various national and international conferences and workshops. The Commission has continued to be active in the promotion of aperiodic crystallography, in organizing meetings as well as in coordinating activities between the quasicrystalline and incommensurate structure communities. As a major part of these activities, the Commission continued to promote aperiodic crystallography at national, regional and international meetings.

During the Florence Congress, aperiodic crystallography was again strongly represented. Prior to the opening of the Congress itself, a full one-day, pre-Congress Workshop on the Structural Analysis of Aperiodic Crystals was held. The Workshop was organized under the auspices of the Commission by S. van Smaalen and R. Withers. During the Congress, two Keynote Lectures on Aperiodic Crystallography were presented in well attended sessions. In addition, three separate Microsymposia were also held and again were well supported.

During 2006, the (ninth) triennial flagship meeting of the Commission, Aperiodic 2006, was held in Zao, Japan, 17-22 September. Aperiodic 2006 was very ably organized by A. Yamamoto, A. P. Tsai, K. Saitoh, Y. Gotoh, Y. Miyazaki and Y. Michiue. The Conference Chairs were A. P. Tsai and A. Yamamoto. 128 delegates attended the Conference coming from 21 different countries. Over half the delegates were from Asia with 60 from Japan alone. It was decided at this meeting that Aperiodic 2009 will be held in Liverpool, UK, probably in mid-September and will be organized by R. McGrath and U. Grimm (the web site for this meeting is http:// www.aperiodic09.org/index.html). The Proceedings of Aperiodic 2006 have been published as Volume 87 (2007, Issue 18-21) of the journal Philosophical Magazine (Taylor and Francis). Further to the activities associated with Aperiodic 2006, a Microsymposium as well as a Plenary Lecture on aperiodic crystallography were given as part of the 23rd European Crystallography Meeting, ECM-23, held in Leuven, Belgium, 6-11 August 2006. In addition, a Microsymposium in the area co-organized by S. van Smaalen was held during the German Crystallographic Association meeting held in Freiburg, Germany, 3-6 April 2006.

During 2007, two very successful meetings in the field of aperiodic crystallography were held: (i) the Fifth Workshop on the Structural Analysis of Aperiodic Crystals, Bayreuth, Germany, 1-4 March, organized by S. van Smaalen and (ii) Quasicrystals - The Silver Jubilee, Tel Aviv, Israel, 14-19 October, organized by R. Lifshitz, D. Shechtman and S. Ben-Abraham. Both meetings were well attended and appreciated.

Very important upcoming meetings for the Commission in 2008 include (i) the Osaka Congress and (ii) the 10th International Conference on Quasicrystals, ICQ10, Zürich, Switzerland, 6-11 July. Planning for both meetings is well advanced. There will be two Keynote Lectures and four separate Microsymposia in the field of aperiodic crystallography at the Osaka Congress, which the Commission has helped organize.

Two important new books on aperiodic crystallography were published by long-standing members of the community in 2007: (i) Aperiodic Crystals from Modulated Phases to Quasicrystals by T. Janssen, G. Chapuis and M. de Boissieu, published by Oxford University Press and (ii) Incommensurate Crystallography by S. van Smaalen, again published by Oxford University Press as an IUCr/ OUP Monograph on Crystallography (No. 21). Both are highly recommended.

Work has continued on updating the CIF dictionary for modulated structures to allow for non-sinusoidal modulation functions as well as the possibility of making it applicable to quasicrystals. G. Madariaga is the Commission representative most involved with this in cooperation with the Committee for the Maintenance of the CIF Standard. The CIF standard is available at the IUCr web site.

The Commission maintains internet pages at the web site of the IUCr at http://ww1.iucr.org/comm/capd/index.html. A web site on all aspects of the crystallography of aperiodic crystals is maintained by the special interest group (SIG) on aperiodic crystals of the European Crystallographic Association. It is maintained by M. Dusek (Prague, Czech Republic), and can be found at http://www-xray.fzu.cz/sgip/ aphome.html.

\section{R. Withers, Chair}

A4.4. Commission on Biological Macromolecules. The Commission has continued to support the vitality of the biological crystallography community, particularly through recommending and supporting IUCr proposals to hold meetings, workshops and schools. Many meetings of this type have been held worldwide from 2005 to 2008, and additional meetings are planned and underway. The Commission also continues to work with various groups within the community to develop recommendations for an updated set of crystallographic publishing standards that will require structurefactor deposition (compliance is already over 95\%) and to remove the option for delaying the release of PDB structures following 
publication. The PDB itself is taking the lead on these important activities.

A key activity of the Commission has been to contribute to the planning of the Osaka Congress. Structural biology will be represented at all levels, with the revelation of spectacular novel macromolecular structures and evolving methods described in Plenary Lectures, invited presentations, topical sessions and posters. A large number of students will attend and participate from all corners of the world and the travel of many young scientists will be sponsored by the IUCr. Three members of the Commission (E. Arnold, A. Podjarny and T. Tsukihara) met with the International Programme Committee to develop suggestions for Plenary Lectures, Keynote Lectures, topicoriented Microsymposia, and Chairs for all of the suggestions. The programme has been developed and refined based on speaker acceptance from invitation and abstract submission, and the Osaka Congress Programme promises to be exciting and action-packed.

Upcoming activities for the Commission include appointments of new members and Chair. A related activity is the development of a second edition of International Tables for Crystallography Volume F: Crystallography of Biological Macromolecules by E. Arnold, M. G. Rossmann and D. M. Himmel, which should be ready by 2010 . Additional schools and meetings will be sponsored by the IUCr to help in disseminating crystallographic knowledge in the most effective ways to deserving bodies of students. The Annual Reports of the Commission have referred to specific meetings that have occurred and been sponsored by the IUCr during this period.

The current and future importance of structural biology involving biological macromolecules is great and continually growing. We will see more important intersections with other areas of science and medicine developing in coming times. Crystallography of biological macromolecules has attained a central role in medical discovery and this role and others will expand in the coming years.

\section{E. Arnold, Chair}

A4.5. Commission on Charge, Spin and Momentum Densities. During the triennium, the Commission was actively engaged in the organization of meeting sessions to promote the field among different disciplines and among young scientists. Special sessions on charge, spin and momentum densities were organized by the Commission or with the help of the Commission for the following crystallographic meetings: the Florence Congress in 2005, ECM-22 in 2006 (Leuven, Belgium), ECM-23 in 2007 (Marrakech, Morocco), AsCA '06 in 2006 (Tsukuba, Japan) and AsCA '07 in 2007 (Taipei). The triennial Inelastic X-ray Scattering (IXS) conference was held at Awaji Island, Japan, May 2007.

International special charge density meetings were all very successfully attended. Sagamore XV was organized (Warwickshire, UK) by M. J. Cooper in 2006: 100 participants and 20 accompanying members from 16 countries; eight themes in 12 oral sessions. The next Sagamore meeting (Sagamore XVI) will be organized by P. Coppens and T. Proffen in August 2009 (Santa Fe, USA). The last Gordon Conference (Mount Holyoke, USA, 2007) was organized by C. Gatti: there were close to 100 participants, all the sessions were well organized and the discussions were very satisfactory. The next Gordon Conference will be chaired by D. Jayatilaka in 2010.

Europe is still very active in the field of electron density with the organization every two years of the European Charge Density Meeting. ECDM-4 was organized by U. Pietsch at Brandenburg, Germany, in January 2006. The next (ECDM-5) will be held at Gravedona, Italy, in June 2008, organized by C. Gatti, R. Destro and P. Macchi; the meeting will be held jointly with the annual colloquium of the DFG1178 Project, which is a German-funded project in the field of electron density research.

The 6th International Conference on Inelastic X-ray Scattering (IXS2007) was held at Awaji Island, Hyogo, Japan, 5-11 May 2007. It was organized by a joint team from SPring-8 (JASRI, JAEA and RIKEN) and KEK (IMSS-PF); the conference Chair was H. Kawata. The conference was well attended with 115 participants from 53 institutions in 11 countries; among them 18 were students. The next conference will be held in Grenoble, France, in 2010, hosted by ESRF and the Politecnico di' Milano. A satellite workshop on RIXS in extreme conditions will be hosted by University of Paris and SOLEIL.

In addition to all these conferences, there were workshops aimed at the training of young scientists to encourage them to enter the field. P. Marchi organized an XD workshop in Italy in September 2007. The workshop was well received with lectures and practicals.

The need for education becomes more and more important; in order to develop the field with our young colleagues, a school is certainly important. This school should be open to scientists from Africa and South America because these two continents did not participate in the Gordon Research Conference or Sagamore meetings: fundamental and methodological research is still very important; the Commission will try its best to promote such research worldwide.

A project entitled Constrained Experimental Wavefunction was begun in 2005 , organized by D. Jayatilaka: it concerns the possibility of extracting wavefunctions from accurate X-ray and polarized neutron experimental data. This project was launched during the 2004 Gordon Research Conference. Seven groups participated and we expect results to be discussed during the Osaka Congress.

The field covers electron, spin and momentum density, attracting not only crystallographers but also chemists, physicists, biologists and materials scientists. With the help of the ongoing DFG1178 project, I believe more newcomers will join the community and hopefully we will make some contributions to frontier science and technology. The community is also open to new complementary techniques such as convergent-beam diffraction, surface diffraction, synchrotron and inelastic scattering, X-ray absorption and new DFT techniques: in particular, time-resolved experiments, which can be applied to new functional materials, molecular materials, macromolecules and surface science. Forefront projects, e.g. electron density of atoms, molecules and crystals under thermodynamic constraints: pressure, electric field, photoexcitation, are encouraged. We must take a look at the present forefront research in the field, and at the same time be prepared for the coming new directions, those that will be promoted by the advent of the X-ray free electron laser facilities and the exciting opportunities and challenging problems of single-particle $\mathrm{X}$-ray diffraction imaging. Indeed, these instrumental and basic science advances are increasingly widening the traditional field of this community. All these aspects will be the future of our field experimentally and theoretically.

\section{Yu Wang, Chair}

A4.6. Commission on Crystal Growth and Characterization of Materials. Providing active support for crystal growth conferences and workshops around the world was the main activity of the Commission during the triennium.

As in previous years, the Commission received and carefully considered for recommendation to the IUCr Sub-committee on the Union Calendar the applications for support for different meetings (conferences, schools and workshops) covering various topics in crystal growth and characterization - from crystal genesis and growth 
fundamentals, to organic and biological crystallization and new approaches to in situ characterization. The majority of Commission work was performed via e-mail communications but we were able to get together at Salt Lake City, USA, August 2007, where we discussed future plans and the shape of the Commission.

Two meetings of utmost importance for the crystal growth community in this period took place in Utah, USA. The first meeting, the 15th International Conference on Crystal Growth (in conjunction with the 13th Conference on Vapour Growth and Epitaxy and the US Biennial Workshop on Organometallic Vapour Phase Epitaxy), held in August 2007 in Salt Lake City, was attended by 751 people and more than 640 papers were presented (http://www.crystalgrowth.us/ iccg15/index.php). The other meeting was the 13th International Summer School on Crystal Growth, Park City (http://www. crystalgrowth.us/isscg13/index.php). The school was attended by 159 scholars from 24 countries. Financial support from the IUCr for this school was greatly appreciated.

The Commission members and consultants were heavily involved in both venues either as invited or plenary speakers (E. Vlieg, P. Rudolf and K. Kakimoto) or as the sessions' organizers (D. Bliss, T. Duffar and T. Ohachi).

Other important activities during 2005-2007 were the following:

(1) International School on Crystal Growth: Fundamentals, Methods and Applications to Biological and Nano Crystals (http://www.ifuap.buap.mx/ISCG05/school.html), which took place in Puebla de Los Angeles, Mexico, in March 2005. The main objective of this meeting was to present basic crystal growth concepts along with an overview of different growth technologies. The school was organized by A. Moreno and Commission members (H. Dabkowska, R. Fornari, J. M. Garcia-Ruiz and P. Rudolph) were involved as lecturers.

(2) The International Workshop on Crystal Growth and Characterization of Advanced Materials, Chennai, India, January 2006 (Commission member R. Fornari was one of the Co-Chairs of the workshop and the IUCr sponsored the event).

(3) The International School on Biological Crystallization (ISBC), Granada, Spain, organized by J. M. Garcia-Ruiz [see IUCr Newsletter (2006), 14(2), p. 17]. This school provided five days of lectures and practical demonstrations related to the crystallization of biological macromolecules, the crystallization of drugs and natural products, and polymorphism, biominerals and biomimetic materials. It was a very successful meeting and it was noticed by the international community. The school was partially sponsored by the IUCr. A similar meeting will be organized by J. M. Garcia-Ruiz in May 2009, also in Granada, Spain.

(4) The Fifth International Conference on Solid State Crystals and the Eighth Polish Conference on Crystal Growth (ICSSC-5 and PCCG-8) were organized in Zakopane, Poland, in May, 2007 (http:// science24.com/event/icssc2007) and attended by more than 100 participants. Consultants S. Baldochi, K. Kakimoto, A. Moreno and A. Pajaczkowska presented invited talks. This was an important international event covering novel achievements in many topics concerning growing and characterizing crystals and thin films of oxides and semiconductors. A short report from the conference was submitted to the IUCr Newsletter. The event was partially sponsored by the IUCr, which allowed for the partial subsidizing of more than 30 young scientists.

(5) A very successful and much appreciated workshop entitled Crystallization: Focus on Membrane Proteins was hosted at Brookhaven National Laboratory, USA (http://www.nsls.bnl.gov/newsroom/ events/workshops/2007/crys/). Thanks to the IUCr support of this meeting, young scientists from developing countries had an oppor- tunity to participate. Consultant A. Moreno taught at this venue. A similar workshop is being organized in 2008.

During the last two years of the triennium a great deal of work and planning was devoted to organizing the Osaka Congress. E. Vlieg represented the Commission on the International Programme Committee. Commission member J. M. Garcia-Ruiz will be a Keynote speaker on the first day of the Congress and the Commission is responsible for organizing four Microsymposia covering different approaches to crystal growth and characterization (see http:// www.iucr2008.jp/scientific_program.html).

It is important to mention that members and consultants of this Commission (S. Baldochi, H. A. Dabkowska, T. Duffar, R. Fornari, K. Kakimoto, A. Moreno, T. Ochachi, P. Rudolph and J. Wang) are very active in the International Organization for Crystal Growth (IOCG). This mutual interaction helps with understanding the goals and needs of both the IUCr and the IOCG.

\section{H. Dabkowska, Chair}

A4.7. Commission on Crystallographic Computing. There were three main activities of the Commission during the triennium.

(1) The organization of a traditional Crystallographic Computing School prior to the Osaka Congress. The school will be held 18-23 August 2008 in the Kansai Seminar House, Kyoto, Japan. The school is structured to foster the exchange of ideas via formal lectures, afternoon tutorials, coding challenges and code-comparison sessions. One of the issues to be addressed is the 'retiring crystallographers problem'. A new generation of developers knowledgeable in both crystallography and software development will have to be trained to replace them. Detailed information can be found on the web pages of the school at http://www.iucr-top/comm/ccom/kyoto2008/index.html.

(2) The organization of crystallographic computing sessions at the Osaka Congress. Computing-related sessions are traditionally well attended. Interesting new developments that are addressed include the 'charge flipping' algorithm for $a b$ initio structure determination.

(3) The Commission produces a Newsletter at least once a year. Every issue has a special theme for which contributing papers are invited. One of the 2005 issues (No. 6) includes the material of all lectures from the 2005 Siena Computing School. Other issues address topics such as incommensurate structures, 'understanding crystal structures' and refinement. More details may be found at http://www.iucr.org/resources/commissions/crystallographic-computing/ newsletters.

\section{A. L. Spek, Chair}

A4.8. Commission on Crystallographic Nomenclature. The Commission met in closed session at the Florence Congress. The suggestion to establish an 'Online Dictionary' of crystallographic terms based on the WiKi software and principle was presented by the Chair and the technical aspects were discussed by the IUCr Research and Development Officer, B. McMahon. There was discussion of the main idea among the Commission members present. It was favourably received and a consensus ensued to implement it.

Online Dictionary. One of the major activities of the Commission has been the development of appropriate WiKi software, monitored by a Working Group consisting of A. Authier, I. D. Brown, W. Clegg, J. R. Helliwell, B. McMahon and P. Spadon. Several software packages were tested for the pilot project by B. McMahon. The one chosen for further development was MediaWiki, which offers a rich set of features suitable for technical material (such as advanced handling of graphics and mathematics). The Online Dictionary is now operational. By May 2008 almost 200 substantial definitions had been 
entered and grouped into categories. Early work had also been carried out to provide hyperlinks to these definitions from articles published on the Crystallography Journals Online server. The nomination of Editors for the dictionary categories is under way. The next step will be opening the Online Dictionary to the general public, but this requires developing an appropriate filter so that suggestions for new definitions or modifications of existing ones will be checked by the appropriate Editor before they are made definitive. Cooperation is also being established with other community resources such as the WiKis being developed by the CCP4 users in the field of biocrystallography. The Online Dictionary may be consulted at the web page: http://reference.iucr.org/dictionary/Main_Page.

Nomenclature issues. Several e-mail debates took place on nomenclature issues. One concerned definitions of 'family' and 'clan' in relation to structure types. Another concerned the nomenclature of ordered structures with split occupancy. However, after lengthy discussions between members, no definitive conclusions were reached and no new definitions were introduced.

ICTNS (IUPAC). The following Technical Reports and Recommendations have been reviewed by referees chosen among IUCr members: Graphical Representation Standards for Chemical Structure Diagrams; International Vocabulary of Metrology - General Concepts and Associated Terms; and Guide to the Expression of Uncertainty in Measurements.

\section{A. Authier, Chair}

A4.9. Commission on Crystallographic Teaching. At meetings held during the Florence Congress the Commission widely discussed the general request for basic crystallographic courses that are required because basic crystallographic curricula are regressing in the academic bachelors and masters formation. This led to the decision to organize an International School on Basic Crystallography.

This School was held in August 2006 in Pontignano, near Siena, Italy, with G. Chapuis (Coordinator; EPFL, Lausanne, Switzerland), A. J. Blake (Nottingham, UK), A. Gavezzotti (Milan, Italy), R. Neder (Würzburg, Germany) as Programme Committee and M. Mellini (University of Siena) and P. Spadon (University of Padova) as Local Organizers.

The students attending the School comprised 44 from 14 different countries; 20 of them were supported financially by the organizers and obtained reduced fees. The total number of applicants was much higher but many of them could not participate because the Organizing Committee was not able to provide them with full travel support. There were 11 lecturers/tutors from different European countries and the sessions were organized in such a way that the time was nearly equally distributed between frontal lectures and tutorial sessions. At the end of the School a questionnaire was distributed to students, which gave a satisfactory result: the course was generally well received, the alternation between lectures and tutorials was much appreciated but it was also stressed that there was a need for more time to be dedicated to point and space groups and symmetry; students in the field of powder diffraction complained because the time allocated to the subject was not sufficient. All the teaching material was made available before the course at the web site of the School.

Following the idea of the importance of improving the teaching of the fundamentals of crystallography, during 2007 the Commission was involved in the organization of The Zürich Crystallography School Bring Your Own Crystals held at the University of Zürich, Switzerland, 5-17 August 2007. G. Chapuis, a member of the Commission, was one of the lecturers and contributed to the finalization of the programme. Hosted by the University of Zürich and organized by A. Linden and H. B. Bürgi, The Zürich Crystallography School took place for the first time in August 2007. Twenty participants interested in crystallography, mainly PhD students from all over Europe, came together to attend this two-week class. Starting with the main principles of diffraction, growing crystals and how to mount them, then discussing difficulties and problems and finally solving and refining their own crystal structures during the practical work, the course covered all topics. The course covered both basic and advanced skills and provided new and more in-depth insights into the subject. Therefore, everyone was able to profit and gain plenty of new knowledge about crystallography. With access to the four different types of diffractometers available, every student had the chance to set up a crystal measurement on a machine similar to the one their own group was using. Each evening, the class ended with a short summary of the day where students had the chance to comment on the day's lectures or to mention things they noticed. The commitment of all of the tutors was extraordinary; there was a total of 90 hours of crystallography.

The Commission also collaborated in the organization of the International School on Mathematical and Theoretical Crystallography held at the University of Havana, Cuba, 15-20 July 2007, together with the Commissions on Mathematical and Theoretical Crystallography and Inorganic and Mineral Structures. The programme included: group theory applied to crystallography; dimension-independent fundamental notions of crystallographic groups (lattices, point groups, vector systems); classification of crystallographic groups (arithmetic/geometric classes, crystal systems, lattice systems, crystal families); application of crystallographic group theory to concrete problems in lower-dimensional space; twinned crystals as polychromatic objects; polychromatic point groups and their mathematics; reticular and symmetry theory of twins; orderdisorder structures; the mathematics of polytypes; and modelling modular inorganic structures. There were about 40 students, mainly from Cuba and Mexico but also from South America and Europe.

The Commission has also agreed on the need to reformat and update the Commission web site and edit an online Commission Newsletter. L. M. D. Cranswick volunteered to coordinate this work and succeeded in producing a Newsletter that now contains several interesting contributions.

G. Chapuis and P. Spadon were involved in the organization of MS45 Communicating and Educating Crystallography at ECM-23, Leuven, Belgium, August 2006.

P. Spadon with K. El Sayed as Co-Chair was involved in the organization of MS40 Teaching Crystallography at ECM-24, Marrakech, Morocco, August 2007.

Commission members K. Ogawa, E. Boldyreva and L. M. D. Cranswick with the help of P. Spadon also actively worked as members of the International Programme Committee for the Osaka Congress. In particular, the Commission is involved in the organization of MS11 Pitfalls and Successes in Crystallographic Teaching, MS44 Teaching Macromolecular Crystallography (with the Commission on Biological Macromolecules) and MS25 Crystallographic Teaching Using New Computer and Internet Based Approaches (with the Commission on Crystallographic Computing). In addition, the Commission is organizing a pre-Congress Workshop on Teaching Crystallography in the 21st Century.

\section{P. Spadon, Chair}

A4.10. Commission on Electron Crystallography. Over the last three years, the Commission has been involved in two main activities: 
expansion of the number of workshops/schools involving electron crystallography, particularly increasing the number of these outside of Europe and the USA, and establishing the Gjønnes Medal for Electron Crystallography.

In addition to the annual European electron crystallography school, satellite meetings or sessions at ACS or MSA in the USA, several new workshops/schools have now been held and will hopefully continue on an annual or biannual schedule. One of these was the 1st IUCr International School of Crystallography in Asia on Electron and X-ray Diffraction which was held in Taiwan in November 2007. It is hoped that this will continue on a biannual schedule in different Asian countries. Another was the first K. H. Kuo Summer School of Electron Microscopy (EM), which was held in Beijing, People's Republic of China, on the topic of Cryo-EM in Structural Biology, and which it is hoped will continue on an annual basis rotating between Biological EM and EM of hard materials. A third was Electron Microscopy and Multiscale Modeling 2007 (EMMM-2007) which was held in Moscow, Russia, 3-7 September 2007. The EMMM-2007 Conference brought together leading experts in electron microscopy and materials modeling from around the world to explore how to combine synergistically atomic scale characterization and modeling to enhance the development of new materials. Preliminary discussions are taking place to hold the second of these conferences in 2009.

The Commission has also been involved in a number of related activities, for instance in helping to organize a reasonably large number of sessions at the Osaka Congress involving electron crystallography (more than in several of the prior IUCr Congresses), as well as a satellite meeting to be held after the meeting in Nagoya.

The Commission was actively involved in raising funding for the Gjønnes medal. The Gjønnes Medal in Electron Crystallography is an award made to a scientist for lifetime achievement in electron crystallography. This will be a medal awarded at the IUCr triennial Congresses. The first Gjønnes Medal will be awarded at the Osaka Congress to Dr Jon Gjønnes.

We are currently seeing dramatic changes in electron microscopy with the advent of $C_{s}$-corrected instruments, with the resolution of these instruments very rapidly improving. There are associated changes taking place in how electron microscopy is done, both in terms of interactions with the user as well as in the costs, since the price of these instruments is in many cases increasing faster than the resolution. The Commission intends to remain actively involved in education, outreach and workshops, and crystallography remains a core component of the explosive advances taking place in areas such as imaging, three-dimensional reconstruction and diffractive imaging.

The Commission's home page is maintained by the Chair, L. D. Marks, and can be found at http://www.numis.northwestern.edu/ IUCR_CED.

\section{D. Marks, Chair}

A4.11. Commission on High Pressure. As usual for new triennia, the Commission started its fourth triennium with a new composition. Four very active members (J. B. Parise, R. Hemley, W. Kuhs and I. Goncharenko) reached the limit of their terms and were replaced by V. Soloshenko, S. A. T. Redfern, A. Katrusiak and G. Galli. The Commission furthermore benefitted from the advice of the following consultants: R. J. Nelmes, I. Goncharenko, P. Dera, G. Shen and R. Angel.

The unusual size of the Commission (ten members plus the Chair) is essential to maintain competent expertise throughout the broad range of different scientific topics covered by the interdisciplinary field of high-pressure crystallography.
The past triennium was marked by the tragic and unexpected passing of Commission consultant Igor Goncharenko in a scubadiving accident. The Commission lost an exceptionally active and supportive member and the high-pressure crystallography community lost an outstanding scientist among its ranks. Igor was nominated for a Keynote Lecturer for the upcoming Osaka Congress.

The past three years brought a range of new developments in highpressure crystallography, but also a consolidation of high pressure as a technique to explore the interdependence between structure and properties in condensed materials. One of the exciting new developments in the past three years is the increasingly sophisticated exploration of amorphous and liquid structures at high pressure. The simultaneous combination of neutron and/or X-ray scattering techniques with other probes, such as, for example, Brillouin spectroscopy or transport property measurements, allows a very accurate correlation of structure and property with pressure and temperature as variable parameters. New developments at neutron and synchrotron sources continue to play an important role in these improvements, as much as successful programmes at small research groups across the world. The recognition of the importance of complementary experiments for obtaining a comprehensive picture of the interdependence of structure and properties led to an increase in coordinated collaborations between different techniques. A prominent example is the formal establishment of the High Pressure Synergetic Consortium, HPSynC, at the APS.

The past three years have also seen a renewed interest in 'old' techniques such as high-pressure single-crystal diffraction, which we find moving more and more from its established place in small university laboratories to large-scale facilities, such as synchrotrons (ESRF, APS, SPring-8) and neutron sources (ISIS, SNS). This enables the expansion of accurate crystallography to higher pressures and temperatures.

The role adopted by the Commission in this dynamic field is to facilitate and enable the exchange of new ideas and developments at as early a stage as possible. The Commission is also dedicated to help connect talented young researchers with established and experienced high-pressure crystallographers. This is not only to help the young people with their research problems, but also for the benefit of the high-pressure community in that it helps grow new ideas from fresh minds.

The main tools available to the Commission to achieve this goal are annual workshops on high-pressure crystallography. The Commission also helps to shape a strong high-pressure programme at the triennial IUCr Congresses. In addition, Commission members and consultants are heavily involved in organizing a variety of summer schools dedicated to high-pressure crystallography (e.g. Erice, 2003; Isle of Skye, 2008; Erice, 2009).

Symposia and workshops. During the Florence Congress, the Commission organized six Microsymposia. The topics covered were: Biological and Organic Soft Condensed Material under Pressure; Computational Crystallography Applied to Extreme Conditions; Novel Materials under High Pressure; Structural Phase Transitions and Properties at High Pressure; Crystallography at Conditions of Earth and Planetary Interiors; and Liquids and Amorphous Systems at High Pressure. In addition, Commission members J. S. Loveday and I. Goncharenko organized two Open Commission Meetings (OCMs) on the topics Technical Development in High-Pressure Crystallography on the one hand and Advances in High-Pressure Single-Crystal Diffraction on the other. The Microsymposia and OCMs were very well supported with attendances between 60 (OCMs) and 100 (Microsymposia). The Commission was also happy to see two of the Keynote Lectures to be given by high-pressure 
scientists, namely J. Tse (Canadian Light Source, Commission member) and M. McMahon (University of Edinburgh, UK).

The Commission makes a conscious effort to be as internationally inclusive as possible. For this reason a workshop was held in Russia in 2006, and the 2009 workshop is planned in the People's Republic of China.

The International Workshop on Crystallography at High Pressure 2006 followed the sequence of workshops organized on behalf of the Commission and also the sequence of meetings on Neutron Scattering at High Pressure organized by the FLNP JINR (NSHP-I in 1994 and NSHP-II in 1999, Dubna, Russia). It was organized at the Frank Laboratory of Neutron Physics and Joint Institute for Nuclear Research in Dubna, Russia, 28 September - 1 October 2006. The organization was coordinated by D. P. Kozlenko. I. Goncharenko served as the liaison to the Commission. The Workshop attracted nearly 80 scientists from ten countries. Its scientific programme contained ten oral sessions and two poster sessions, covering the full range of scientific activities of the Commission.

The 2007 workshop was held at Wadham College, Oxford, UK, 3-7 September. Commission Secretary J. S. Loveday acted as the local organizer. This workshop was again a big success. 85 participants gathered in a historic music pavilion to follow 11 oral sessions and poster presentations. The workshop finished with a tour through the new synchrotron facility (Diamond) and the highly successful ISIS neutron spallation source at Rutherford Appleton Laboratory.

Presently, the Commission's focus is on helping to shape an attractive high-pressure programme within the Osaka Congress. N. Hamaya is the Commission's representative on the International Programme Committee. The Commission is able to organize six Microsymposia (two of which are held jointly with the Commissions on Structural Chemistry and Inorganic and Mineral Structures, respectively). Furthermore, two candidates proposed by the Commission were accepted as Keynote speakers (G. Galli and I. Goncharenko). Owing to Igor's tragic death, his Keynote slot has been filled by S. Klotz.

Commission meetings. The Commission held a meeting during the 2006 high-pressure workshop. Seven Commission members were present. One of the most important topics discussed was the replacement of retiring Commission members in 2008. Further points of discussion were the high-pressure programme for the Osaka Congress, as well as an alternative and more reliable way of maintaining the Commission's web page.

Future plans and activities. The Commission plans more of its workshops in the years 2009 and 2010. In order to facilitate scientific exchange with the Chinese high-pressure crystallographic community, it was decided to organize the 2009 workshop in Harbin (Heilongjiang Province, NE China). Commission consultant P. Dera is co-organizer of the 2009 edition of a summer school for highpressure crystallography in Erice, Italy. The venue of the 2010 workshop has yet to be decided.

\section{Kunz, Chair}

A4.12. Commission on Inorganic and Mineral Structures. This report deals with the second triennium of activity of the Commission (CIMS) which, following a proposal by G. Ferraris, had been established in 2002 at the Geneva General Assembly; it was recognized that a Commission can better attract within the IUCr orbit inorganic crystallography, particularly that related to materials and minerals science. After six years of activity, the achievement of this goal can be appreciated at a glance by looking at the list of activities reported below for the triennium 2005-2007, and in the report for the first triennium.

In detail, the aims of CIMS are as follows:

To strengthen links and interactions of structural inorganic scientists with the crystallographic community.

To promote the presence at the IUCr meetings of Microsymposia specifically dedicated to the Commission purposes.

To promote and organize symposia, workshops and schools of interest to the crystallographic inorganic community.

To promote the publication of inorganic crystallography matter in the IUCr journals and Book Series of the Union and elsewhere.

Contacts between members and consultants. Contacts among the members and consultants of CIMS have been maintained mainly via e-mail and the web site http://www.crystallography.fr/cims/ administered by M. Nespolo.

Occasions for personal contacts and meetings have been:

Florence Congress (August 2005).

19th Meeting of the International Mineralogical Association (IMA) (Kobe, Japan, 2006).

ECM-23 (Leuven, Belgium, August 2006).

Satellite of AsCA '06: Theoretical Crystallography and Materials Science (Tsukuba, Japan, November 2006).

ECM-24 (Marrakech, Morocco, August 2007).

Co-organization and support of scientific meetings. The following meetings and sessions of conferences have been proposed/organized/ supported by CIMS. The presence of members of CIMS as organizers/convenors/lecturers is shown.

Florence Congress (August 2005): Open Commission Meeting (Convenor G. Ferraris); MS7 Crystal Chemistry of Inorganic and Mineral Compounds (Convenor W. Depmeier); MS35 Polytypism and Twinning (Convenor G. Ferraris); MS79 Inorganic and Mineral Structures Solved and Refined by Powder Diffraction Data (Convenor J. Rius); MS14 Modularity and Modulation in Inorganic and Mineral Structures; MS28 Structure/Properties Relationships of Technologically Relevant Inorganic and Mineral Compounds (Convenor J. Rocha); Keynote Lecture: L. B. McCusker; oral contributions: G. Ferraris, D. Yu. Pushcharovsky, I. D. Brown, M. Matsui, M. Nespolo, D. Pandey and J. Rocha.

International School on Mathematical and Theoretical Crystallography organized by M. Nespolo as Chair of the Commission on Mathematical and Theoretical Crystallography (MaThCryst) (Nancy, France, June 2005). A Special Issue of Acta Crystallographica Section A (Guest Editor M. Nespolo) containing articles contributed by lecturers and participants has been published.

ECM-22 satellite meeting Crystallography at the Start of the 21st Century: Mathematical and Symmetry Aspects organized by M. Nespolo as Chair of MaThCryst (Budapest, Hungary, August 2004). A Special Issue of Zeitschrift für Kristallographie containing articles contributed by lecturers and participants has been published.

Satellite of ECM-23 Mathematical and Theoretical Crystallography organized by M. Nespolo as Chair of MaThCryst (Leuven, Belgium, August 2006). G. Ferraris lectured on Symmetry Constraints and Modularity: Tools to Model Inorganic Crystal Structures.

Satellite of AsCA '06 Theoretical Crystallography and Materials Science, main organizer M. Nespolo as Chair of MaThCryst (Tsukuba, Japan, November 2006). The following lectures were delivered by members of CIMS: G. Ferraris, Symmetry Constraints on the Physical Properties of an Anisotropic Material; M. Matsui, Computer Simulation of Temperature-Pressure-Volume Equations of State of Melts in the System $\mathrm{CaO}-\mathrm{MgO}-\mathrm{Al}_{2} \mathrm{O}_{3}-\mathrm{SiO}_{2}$; D. Pandey, Phase Transitions in Mixed Perovskites. 
XVI International Conference on Crystal Chemistry and Diffraction Studies of Minerals (Miass, Russia, July 2007). W. Depmeier, G. Ferraris and D. Yu. Pushcharovsky were members of the Programme Committee; W. Depmeier and G. Ferraris were also invited speakers.

Workshop 'Minerals as Advanced Materials' (Apatity, Russia, July 2007). W. Depmeier and G. Ferraris were invited speakers. As an outcome of this Workshop the volume Minerals as Advanced Materials I (Editor S. V. Krivovichev) was published by Springer.

International School on Mathematical and Theoretical Crystallography (Havana, Cuba, July 2007). G. Ferraris and M. Nespolo (as Chair of MaThCryst) were organizers and speakers.

ACA Annual Meeting (Salt Lake City, USA, 21-26 July 2007).

Structural Aspects of Crystalline Materials (from inorganic to macromolecular) as a Section of the 41st IUPAC World Chemistry Congress (Torino, Italy, August 2007); G. Ferraris was a proponent.

ECM-24 (Marrakech, Morocco, August 2007) and its satellite The Enchanting Crystallography of Moroccan Ornaments organized by M. Nespolo as Chair of MaThCryst; P. Thomas and W. Depmeier served on the Programme Committee; J. Rocha was a Keynote speaker; G. Ferraris and P. Thomas were Chairs of a Microsymposium.

II International Conference 'Crystallogenesis and Mineralogy' (St Petersburg, Russia, October 2007) and its satellite Structural Chemistry of Inorganic Actinide and Lanthanide Compounds. W. Depmeier was Chair and an invited speaker at both meetings. G. Ferraris and D. Yu. Pushcharovsky were members of the International Programme Committee.

Workshop on Structure Elucidation by Combining Magnetic Resonance, Computation, Modelling and Diffraction (SMARTER), Aveiro, Portugal, September 2007, organized by J. Rocha; G. Ferraris was a member of the International Programme Committee.

MSA-GS-ANL Short Course on 'Amphiboles' (Rome, Italy, October 2007). F. C. Hawthorne was organizer and speaker. The volume Amphiboles: Crystal Chemistry, Occurrence, and Health Issues (Editors F. C. Hawthorne, R. Oberti, G. Della Ventura and A. Mottana), No. 67 of the series Reviews in Mineralogy and Geochemistry, has been published.

II International Workshop on Layered Materials - Structure and Properties (Vercelli, Italy, March 2008). G. Ferraris: member of the Organizing Committee; W. Depmeier, G. Ferraris and D. Pandey: members of the Programme Committee; J. Rocha: invited speaker. Based on contributions to this Workshop, a Special Issue of Zeitschrift für Kristallographie is in preparation (Editor G. Ferraris).

The following events at the Osaka Congress (co)organized by CIMS: MS70 Crystal Chemistry and Crystallography of Aperiodic Crystals; MS77 Diffuse Scattering in Partially Ordered/Disordered Systems; MS93 Crystallography of Planetary Materials at Extreme Conditions; MS94 From Minerals to Materials; MS95 MultiTechnique Approach to the Determination of Inorganic Structures; MS97 Perovskites and Related Materials; MS98 Structure-Properties Correlations and Phase Transition in Inorganics; KN11 Crystallochemical Basis of Synthetic Mineral Immobilizations, speaker T. White; KN36 Structure Refinement and Structure Modelling: a Chemical Probe for Complex Mineral Groups, speaker R. Oberti; KN23 Structural Phase Transitions, speaker J. M. Perez-Mato; W. Depmeier, G. Ferraris, L. B. McCusker, M. Nespolo and D. Pandey are Chairs of Microsymposia or Keynote sessions; P. Thomas is a member of the Programme Committee.

Other activities of CIMS members. The following activities of members related to the CIMS purposes and not mentioned above have been reported to the Chair for the triennium.
Following the meeting Micro- and Mesoporous Mineral Phases (Rome, Italy, December 2004), the twelve invited lectures were published in 2005 as Volume 57 of the series Reviews in Mineralogy and Geochemistry of the Mineralogical Society of America (same title as the meeting; Editors: G. Ferraris and S. Merlino; CIMS contributors: L. B. McCusker, W. Depmeier, G. Ferraris and J. Rocha). Ten other contributions were published in a dedicated issue of the European Journal of Mineralogy (Issue 2005/6).

CIMS contributed to suggestions for topics and authors for the Special Issue '60 Years of Acta Crystallographica and the IUCr'; D. Pandey co-authored the article Stability of Ferroic Phases in the Highly Piezoelectric $\mathrm{Pb}\left(\mathrm{Zr}_{x} \mathrm{Ti}_{1-x}\right) \mathrm{O}_{3}$ Ceramics.

G. Ferraris: member of the Programme Committee and Convenor of the 19th Meeting of the International Mineralogical Association (IMA) (Kobe, Japan, July 2006); Vice-Chair of the Commission on New Minerals and Mineral Names (CNMMN) of IMA; co-author with E. Makovicky and S. Merlino of the IUCr monograph Crystallography of Modular Materials (paperback edition, 2008).

W. Depmeier: co-organizer of the meeting Mineralogical Museums (St Petersburg, Russia, June 2005); a volume with the same title was edited by V. G. Krivovichev and W. Depmeier (St Petersburg, 2005); Chair of the ECA Special Interest Group SIG5 Mineralogical Crystallography; member of the Programme Committee for ECM-23 (Leuven, Belgium, August 2006); Keynote Lecture at the Jahrestagung 'Deutsche Gesellschaft für Kristallographie' (Bremen, Germany, March 2007); invited speaker at the workshop Time- and Temperature-Resolved X-ray Powder Diffractometry: New Developments in Techniques and Applications (Fraunhofer ICT, Berghausen, Germany, November 2007).

M. Jansen: co-organizer of the workshop In situ Powder Diffraction (Stuttgart, Germany, October 2005).

M. Matsui: Meeting Secretariat for IMA-2006 (Kobe, Japan, July 2006) and Convenor of the session Computational Study of Mineral Structures and Properties at the same meeting; Editor of Physics and Chemistry of Minerals; invited speaker at the 15th Annual Goldschmidt Conference (Moscow, Idaho, USA, May 2005).

L. B. McCusker: invited lecturer at Jilin University (People's Republic of China), Kiel University (Germany), Heyrovsky Institute (Prague, Czech Republic), Winnipeg (Canada), University of Stockholm (Sweden), Dijon (France); member of the Organizing/ Programme Committees for ZMPC2006 (Yonago, Tottori, Japan, 2006), EPDIC-10 (Geneva, Switzerland, 2006) and 15th IZC (Beijing, People's Republic of China, 2007); Co-editor for Acta Crystallographica Section B; co-maintains the IZA web sites http://www.izaonline.org/ and http://www.iza-structure.org/ (Database of Zeolite Structures); co-author (with C. Baerlocher and D. H. Olson) of the 6th revised edition of the Atlas of Zeolite Framework Types (Elsevier).

M. Nespolo: Chair of MaThCryst; Associate Editor of the European Journal of Mineralogy; Secretary of the Special Interest Group SIG5 Mineralogical Crystallography of the ECA; Chair of MS19 at ECM-23; Co-Convenor of MS8 at IMA-2006 (Kobe, Japan, July 2006).

D. Pandey: Microsymposium Chair at the International Conference on Advanced Materials (Bangalore, India, 2007); Chair of Materials Science Session of AsCA '06 held at Tsukuba, Japan; Coeditor for Acta Crystallographica Section A; invited speaker at the Workshop on Morphotropic Phase Boundary Ceramics held at TU Darmstadt, Germany.

D. Yu. Pushcharovsky: represented CIMS on the Programme Committee of the Florence Congress; Plenary Lecture at ECM-23; Associate Editor of the European Journal of Mineralogy. 
P. Thomas: member of the Programme Committee for ECM-23.

J. Rocha: member of the editorial board of the European Journal of Inorganic Chemistry.

E. Tillmanns: Chief Editor of the European Journal of Mineralogy; Chair of the Organizing Committee of the 20th General Meeting of the International Mineralogical Association (IMA) (Budapest, Hungary, 2010).

\section{G. Ferraris, Chair}

A4.13. Commission on Mathematical and Theoretical Crystallography. The Commission (MaThCryst) was formally approved by the Florence General Assembly, from an original nucleus of crystallographers who gathered in September 2002 as an informal MaThCryst working group.

Meetings and schools. In the triennium MaThCryst has organized the following meetings and schools:

Summer School in Nancy, France, 20-24 June 2005 (http:// www.crystallography.fr/mathcryst/nancy2005.htm), in cooperation with the Commission on Inorganic and Mineral Structures (CIMS).

Satellite meeting of the 23rd European Crystallographic Meeting, Leuven, Belgium, 4-6 August 2006 (http://www.crystallography.fr/ mathcryst/leuven2006.htm), in cooperation with CIMS.

Satellite meeting Theoretical Crystallography and Materials Science, on the occasion of AsCA '06, Tsukuba, Japan, 18-19 November 2006 (http://www.crystallography.fr/mathcryst/ asca2006.php), in cooperation with CIMS.

Summer School in Havana, Cuba, 15-20 July 2007 (http:// www.crystallography.fr/mathcryst/havana2007.php), in cooperation with CIMS and the Commission on Crystallographic Teaching.

Satellite meeting of the 24th European Crystallography Meeting, Marrakech, Morocco, 20-22 August 2007 (http://www. crystallography.fr/mathcryst/marrakech2007.php).

Publications. A Special Issue of Zeitschrift für Kristallographie (Issue 2006/1, published in November 2005), Guest Editor H. Grimmer, has been published, containing articles contributed by lecturers and participants at the satellite meeting Crystallography at the Start of the 21st Century: Mathematical and Symmetry Aspects, held on the occasion of the 22nd European Crystallographic Meeting, Budapest, Hungary, 24-26 August 2004 (http://www.extenza-eps.com/ OLD/toc/zkri/221/1_2006; jsessionid=oKNiA6GZLBTaH5H3pN).

A Special Issue of Acta Crystallographica Section A [(2006), 62(2)], Guest Editor M. Nespolo, was published containing articles contributed by lecturers and participants at the Nancy School (http:// journals.iucr.org/a/issues/2006/02/00/issconts.html).

MaThCryst suggested topics and authors for the Special Issue ' 60 Years of Acta Crystallographica and the IUCr': M. Nespolo contributed a feature article with the title Does Mathematical Crystallography Still Have a Role in the XXI Century? [Acta Cryst. (2008), A64, 96-111].

A book on Graph Theory in Crystallography and Crystal Chemistry (by J.-G. Eon, W. Klee and J. Rutherford) is in preparation; publication is expected in 2009 as an IUCr Monograph on Crystallography as part of the IUCr/OUP Book Series.

Didactic material and abstracts. Didactic material and abstracts from oral and poster presentations at MaThCryst schools and satellite meetings are available from the respective web sites with the addresses given above.

Other activities. M. Nespolo represents MaThCryst in the IUCr Online Dictionary project (http://reference.iucr.org/dictionary/ Main_Page), a WiKi-based online dictionary with free reading access but with editing limited to selected authors.
M. O'Keeffe represents MaThCryst on the International Programme Committee of the Osaka Congress.

Future activities. A Summer School at Gargnano, Lake Garda, Italy, will be held 27 April - 2 May 2008 (http://www. crystallography.fr/mathcryst/gargnano2008.htm), in cooperation with the Commission on Crystallographic Teaching.

The following activities took place within the framework of the Osaka Congress:

(1) KN29 Keynote Lecture on Crystal Design and Synthesis: Reticular Chemistry by O. M. Yaghi, Chair D. Proserpio.

(2) MS89 Microsymposium in honour of E. Ascher and J. J. Burckhardt, Chairs H. Grimmer and M. Nespolo, invited speakers: A. Janner, M. Senechal.

(3) Evening Session on Art and Crystallography, Chair M. Nespolo.

A satellite conference of ECM-25 on Symmetry and Crystallography in Turkish Art and Culture, will be held in Istanbul, Turkey, 7-9 August 2009 (http://www.crystallography.fr/mathcryst/ istanbul2009.php).

MaThCryst also plans to organize a thematic school on graph theory, to be held after the publication of the above-mentioned Monograph with the authors of the Monograph as lecturers, as well as a thematic school on irreducible representations of space groups, with main lecturers M. I. Aroyo and B. Souvignier. The venues and precise schedules have not been decided.

\section{Nespolo, Chair}

A4.14. Commission on Neutron Scattering. A significant event and important gathering of the neutron community in the triennium was the International Conference on Neutron Scattering (ICNS 2005), held in Sydney, Australia, 27 November - 2 December 2005. ICNS provides an international forum for the presentation and discussion of recent developments in neutron sources, the techniques of neutron scattering, and their application to physics, chemistry, biology, materials science and industry.

On the occasion of ICNS 2005 the Commission held a meeting where the tasks of the Commission were discussed and arranged and new members introduced themselves.

At a special session of ICNS the prestigious Walter Hälg Prize was awarded to A. Furrer (ETH Zürich and Paul Scherrer Institute, Switzerland) and H. U. Güdel (University of Bern, Switzerland). The Prize is awarded biennially by the European Neutron Scattering Association (ENSA) to European scientists for outstanding work in neutron scattering with a long-term impact on scientific and/or technical neutron scattering applications.

In 2007 the Walter Hälg Prize was awarded to J. Penfold (Rutherford Appleton Laboratory, UK) at the European Conference on Neutron Scattering (ECNS 2007, Lund, Sweden, 25-29 June 2007). Furthermore at ECNS, the Erwin Felix Lewy Bertaut Prize was awarded by the European Crystallographic Association (ECA) and the European Neutron Scattering Association (ENSA). This Prize is intended for young European scientists in recognition of notable experimental, theoretical or methodological contributions in the field of the investigation of matter using crystallographic or neutron scattering methods. In 2007, the Prize Committee decided to award the Erwin Felix Lewy Bertaut Prize to H.M. Rønnow (Ecole Polytechnique Fédérale de Lausanne, Switzerland).

Besides ICNS and ECNS several conferences relevant to neutron scattering were held during the triennium; for example, the American Conference on Neutron Scattering (ACNS 2006, St Charles, USA, 18-22 June 2006) and the 1st International Symposium of the 
Quantum Beam Science Directorate of JAEA (QuBS 2006) entitled Advances in Neutron, Synchrotron Radiation, $\mu \mathrm{SR}$ and NMR Researches (Tokyo, Japan, 28-30 August 2006). QuBS 2006 was one of the satellite meetings of the 17th International Conference on Magnetism (ICM 2006, Kyoto, Japan) and focused on magnetism, superconductivity and related materials studied with four complementary probes: neutrons, synchrotron radiation, $\mu \mathrm{SR}$ and NMR.

Additionally, increasing efforts were put into the training of young researchers in the field of neutron scattering. Well established annual courses/schools for young scientists include the Oxford School on Neutron Scattering (Oxford, UK), the PSI Summer School on Condensed Matter Research (Zuoz, Switzerland), the JCNS Laboratory Course on Neutron Scattering (Jülich/Garching, Germany) and the HMI School on Neutron Scattering (Berlin, Germany).

Concerning neutron sources worldwide, the last three years have been successful and favourable for users as new sources were set in operation and important upgrades/changes at existing neutron sources have been made.

In April 2006 the new accelerator-based Spallation Neutron Source SNS at Oak Ridge National Laboratory (USA) produced its first neutrons. This marks a great step for the neutron community in realizing the first accelerator-based neutron source, which uses a liquid target to generate neutrons. SNS will provide the most intense pulsed neutron beams in the world for scientific research and industrial development. In 2006 the first three instruments were available for initial users. According to plan the SNS instrument hall will contain 24 instruments on 18 beamlines.

At ISIS, the pulsed spallation source at Rutherford Appleton Laboratory (Oxfordshire, UK), the Second Target Station Project is ongoing. The construction of the Second Target Station, which began in 2003, achieved a major milestone in December 2007, when the first proton beam was successfully delivered to the new target station. The Second Target Station Project will double the capacity of the ISIS research centre and open new opportunities in biomolecular science, nanoscale science, advanced materials and soft condensed matter. It will open for experiments in autumn 2008.

The Japan Proton Accelerator Research Complex (J-PARC) in Tokai is currently under construction, and its completion is scheduled for 2008. J-PARC is a three-stage accelerator complex with a Linac, a $3 \mathrm{GeV}$ rapid cycling synchrotron and a $50 \mathrm{GeV}$ proton synchrotron, built by the Japan Atomic Energy Agency (JAEA) and High Energy Accelerator Research Organization (KEK). The $3 \mathrm{GeV}$ rapid cycling synchrotron will be used for a $1 \mathrm{MW}$ spallation source, the Japanese Spallation Neutron Source (JSNS).

In the People's Republic of China, the construction of a new neutron research reactor is making good progress. The China Advanced Research Reactor (CARR), a $60 \mathrm{MW}$ facility, is expected to become critical in 2008. In 2007 the first meeting of the International Advisory Committee of CARR took place in Beijing.

In the USA, an expansion of the NIST Center for Neutron Research (NCNR, Gaithersburg) is underway. The project comprises the development of a new cold neutron moderator, and a new guide hall with five state-of-the-art instruments.

The ILL (Institut Laue-Langevin) in Grenoble (France), the world's most intense reactor neutron source, is running successfully after a ten-month shutdown between August 2005 and June 2006 in conjunction with a refit programme. In 2007 the ILL celebrated its 40th anniversary and launched the second phase of the Millennium Programme. The overall goal of the Millennium Programme, which started in 2000, is to modernize the infrastructure and instrument suite to provide the best possible experimental facilities and support to its European users over the next two decades. In this second period (2007-2013) five new instruments will be built and four others will be upgraded.

In Australia a new research reactor, known as OPAL (Open Pool Australian Lightwater), replaces Australia's first nuclear reactor HIFAR (High Flux Australian Reactor), which was shut down in 2007 after 49 years of successful operation. OPAL went critical in August 2006 and reached its full power of $20 \mathrm{MW}$ for the first time in November 2006. The official opening ceremony took place in April 2007 at the Australian Nuclear Science and Technology Organization (ANSTO) Research Establishment in South Sydney, Australia. Unlike HIFAR, OPAL has a cold neutron source to enable research on biological materials.

A further outstanding event was the beginning of the routine operation of the new reactor FRM II (Forschungsneutronenquelle Heinz Meier-Leibnitz) in Munich, Germany, in April 2005. In May 2006 FRM II reached its nominal power of $20 \mathrm{MW}$ when the first neutrons were delivered to users in the experimental hall. One year later the neutron guide hall was inaugurated; it includes cold and thermal neutron guides and a positron beam. Eight of the scattering instruments in the neutron guide hall at FRM II, which were formerly located at FRJ-2, are operated by the Forschungszentrum Jülich with its own team of scientists, engineers and technicians. The Forschungszentrum Jülich inaugurated the Jülich Centre for Neutron Science (JCNS) at FRM II in February 2006 and herewith strengthens its activities at external neutron sources after the shutdown of their own research reactor FRJ-2 in May 2006.

Unfortunately, another shutdown of a medium-flux source took place in the past period. The decommissioning phase of the 45-yearold research reactor R2 at Studsvik, Sweden, started in 2005.

At the research reactor BER II, operated by Hahn-MeitnerInstitut Berlin (Germany), a second neutron guide hall was completed in January 2005. The world's strongest magnet for neutron experiments (between 25 and $30 \mathrm{~T}$ ), the High Field Magnet, will be installed there. This new magnet will be built in cooperation with the National High Magnetic Field Laboratory (NHMFL) at Florida State University, Tallahassee, USA, and is planned to be completed by 2011. Two new instruments, an Extreme Environment Diffractometer for the use of the High Field Magnet and a second small-angle scattering instrument, will also be located in the second guide hall.

Another important topic concerning neutron sources worldwide is the discussion about the European Spallation Source (ESS). After several years of standstill, the ESS project has regained momentum by becoming one of the 35 priority projects endorsed by the 2006 report of the European Strategy Forum on Research Infrastructures (ESFRI) and by the announcement of a number of European regions to be ready for financial commitments for hosting this project. In 2007, three governments (the Spanish, Swedish and Hungarian) have put forward official bids for the investment costs in order to host the ESS but so far the final location of the world's most powerful spallation source remains to be decided. The ESS project is very important for the future of neutron science and the neutron community is looking forward to the realization of this exciting project in the near future.

\section{Steiner, Chair}

A4.15. Commission on Powder Diffraction. The Commission (CPD) has supported a number of events and projects during the triennium and has been delighted to endorse regional meetings in emerging regions across the world. The Latin-American Workshop on Applications of Powder Diffraction and the two-day satellite 
workshop Methods of Powder Diffraction, Laboratório Nacional de Luz Síncrotron, Campinas, Brazil, 16-20 April 2007, were a particular success. The CPD has also strongly encouraged small, focused workshops on advanced aspects of powder diffraction and meetings have discussed the state-of-the-art in pair distribution function analysis, protein crystallography from powder diffraction data, Rietveld analysis and structure determination from powders.

Meetings/workshops/schools. The CPD meetings of the current triennium were held at the Florence Congress in 2005, the 2006 EPDIC Meeting in Geneva, Switzerland, and the 2007 ECM in Marrakech, Morocco. Regional meetings in Indonesia and Brazil and two workshops at the ESRF, Grenoble, France, have been supported by the CPD, which continues to encourage crystallographers around the world to promote powder diffraction research and education. The fifth Size-Strain Conference, Diffraction Analysis of the Microstructure of Materials, Garmisch-Partenkirchen, Germany, 2-9 October 2007, was also endorsed by the CPD. The CPD also supported the Powder Diffraction and Rietveld Refinement School at the University of Durham, UK, in March 2008 and the Joint PSIAIC-SGK Summer School on Structure Determination from Powder Diffraction Data held at PSI Villigen, Switzerland, in June 2008.

Projects. One ongoing CPD initiative is the project on best practice for the analysis and deposition of organic structures from powder diffraction data and is providing substantial input into an advanced monograph on powder diffraction edited by $\mathrm{R}$. Dinnebier and $\mathrm{S}$. Billinge.

$C P D$ web site. The Commission web site has been rewritten and is now located at http://www.iucr-cpd.org.

Newsletters. There have been three Newsletters published in this period edited by Commission members R. Rizzi, N. Masciocchi, D. Rafaja, and by former Commission Chair R. Dinnebier. Three further Newsletters are in preparation and are edited by M. Delgado, S. Billinge, and P. Stephens and P. Whitfield. All CPD Newsletters are now available online in pdf format at http://www.iucr-cpd.org/ Newsletters.htm. The CPD has taken the decision that all future Newsletters will only be available electronically from the CPD web site. Various members of the Commission have agreed to produce Newsletters on a twice-yearly basis. The computer software pages in the CPD Newsletter are produced by L. M. D. Cranswick and are very much appreciated by readers for their informative content and their effective presentation. News from ICDD and from IXAS is also present in all issues, together with news on forthcoming events.

\section{W. I. F. David, Chair}

A4.16. Commission on Small-Angle Scattering. The details of the Commission's activities are presented in the corresponding Annual Reports. The present report provides a general overview of the work of the Commission in the reporting period and outlines the directions of future activity.

Communications and personnel. At the Florence Congress, a new Commission Chair (D. I. Svergun) and new members (J. Trewhella and A. Benedetti) were appointed. T. Sabine left the Commission and I. Torriani became a consultant.

Most of the communications between Commission members were by e-mail or during personal meetings at different international conferences.

Scientific meetings. The triennial Small-Angle Scattering (SAS) conference. The International Conference on Small-Angle Scattering is the main occasion for scientists using this technique worldwide. The Conference has been held on a triennial term for over 40 years and provides a forum for exchanging ideas related to SAS itself across the boundaries of the various scientific disciplines and applications. At the XII SAS Conference in Venice, Italy (2002), the problem of collision with the triennial IUCr Congress was considered and it was decided to postpone the next SAS Conference by a year to avoid the conflict. The XIII SAS Conference (Kyoto, Japan, 8-13 July 2006) was the first to be considered a satellite meeting of the IUCr Congress, and it was by far the largest SAS event so far. The Conference attracted 548 participants from 33 countries and five continents, with a total of 538 presentations (125 oral and 413 posters), which was almost a $30 \%$ increase over SAS 2002 .

Most of the Commission members served on the International Advisory Committee of SAS 2006. N. Yagi was a Vice-Chair of the Organizing Committee and Y. Amemiya was a Chair of the Programme Committee. The scientific programme of the Conference contained seven plenary lectures on hot topics covering various scientific fields, 19 general sessions and five special sessions.

Young researchers from 14 countries were supported financially by the IUCr. The Commission Prize initiative, which was well received by the SAS community at the Venice 2002 Conference, was sustained at SAS 2006, where the Commission worked together with the organizers to award SAS prizes. A Prize for a significant contribution to the advancement of the SAS technique was given to H. Stuhrmann, and three Young Scientist Prizes were also awarded. The Proceedings of SAS 2006 were published in a Special Issue of Journal of Applied Crystallography (April 2007), for which Commission members G. Kostorz and A. Allen served as Guest Editors.

The scope of the work of the Commission was presented to the participants of the Conference and plans for future activity were highlighted. Among the topics discussed were a possible textbook on SAS, the use of the SAS listserver, standard samples and standard data formats.

In coordination with the organizers of SAS 2006 the Commission made a call to the SAS community for bids to host the next SAS Conference, and after a ballot of the participants Oxford, UK, was selected as the venue of SAS 2009. The Commission is now working together with the International Advisory Committee of the Oxford SAS conference in soliciting applications for SAS 2012. It is planned to come up with a balanced recommendation for the SAS 2012 venue (to be approved by the SAS 2009 attendees). Such a selection scheme will also be proposed for future SAS conferences. G. Kostorz agreed to act as a liaison person from the Commission in establishing this mechanism.

IUCr Congresses. The Commission participated in providing visibility for SAS during the Florence Congress. A Keynote Lecture in SAS from Biological Macromolecules was given (D. I. Svergun) and J. S. Pedersen organized a one-day satellite workshop on Small-Angle Scattering. Several Commission members gave tutorial lectures at the workshop. Y. Amemiya and I. Torriani organized a Microsymposium on Analysis of Anisotropic Materials.

The Commission has been actively preparing for the Osaka Congress. A suggestion was made for the topic of the Keynote Lecture in SAS (Advances in Micro and Nano-SAXS), which will be given by Commission member P. Fratzl. Moreover, topics for four SAS-related Microsymposia were suggested and approved for the IUCr meeting, and these Microsymposia will be Co-Chaired by Commission members J. Trewhella, P. Fratzl, P. Thiyagarajan and A. Allen.

Educational activity. During 2005-2007 all Commission members were active in organizing and participating in courses, schools and tutorial workshops to promote the small-angle scattering technique worldwide. In particular, J. S. Pedersen organized a one-day tutorial Workshop on SAS in connection with the Florence Congress and D. I. 
Svergun organized an EMBO Practical Course on Solution Scattering from Biological Macromolecules (Hamburg, Germany, October 2006). Members of the Commission acted as lecturers and tutors at both events. N. Yagi gave a practical course on SAXS at Cheiron Summer School (Himeji, Japan, September 2007). J. Trewhella promoted educational activities in the Pacific Rim Countries with SAS strongly featured at several regional workshops and meetings. A. Allen and P. Thiyagarajan were involved in the preparation of various new SAS guides and tutorials in the USA (at NIST, Gaithersburg, and APS, Argonne). I. Torriani organized a short tutorial course on SAXS during the 2006 Meeting of the Argentinian Crystallographic Association in Puerto Madryn.

Further, several Commission members are running SAXS or SANS instruments at large-scale facilities, and they educate and train students and postdocs from the visiting user groups in the practical aspects of small-angle scattering.

Publications. The proceedings of the Kyoto 2006 SAS Conference, similar to many previous triennial conferences, were published in Journal of Applied Crystallography. The high quality of the published papers is largely thanks to G. Kostorz (consultant of the Commission), who regularly acts as the Editor of the SAS Proceedings issues. The Commission has an opinion that the Proceedings should continue to be published in a highly ranked journal like Journal of Applied Crystallography, since each new volume serves as an important reference for the SAS community. This opinion was also expressed to the organizers of the SAS 2009 Conference.

The idea of writing a textbook on small-angle scattering was raised publicly by the members of the Commission (in particular at SAS 2006), and the need for an entry-level book written by a few authors was emphasized. Discussions showed that some scientists would be prepared to contribute a chapter to a larger volume, but they were less willing to take responsibility for writing a full textbook covering all major aspects of SAS. Members of the Commission continue to discuss this issue with prominent representatives of the SAS community who might act as authors/contributors.

Software development. The Commission maintained contacts with the initiatives canSAS and NOBUGS related to software, data handling and analysis. In particular, A. Allen's home institute, NIST (Gaithersburg, USA), hosted the canSAS V workshop in October 2007. The software package ATSAS developed in the group of D. I. Svergun is publicly accessible for academic institutions and is currently used by more than 1000 users from over 500 laboratories. P. Thiyagarajan provided a SAXS/SANS analysis package on the Igor Pro platform to numerous users at Argonne National Laboratory, USA.

Community building. During 2005-2007, numerous scientific presentations were given by members of the Commission at conferences, workshops and round-table meetings devoted to the future development of SAS and also to interactions with adjacent scientific methods. In particular, J. S. Pedersen participated in the round-table discussion of the future of SANS activities at the Frank Laboratory of Neutron Physics (Dubna, Russia, October 2006). D. I. Svergun was invited to highlight the biological SAS scientific case to a workshop at the Canadian Light Source in Saskatoon, Canada (2007) where recommendations for the future construction of beamlines at this synchrotron were presented. J. Trewhella has been appointed to the Neutron Decadal Planning Group to draft the plan for neutron scattering in Australia for the next decade.

Most Commission members serve on scientific committees at largescale facilities, national as well as international, in many countries, including e.g. Germany, France, UK, Italy, Denmark, USA, Japan, Australia and Brazil. They not only evaluate beam-time applications, but also participate in important discussions about the future development of the instrumentation and strategies of the facilities. The members of the Commission further contributed to the widening of the user community of the SAS instruments in their home laboratories and large-scale facilities, offering service, help in data collection and analysis as well as hands-on courses.

Given the constantly increasing importance of the Internet for scientific communications, significant effort was invested by the Commission in this direction. The new joint moderators of the $\mathrm{IUCr}$ SAS listserver (S. King, N. Terrill and M. Malfois, ISIS/Diamond, Oxford, UK) ensured a more active use of this listserver by the community from August 2006. A WiKipedia entry on biological smallangle X-ray scattering was made at http://en.wikipedia.org/wiki/ Biological_small-angle_X-ray_scattering. A web SAS forum was created at http://www.saxier.org/forum, which now has about 100 registered users, largely discussing software issues. P. Fratzl was appointed as a liaison person from the Commission to the working group on the Online Dictionary. Further work with web communications, including refurbishing of the Commission web site, is ongoing.

Organizational activity. All Commission members either organized or were members of the organizing committees or advisory boards of numerous conferences, workshops, schools or round tables around the world, related to SAS. These include major events such as the Florence Congress, SAS 2006, American Crystallographic Association Meeting 2007, Biology and Synchrotron Radiation Conference (2007) etc. More complete information can be found in the relevant Annual Reports of the Commission.

Technical issues. Commission members contributed to the development of standards for SAS. In particular, A. Allen participated in the work at NIST (Gaithersburg, USA) to develop nanoparticle reference materials for use in biological research applications. D. I. Svergun worked together with I. D. Brown (Chair of COMCIFS) to finalize and ultimately approve the sasCIF data format. In a move to establish standards for publication and deposition of SAS data, J. Trewhella is organizing a meeting with the representatives of the IUCr Commission on Journals and the Protein Data Bank at the Osaka Congress.

All Commission members continued to endorse and pursue novel technical developments at their home institutions and local SAXS/ SANS facilities. As examples, P. Thiyagarajan advised on the developments of new capabilities for SAXS, GISAXS, ASAXS and areadetector development at Argonne National Laboratory (USA); D. I. Svergun made available for the users of the EMBL beamline in Hamburg (Germany) the first liquid-handling robot for solution SAXS experiments and the novel PILATUS pixel X-ray detector; and I. Torriani finished the commissioning of the second (D02SAXS2) beamline at the LNLS source (Campinas, Brazil), which is open to external users from Brazil and other South American countries.

Summary. The Commission has worked on a broad range of organizational, educational and technical tasks during the triennium. Overall, the interest in SAS has grown rapidly in all continents and in all scientific disciplines (physics, chemistry, biology etc.). Commission members contributed to this process through their activities (see Annual Reports for more complete information) and will continue to do so.

\section{I. Svergun, Chair}

A4.17. Commission on Structural Chemistry. According to the guidelines expressed by the Executive Committee at the Florence 
Table 8

Responsibilities for members and consultants of the Commission on Structural Chemistry.

\begin{tabular}{lll}
\hline & Responsible co-workers & Consultants \\
\hline IUCr Newsletter reporter & D. C. Levendis, A. Beatty, A. Bacchi & J. Flippen-Anderson \\
World Directory & P. Bombicz, P. Piro, M. Hong & E. Gutierrez-Puebla \\
Teaching and schools & M. T. L. Duarte, P. R. Raithby & F. Lahoz, J.C. Daran \\
Nomenclature & P. R. Raithby, M. Hong & \\
Journals & H. Uekusa. L. Brammer & F. Lahoz, J.C. Daran \\
International Tables & O. Piro, M. T. L. Duarte & \\
IUCr/OUP Book Series & A. Beatty, P. Bombicz & J. Flippen-Anderson \\
Webmaster & A. Bacchi, H. Uekusa & E. Gutierrez-Puebla \\
60th Anniversary of Acta and IUCr & L. Brammer, D. C. Levendis & \\
\hline
\end{tabular}

molecular solids; uncommon organic and organometallic structures and functions; electric and magnetic properties of molecular crystals; crystal design from hydrogen bond to halogen bond and beyond; host-guest crystal chemistry; chemical recognition and supramolecular architectures; co-crystals: theory, synthesis and use; structurefunction relationships of MOFs (Metal Organic Frameworks); understanding and controlling polymorphism; design and applications of nanoscale materials; and knowledge-based applications in structural chemistry. A Microsymposium in tribute to Pierre-Gilles de Gennes on Liquid Crystals and Crystallography is also planned. Joint Microsymposia with other Commissions (High Pressure;

Congress, the Commission established a list of responsibilities for members and consultants (D. Braga was another active consultant), as shown in Table 8.

Activities. The Commission has updated and restyled its web site, by providing sections containing information on the scientific events supported by the Commission, reports on past events, present activities of the Commission and historical background.

During 2006 many issues have been addressed under the responsibilities of different members. In particular, suggestions were submitted for the 60th Special Anniversary Issue of Acta Crystallographica Section A, lists of attendees to crystallographic schools and meetings have been collected for extending the World Directory of Crystallography, and suggestions for implementing crystallographic nomenclature have been forwarded to the Working Group designated by the Commission on Crystallographic Nomenclature to implement a pilot project for an Online Dictionary. Commission members have been actively involved in the Organizing Committees and Programme Committees of many regional meetings.

The Commission met in 2006 at the Kruger National Park (South Africa), during Indaba 5. Current and future activities were discussed, in particular regarding the programme for structural chemistry for the Osaka Congress.

During 2007 the Commission has promoted the activity of the structural chemistry crystallography community, by recommending and supporting meetings addressing scientific themes of particular interest for structural chemistry. Several meetings of this type have been held in 2007.

Commission members have also contributed to the planning and organization of Microsymposia covering the most emergent topics in structural chemistry within national and international congresses, workshops and schools during 2007.

A key activity of the Commission during 2007 was contributing to the planning of the Osaka Congress. The Commission Chair, A. Bacchi, together with A. Nangia were members of the International Programme Committee (IPC), while E. Gutierrez-Puebla, Commission Consultant, contributed as an ex officio member. C. Mealli and K. Ogawa, whose scientific interests are closely related to structural chemistry, were also appointed members of the IPC. A. Bacchi and A. Nangia collected suggestions from all members and Consultants of the Commission to contribute to the planning of topics for Plenary Lectures, Keynote Lectures, Microsymposia and Chairs. Structural chemistry will be represented in Osaka at all levels (Plenary Lectures, invited presentations, topical sessions and posters), showing the vitality of the discipline and the growing interest of the crystallographic community in topics related to structural chemistry. The topics covered in Osaka will include: modelization of structure of molecular compounds and implications for reactivity; water clusters in molecular crystals; symmetry, asymmetry and chirality in molecular aggregation; photochemistry and solid-state transformations of
Biological Macromolecules; Crystallographic Teaching; Crystal Growth and Characterization of Materials; Crystallographic Computing; Charge, Spin and Momentum Densities; Powder Diffraction) on common topics have also been encouraged as a way of highlighting the interdisciplinarity of structural chemistry.

Events supported by the Commission. Several requests for the support of the Commission have been received during the triennium. All applications were thoroughly examined and discussed among Commission members; in particular, organizers were advised to encourage the participation of young researchers from less advantaged countries, and to ensure a gender balance in the scientific programme.

During 2006 support was given to the Russian Fourth National Crystal Chemical Conference (Chernogolovka, Russia, 26-30 June 2006), the French Crystallographic School (Nancy, France, 28 August - 2 September 2006) and Indaba 5 (Kruger National Park, South Africa, 20-25 August 2006).

During 2007 the Commission supported the American Crystallographic Society Annual Meeting (Salt Lake City, 21-26 July 2007), the School on Materials Applications of the Organic Solid State (SMAOSS) and the XVIII International Conference on the Chemistry of the Organic Solid State (XVIII-ICCOSS) (Merida, Venezuela, 1-6 July and 8-13 July 2007).

The American Crystallographic Association Annual Meeting (Knoxville, USA, 31 May - 5 June 2008) will be supported by the Commission in 2008.

\section{A. Bacchi, Chair}

A4.18. Commission on Synchrotron Radiation. The aim of the Commission is to promote access and awareness of crystallographers worldwide to the world's synchrotron radiation (SR) facilities. Two subcharges are to promote the development of crystallographic instrumentation technology and standards, and to promote synergies between classical storage rings and future free-electron-laser- (FEL-) based sources. As the best means to achieve these goals, the Commission supports international meetings.

The Commission supported the following meetings and activities during the triennium.

(1) The Commission endorsed the establishment of the Asian/ Oceanic Forum for Synchrotron Radiation Research (AOFSRR), and supported funding requests for their annual meetings. One of the goals of the AOFSRR is the coordination of synchrotron-related activities in Asia and Oceania, via joint user and scientific meetings. The first meeting of the AOFSRR was held 23-24 November 2006 at KEK, Tsukuba, Japan (http://pfwww.kek.jp/AOF2006/). The number of participants was 127, including 13 students (Australia 10, China 14, Korea 16, Singapore 1, Taiwan 11, Thailand 2 and Japan 73). There were 18 oral presentations, 57 posters and 20 facility reports. During 
the first AOFSRR, the Forum's constitution was finalized and the Memorandum of Understanding formally establishing the AOFSRR was signed. The second AOFSRR workshop was held at National Chao-Tung University, Hsinchu, Taiwan, 1-2 November 2007 (http:// aof.nsrrc.org.tw/aboutus/index.php) in conjunction with the NSRRC Users' Meeting. The total number of participants was 561, among which 80 were international, from Australia (14), China (12), India (4), Japan (34), Korea (6), Singapore (2), Thailand (7) and France (1).

One of the outcomes of the establishment of the AOFSRR is an international summer school on synchrotron radiation organized by SPring-8 (http://cheiron2007.spring8.or.jp/). The first Cheiron School was held at SPring-8, 10-20 September 2007, and was attended by about 50 young students from Asia and Oceania. The school curriculum covered all aspects of synchrotron science and technology, with lectures and tutorials given by international experts, and included practical sessions on the SPring- 8 beamlines. The Cheiron School will be held annually: the second school will be hosted by SPring-8, 29 September -8 October 2008.

The third AOFSRR workshop will be held in Australia in December 2008, hosted by the Australian Synchrotron. Once again the meeting will be held in conjunction with the facility Users' Meeting. A one-day workshop on the potential scientific applications of next-generation sources (FELs and ERLs) is also planned.

(2) The Commission continued to support the RapiData courses (2006 and 2007) on automated data collection; in particular, it encouraged the participation of scientists from South and Central America.

(3) The Commission supported funding requests for a School and Workshop on X-ray Micro- and Nanoprobes: Instruments, Methodologies and Applications, which was held in Erice, Italy, in June 2007.

(4) The Commission supported a funding request for the 6th International Conference on Inelastic X-ray Scattering (IXS 2007). This is a well established conference, with a large international participation and very relevant to the Commission's goals and mission.

(5) The Commission reluctantly gave its support for a funding request by the VIII Latin-American Workshop on Magnetism, Magnetic Materials and their Applications (LAW3M 2007), held in Rio de Janeiro, Brazil, 12-16 August 2007. The reluctance was not due to the goals of the Workshop, but more to the fact that it was on the border of the Commission's aims.

(6) The Commission supported the funding request for the 9th International Biology and Synchrotron Radiation Conference, Manchester, UK, 12-17 August 2007.

Besides these supported meetings, members of the Commission have been involved in the triennial International Synchrotron Radiation Instrumentation meeting in Deagu, Korea, May/June 2006. Preparations for the 2009 meeting, to be held in Melbourne, Australia, in September 2009 are well under way. Members of the Commission will again be involved in developing the programme of SRI 2009.

H. Graafsma represented the Commission on the International Programme Committee for the Osaka Congress. The Commission has teamed up with the Commissions on Electron Crystallography and Mathematical and Theoretical Crystallography, to establish a block of Microsymposia on the use of coherence in X-ray studies. In addition, special sessions on new sources and detectors have been organized.

Detectors. One of the sub-aims of the Commission is to stimulate appropriate funding and activities for detectors. In 2006 a Special Issue of Journal of Synchrotron Radiation on X-ray detectors was published, which was extremely well received. Also, for the first time, new sources (both the LCLS and the European XFEL) have dedicated detector development programmes with substantial funding. It is expected to have the first detectors available in 2009, when the LCLS comes online. The European projects have an expected delivery in 2011 or later. Besides these dedicated developments for the FELs, large-area pixel detectors are starting to make their appearance and impact at the storage-ring sources. With these large and fast detectors, increased attention will be needed for dataacquisition systems, and synergies with high-energy experiments will be needed.

LINAC-based sources. Another field of attention has been the new emerging sources based on linear accelerators (such as ERLs and FELs). The Commission will keep making special efforts to promote awareness and access to these sources in the worldwide crystallographic community.

\section{H. Graafsma, Chair}

A4.19. Commission on XAFS. The main goal for the Commission is to promote XAFS in the crystallographic community and to drive new developments. The increase in size of the Commission agreed at the Florence Congress gave rise to a higher level of activity during the triennium.

An announcement on the new IUCr Commission on XAFS was published in the IUCr Newsletter [A. Molenbroek \& I. Ascone (2006), IUCr Newsletter 14(2), p. 2].

At the Florence Congress a successful Microsymposium on Combined XAFS and XRD Techniques in Physics, Chemistry and Material Science was organized by S. Mobilio and J. Garcia-Ruiz.

A web site with information on XAFS for crystallographers has been developed. It is linked to directly from the Commission page at the IUCr site (http://www.iucr.org/iucr/commissions/cxafs.html). This is hosted by the Physics Department of the University of Bologna, Italy, and maintained by F. Boscherini. At the moment it includes, for example, a list of XAFS-related events (conferences, workshops, schools), a compendium of XAFS beamlines at synchrotron facilities and a list of the names and e-mail addresses of the members of the Commission.

The contacts with the International XAFS Society (IXAS) were strengthened. Some of the members of this Commission have dual membership and are eager to improve mutual relations for the benefit of both the XAFS and the crystallographic communities.

Many members of the Commission were present at the 13th International Conference on X-ray Absorption Fine Structure (XAFS-XIII) held at Stanford Campus (http://www-ssrl.slac. stanford.edu/xafs13), 9-14 July 2006. This triennial conference was organized by IXAS (see http://www.i-X-s.org) and covers all fields and disciplines using XAFS and related techniques. Commission members held some good meetings and also some fruitful discussions with the new IXAS Executive Committee. We jointly decided to appoint a small commission to take care of improvement of mutual relations for the benefit of the XAFS and the crystallographic communities. A short presentation on the IUCr and the Commission on XAFS was also given at this conference.

The Commission supported the 9th International Conference on Biology and Synchrotron Radiation (BSR 2007), Manchester, UK, 13-17 August 2007 (http://www.srs.ac.uk/bsr2007). Furthermore, the Commission supported the satellite meeting related to this conference: the 3rd BioXAS Study Weekend at SOLEIL, Saint-Aubin, France, 10-11 August 2007, which was focused on Metalloproteomics (http://www.synchrotron-soleil.fr/workshops/2007/BIOXAS-SWE). 
Many members of the Commission have put considerable efforts into helping to organize the Osaka Congress. A. M. Molenbroek is a member of the Organizing Committee. I. Ascone and Th. Prangé are organizing a Microsymposium (MS63) entitled XAFS in Biocrystallography. K. Asakura and A. Di Cicco are organizing a Microsymposium (MS35) entitled Combined XAFS and Diffraction of Inorganic Structures.

As a joint activity of the Commissions on Charge, Spin and Momentum Densities and XAFS, U. Bergmann and E. Holub-Krappe are organizing a Microsymposium (MS94) on Complementary Low- $Z$ Element Absorption Spectroscopy by X-ray Raman Scattering. As a joint activity of the Commissions on Electron Crystallography and XAFS, D. Saldin and F. Boscherini are organizing a Microsymposium (MS55) on Surfaces.

As a satellite meeting just before the Osaka Congress, a workshop entitled XAFS Tutorials for Crystallographers and Beginners is being organized by the Commission and the Institute of Materials Structure Science (Photon Factory), Tsukuba, Japan, 20-23 August 2008.

\section{A. M. Molenbroek, Chair}

\section{A5. Committee on Electronic Publishing, Dissemination and Storage of Information}

H. D. Flack retired as Chair of the Committee at the Florence Congress. A suitable replacement has yet to be found.

The crystallographic neXus CD-ROM project of L. M. D. Cranswick is continuing. This project involves the production of a standard writable CD-ROM for low-volume distribution in the developing world and contains extracts from web sites, PC-based crystallographic software, web-browsing software and some general-interest software. Another batch of updated CD-ROMs was produced and distributed in 2007.

R. O. Gould has succeeded S. Parsons as the Editor of Crystallography News Online.

M. H. Dacombe, Executive Secretary

\section{A6. Committee for the Maintenance of the CIF Standard}

Introduction. Eighteen years have passed since the IUCr adopted CIF (Crystallographic Information Framework, formerly Crystallographic Information File) as a standard for the submission of crystal structure reports to the Union's journals. We have learned much during that time and COMCIFS, which has responsibility for managing CIF, has been reviewing past progress and planning future directions. Priority in the early years was given to preparing the required CIF dictionaries that now contain an impressive two thousand definitions of crystallographic items. Until recently few other scientific disciplines had a comparable set of dictionaries with such a wide community acceptance, although extensive work is now underway to provide the biomedical sciences with a comparable ontology. The CIF dictionaries are used in conjunction with the STAR file syntax as the format for the extensive current archive of CIF-based structure reports. In the field of small-cell crystallography CIF is widely accepted as the standard for the submission of structure reports to many scientific journals, for their archiving and downloading as well as for transferring crystallographic information between users. In the macromolecular field CIF is used to archive the Protein Data Bank (PDB), and while the file structure does not yet have the same wide community acceptance, the wwPDB exchange dictionary and the official mmCIF dictionary on which it is based provide the definitive definitions of terms in this field.
Dictionary Definition Language (Methods) - DDLm. Eighteen years of experience has shown us how CIF can be enhanced, and at the Florence Congress in 2005 COMCIFS agreed to develop a new dictionary definition language (DDLm) with advanced capabilities. DDLm will make it easier to keep dictionaries up-to-date, to assemble virtual dictionaries customized to individual CIFs, to allow CIFs to include vectors, matrices and tables, and to include in the dictionaries machine-readable expressions that will allow items not present in particular CIFs to be calculated from the information that is present and, more importantly, will allow for consistency checks. The dictionaries will thus not only define individual crystallographic concepts in human-readable form, but will describe how the concepts are related in machine-readable format. Programs written for DDLm dictionaries will be able to read all existing CIFs, and will bring a considerable added value to the task.

During the triennium a final version of DDLm has been created and is currently being evaluated. Work has begun on converting the existing dictionaries to the DDLm standard. It will take some time to complete this conversion, but each new dictionary can be brought online as soon as it is approved. Software that takes advantage of the DDLm features is already being written.

Microsymposium MS96 at the Osaka Congress has been arranged jointly with the Commission on Crystallographic Computing to introduce DDLm and describe the way it will impact on the design of crystallographic software.

Dictionaries. Work continues on the evolving CIF dictionaries. The imgCIF dictionary was designed to record images, specifically those of raw diffraction patterns from two-dimensional detectors. Changes to the imgCIF dictionary to support its use at SLS, Diamond and ESRF are being discussed on the imgCIF list and are the subject of a series of workshops. imgCIF has been adopted as the output format for the new Dectris Pilatus 6M detector at the Swiss Light Source in Villigen, Switzerland, and as of early January 2008, ADSC (Area Detector Systems Corporation) had prepared software to produce imgCIF from all its detectors for use at the Diamond Light Source in Chilton, UK.

The imgCIF group has held a number of workshops during the triennium, including one at the ACA meeting in Hawaii in 2006, one at Brookhaven National Laboratory and another in the UK in connection with the Biology and Synchrotron Radiation Conference in Manchester, in 2007. Further work and workshops will continue in 2008 and the results of this effort will be discussed at the Osaka Congress.

In addition to the construction of DDLm dictionaries, version 2.4 of the core CIF dictionary has been released during the triennium and further revisions are planned. Work on dictionaries for smallangle scattering and reflectivity has resumed after a hiatus.

Software. A notable addition to the suite of CIF programs is the Python package PyCIFRW, which not only reads CIFs using the CIF dictionary, but reads CIF dictionaries using the DDL and even validates DDL against itself [J. R. Hester (2006). J. Appl. Cryst. 39, 621625]. This work leads naturally to the provision of DDLm-compatible software, which will work in the same way.

With financial help from the IUCr, H. J. Bernstein and students have produced updated versions of standard software libraries and tools (the CIFTEST parser test and validation suite, CIFtbx3, cyclops, vcif2, and a new utility to fold and unfold long-line CIFs) that are compliant with the version 1.1 CIF specification. They have also been working on DDLm-compliant software for publications.

The appearance of a number of CIF editors: enCIFer, CIFedit and publCIF, which validate CIFs against the relevant dictionaries, means that definitions of items can be displayed on the screen and syntax 
errors can be detected to ensure that editing produces a conformant CIF.

publCIF, produced by the IUCr editorial office, combines this dictionary-based CIF validation with a sophisticated collection of utilities that will assist prospective authors. These include active links to the checkCIF service, the ability to incorporate validation report forms (VRFs) generated by checkCIF, data-entry wizards, table editors, previews of articles formatted in the styles of the different IUCr structural journals, citation sorting and checking, private databases of authors and citations, and dictionary-browsing facilities. A tool has also been developed for creating enhanced figures in all IUCr journals; these figures are three-dimensional visualizations of molecular structure with associated animations, specified views and schematic representations, and use the CIF (or mmCIF) directly for atomic coordinates and crystallographic symmetry information.

publCIF software is being further developed to support publication of biological macromolecular structures. H. M. Einspahr has worked closely with J. D. Westbrook, of the PDB, and IUCr editorial staff to develop streamlined procedures for incorporating structural data from PDB deposits in associated publications. A set of recommended data items has been drawn up describing information on: the sample and its treatment (including crystallization); data collection and structure solution; and structure refinement details. These can be harvested automatically from an $\mathrm{mmCIF}$ and will generate a table for publication in the article.

Macromolecules. The PDB continues to extend the content of the wwPDB Exchange Data Dictionary (PDBx). PDBx is a superset of mmCIF, which, in addition to macromolecular X-ray methods, includes structure and experimental representations of NMR, 3D electron microscopy, homology modeling, and experimental details of protein production (http://mmcif.pdb.org). A translated version of this dictionary is maintained as an XML schema (PDBML) (http:// pdbml.pdb.org). During the triennium significant extensions have been added to represent large molecular assemblies and more detailed chemical description of both polymer and non-polymer molecular components in macromolecular structures. In 2008 the BMRB partner of the wwPDB released an integrated data deposition tool for NMR and experimental and structure data, NMRADIT, using a consolidated mmCIF dictionary. In other words, there is now a lossless translation between NMR STAR and the PDB Exchange dictionary. The wwPDB has released a remediated version of the PDB archive, which takes advantage of these latter extensions [K. Henrick et al. (2008), Nucleic Acids Res. 36 (Database issue), D426-D433; doi:10.1093/nar/gkm937]. Software related to this work can be found at http://sw-tools.pdb.org/, which contains a broad selection of mmCIF dictionary and data-management tools. This includes the PDB editor tool $A D I T$, dictionary-validating tools, database-loading tools, and data-harvesting tools.

Publicity and housekeeping. A complete documentation of CIF concepts and associated dictionaries was completed in 2005 and published as Volume G of International Tables for Crystallography.

COMCIFS runs a number of discussion lists that can be publicly accessed from the IUCr web site. These include, among others, the main COMCIFS discussion list used for general announcements and discussions of matters relating to CIF itself, and the cif-developers list that has proved popular among software developers for obtaining advice on some of the more esoteric aspects of the standard that are, however, vital for programming.

Now that CIF is firmly established in the crystallographic community and the nature of the work of COMCIFS is moving from the production of dictionaries to the coordination of software, it is time to bring younger members with fresh expertise into COMCIFS.
Together with many of the members of COMCIFS who helped to establish the original CIF standard at the end of the last century, I will be handing over responsibilities at the Osaka Congress to a renewed team. I would like to take this opportunity of thanking H. M. Berman, S. R. Hall and G. Madariaga for the great work they have done in guiding COMCIFS through its first critical years.

\section{D. Brown, Chair}

\section{A7. Committee on Crystallographic Databases}

This Committee deals with matters that pertain to more than one database, and with issues that concern databases and data management in general. F. H. Allen chaired this Committee until August 2005. The Committee also discusses modalities for possible collaborations between the IUCr and existing and upcoming databases. There is general consensus that the IUCr should act as to judiciously support such activities, but that it should be consistent in providing this support and encouragement. The IUCr could play a facilitating role to the data provider wherever there is an overall benefit to the scientific community, and especially if IUCr support would make a key difference to such database generation activity, keeping in mind overall financial viability.

The Committee has noted the decision of the Executive Committee with respect to new databases (taken in Salt Lake City, USA) and that the IUCr will play a neutral, facilitating role with respect to new and existing databases. The Committee also appointed two new members, A. Hannemann, FIZ, Karlsruhe (replacement for P. Luksch) and P. Villars, Materials Phases Data System, Vitznau.

\section{G. R. Desiraju, Chair}

\section{A8. IUCr Newsletter}

The IUCr Newsletter continues to be a vehicle for broadcasting and promoting the interests and activities of the IUCr and its Commissions. It also strives to enhance communication within the global community of crystallographers. Special effort is made to promote meetings and publications sponsored by the IUCr.

This report covers 12 issues (Vol. 13, Nos. 1-4 in 2005, Vol. 14, Nos. 1-4 in 2006 and Vol. 15, Nos. 1-4 in 2007). In the first two issues of 2005 the President's column was written by W. L Duax and all subsequent columns were written by Y. Ohashi. The Newsletter was edited by J. L. Flippen-Anderson until Vol. 14 when she and W. L. Duax began to share editorial responsibilities.

Each issue contained: at least two pages highlighting articles from each of the IUCr journals; news of various IUCr Commissions; notices of elections; awards to crystallographers; and information on web sites, resources and other activities of interest to crystallographic practitioners. The reports covered topics such as high-throughput protein crystallography, materials microstructure, radiation damage, crystals in art and science, crystal growth, synchrotron updates, structural genomics, methods, supramolecular chemistry, small molecules, biomaterials, electron crystallography, applied crystallography, high-pressure studies, new materials, and aperiodic crystals. Contributions are received from crystallographers in many countries and other materials are gathered from the newsletters of crystallographic associations and science news magazines. Almost all submitted contributions are published and all material is edited to varying degrees.

The reports included reviews of the meetings of national crystallographic associations as well as the IUCr Regional Associates and extensive coverage of the IUCr Congresses. Coverage of the Florence Congress was in Issue 4 of Vol. 13 and Issue 1 of Vol. 14. Issues 2 and 
3 of Vol. 13 included an editorial written by J. L. Flippen-Anderson and in Issue 4 of Vol. 13 the IUCr Congress reports were introduced by C. Mealli. Issue 2 of Vol. 14 included a guest editorial written by the newly elected President of the ECA, J. R. Helliwell, and Issue 4 of Vol. 14 carried a guest editorial written by M. Yousef to accompany two articles on the SESAME project (the synchrotron that will be constructed in the Middle East).

A series of articles on crystallography in individual countries began in 2003. In the last triennium issues appeared on Japan (Issues 2 and 3 of Vol. 13, Editor Y. Ohashi), Australia and New Zealand (Issue 1 of Vol. 14, Editor J. Martin), Portugal (Issue 2 of Vol. 14, Editors M. O. Figueiredo, M. M. R. Costa, A. Damas, M. T. L. Duarte and M. A. Carrondo), Singapore (Issue 3 of Vol. 14, Editors K. Swaminathan and J. J. Vittal), Poland (Issue 1 of Vol. 15, Editor Z. Kosturkiewicz) and India (Issue 4 of Vol. 15, Editors G. R. Desiraju, A. Nangia and V. Pattabhi). Together with the articles on Latin America (which covered five member countries), Italy and Russia this brings the total number of countries covered thus far to 14. Material from Egypt is in review and material on the UK, Canada and Taiwan is in preparation.

Reports were published covering meetings in Australia, Brazil, Germany, Czech Republic, Singapore (2), Greece, Portugal (2), Italy (3), India, Japan, Mexico, France, Egypt (3), Indonesia, USA (3), Spain (2), Slovenia (2), Switzerland, Belgium, Russia, South Africa (2), Israel, Pakistan and Poland. Issue 1 of Vol. 13 completed the coverage of ECM-22 in Budapest, Hungary, and contained a special article celebrating the 40th anniversary of the Cambridge Crystallographic Data Centre. An article on NMR crystallography was also included in Issue 1 of Vol. 13. The online version of International Tables was announced in Issue 3 of Vol. 13 and the new IUCr Commission on Mathematical and Theoretical Crystallography was described in Issue 4 of Vol. 13. A book review described Volume G of International Tables and there was an article featuring the IUCr's publication award.

IUCr Regional Associates took advantage of the Newsletter to advertise their upcoming meetings. In addition, a calendar of future meetings throughout the world was published in every issue and, sadly, obituaries of 16 prominent crystallographers were reported during the triennium. Covers highlighted art in crystallography and maps of the countries featured in 'national' issues.

Four of the twelve issues published in the triennium contained 32 pages, seven had 24 pages, one had 40 pages and one had a 28 page insert (the second circular for the Osaka Congress). This amounted to a total of 364 pages compared to the 383 pages for the twelve issues in the previous triennium.

A significant portion of the support for the publication and distribution of the Newsletter comes from advertising revenue. There were between 14 to 21 advertisements in each issue during the triennium with an average of 17.4 advertising pages per issue.

The average distribution is 18456 copies. Twenty-one countries assist in the effective and economic distribution of the Newsletter. Distributors: H. Fodil, Algeria; P. Jensen, Australia; J. Valderrama, Colombia; B. Kojić-Prodić, Croatia; J. Hasek, Czech Republic; C. Lecomte and $\AA$. Kvick, France; A. Nangia, India; Ismunandar, Indonesia; P. Spadon, Italy; A. Satomi, Japan; A. H. Othman, Malaysia; R. Rendle, New Zealand; J. Lipkowski, Poland; M. M. R. Costa, Portugal; W. Klooster, Singapore; L. R. Nassimbeni, South Africa; J. Schefer, Switzerland; Yu Wang, Taiwan; K. Haller, Thailand; H. Kooijman, The Netherlands; G. Díaz de Delgado, Venezuela. Individual distributions were sent to 84 additional countries. P. Coley of the editorial office in Buffalo, New York, is responsible for the desktop preparation of all copy, all negotiations with the printer, postal authorities and distribution houses, maintenance and produc- tion of the mailing list, and solicitation and handling of all advertising. J. Gallmeyer assisted with copy preparation and correspondence with contributors.

\section{J. L. Flippen-Anderson and W. L. Duax, Editors}

\section{A9. IUCr/Oxford University Press Book Series}

The Committee met during the Florence Congress and discussed, among other items, options and wishes for new volumes for the series. All other business in the triennium has been dealt with through e-mail consultations. A satisfying number of proposals has been reviewed, most of them with a positive result. In general the writing of a book is a matter of years rather than months, and therefore it may well be expected that in the coming triennium a similar number of new books with equally attractive titles will appear on the basis of the present number of proposals of successful authors. It may be noted that for the first half of 2008 two new volumes have been announced already and one existing volume will be published in paperback format.

Throughout the whole period the cooperation with S. Adlung, the Science Editor of OUP, has been excellent. At major crystallographic congresses he was present in the OUP booth and had many very fruitful discussions with (potential) authors. At other large meetings contacts with authors have been established through A. J. Sharpe at the IUCr booth.

It should be noted that crystallographers who are registered in the World Directory are entitled to a $20 \%$ discount when buying crystallography books from OUP.

In the reporting period the following six books were published in the IUCr/OUP Book Series. Unless stated differently, the books are published in hardback format.

In the series IUCr Texts on Crystallography:

Crystal Structure Refinement - A Crystallographer's Guide to SHELX, by P. Muller, R. Herbst-Irmer, A. L. Spek, T. Schneider and M. Sawaya (2006).

Theories and Techniques of Crystal Structure Determination, by U. Shmueli (2007, hardback and paperback).

In the series IUCr Monographs on Crystallography:

Crystalline Molecular Complexes and Compounds - Structures and Principles, by F. H. Herbstein, published in two volumes (2005).

Molecular Aggregation Structure Analysis and Molecular Simulation of Crystals and Liquids, by A. Gavezzotti (2006).

Aperiodic Crystals. From Modulated Phases to Quasicrystals, by T. Janssen, G. Chapuis and M. de Boissieu (2007).

Incommensurate Crystallography, by S. van Smaalen (2007).

If a book published in hardback has proven to be successful, a paperback edition may be published as well. In this period two volumes in the series of IUCr Monographs on Crystallography appeared in a paperback edition:

The Chemical Bond in Inorganic Chemistry - The Bond Valence Model, by I. D. Brown (May 2006).

Structure Determination from Powder Diffraction Data, edited by W. I. F. David, K. Shankland, L. B. McCusker and Ch. Baerlocher (August 2006).

These all concern important topics in crystallography and represent the high professional standards adhered to in the IUCr/OUP Book Series.

The Committee is very interested in proposals for new books in the series and encourages prospective authors to contact the Chair of the Committee. Also, readers may suggest topics and/or authors as they know the subjects that are poorly covered in the literature. Manu- 
scripts covering important aspects of crystallography and related fields are very welcome.

H. Schenk, Chair

\section{A10. Sponsorship of meetings: Sub-committee on the Union Calendar}

The composition of the Sub-committee for the past three years was decided at the first meeting of the Executive Committee elected at the last General Assembly and comprised: L. B. McCusker (Switzerland), G. Díaz de Delgado (Venezuela), L. T. J. Delbaere (Canada), R. O. Gould (UK) and S. D. Wakatsuki (Japan), being chaired by D. Viterbo (Italy). The Sub-committee members, including the Chair, for the next triennium will be decided in Osaka.

During the past three years, the Sub-committee has considered and analysed many requests for sponsorship and financial support by the IUCr, and subsequently has made recommendations to the Executive Committee. The main policy consists of giving financial support to help young scientists, meaning graduate students, post-graduate students or post-doctoral fellows, with a maximum age of 30 (exceptionally 35). Additional financial support for organizational expenses was considered by the Executive Committee whenever necessary and justified. Special attention was given to applications from regions where crystallography is less developed, such as African or South American countries. The entire procedure, from the submission of proposals to the final decision by the Executive Committee, was carried out by e-mail. The evaluation process was very efficiently conducted by e-mail discussions involving all members of the Sub-committee.

The total amount used for sponsoring the participation of young scientists in meetings was CHF 108492 in 2005, CHF 143272 in 2006 and CHF 175676 in 2007.

The following meetings received support during this three-year period:

VII Latin-American Workshop on Magnetism, Magnetic Materials and Their Applications, Renaca, Chile, 11-15 December 2005.

African School and Workshop on X-rays in Materials: New Techniques and Practical Applications, Dakar, Senegal, 12-17 December 2005 .

International Workshop on Crystal Growth and Characterization of Advanced Materials, Chennai, India, 9-13 January 2006.

Fourth European Charge Density Meeting (ECDM-IV), Brandenburg, Germany, 25-29 January 2006.

RapiData 2006, Brookhaven, USA, 23-28 April 2006.

Third Moroccan School of Crystallography, Agadir, Morocco, 8-12 May 2006.

Structure and Function of Large Molecular Assemblies, Erice, Italy, 9-18 June 2006.

International School on Biological Crystallization, Granada, Spain, 18-24 June 2006.

Fourth National Crystal Chemical Conference, Chernogolovka, Russia, 26-30 June 2006.

Thirteenth International Conference on Small-Angle Scattering, Kyoto, Japan, 9-13 July 2006.

ACA Annual Meeting, Honolulu, USA, 22-27 July 2006.

23rd European Crystallographic Meeting (ECM-23), Leuven, Belgium, 6-11 August 2006.

Sagamore XV: Electron Charge, Spin and Momentum Densities, Warwick, UK, 13-18 August 2006.

Structural Chemistry - Indaba 5, Kruger National Park, South Africa, 20-25 August 2006.
IUCr Teaching Commission Intensive School on Single-Crystal X-ray Structural Analysis, Siena, Italy, 27 August - 2 September 2006.

Structural Analysis by X-ray Diffraction, Crystallography under

Perturbation, Nancy, France, 28 August - 2 September 2006.

Tenth European Powder Diffraction Conference (EPDIC X), Geneva, Switzerland, 1-4 September 2006.

XX Conference on Applied Crystallography, Wisla, Poland, 11-14 September 2006.

Workshop on Use of Monte Carlo Techniques for Design and Analysis of Radiation Detectors and Tenth International Symposium on Radiation Physics (ISRP-10), Coimbra, Portugal, 15-22 September 2006.

Aperiodic 2006, Miyagi, Japan, 18-22 September 2006.

Crystallography at High Pressure, Dubna, Russia, 28 September -

1 October 2006.

Fundamentals of Modern Methods of Biocrystallography BioCrys 2006, Oeiras, Portugal, 6-13 October 2006.

Joint Conference of the Asian Crystallographic Association and the Crystallographic Society of Japan, Tsukuba, Japan, 20-23 November 2006.

Workshop on Synchrotron-Light Applications in Biological Materials, Cairo, Egypt, 27-30 November 2006.

BCA Intensive Course in X-ray Structure Analysis, Durham, UK, 4 March - 2 April 2007.

Latin-American Workshop on Applications of Powder Diffraction and School on Methods of Powder Diffraction, Campinas, Brazil, 1620 April 2007.

RapiData 2007, Brookhaven, USA, 22-27 April 2007.

6th International Conference on Inelastic X-ray Scattering (IXS 2007), Hyogo, Japan, 7-11 May 2007.

Fifth International Conference on Solid State Crystals and Eighth Polish Conference on Crystal Growth (ICSSC-5 and PCCG-8), Zakopane, Poland, 20-24 May 2007.

Engineering of Crystalline Materials Properties: State-of-the-Art in Modelling, Design, Applications, Erice, Italy, 7-17 June 2007.

Crystallization: Focus on Membrane Proteins, Brookhaven, USA, 11-15 June 2007.

School and Workshop on X-ray Micro- and Nanoprobes: Instruments, Methodologies and Applications, Erice, Italy, 11-17 June 2007.

Gordon Research Conference on Electron Distribution and Chemical Bonding, South Hadley, USA, 1-6 July 2007.

First School on Materials Applications of the Organic Solid State (SMAOSS) and XVIII International Conference on the Chemistry of the Organic Solid State (XVIII-ICCOSS), 1-6 and 8-13 July 2007.

XVI International Conference on Crystal Chemistry and Diffraction Studies of Minerals and Workshop 'Minerals as Advanced Materials', Miass and Apatity, Russia, 2-6 and 8-12 July 2007.

International School on Theoretical and Mathematical Crystallography, Havana, Cuba, 15-20 July 2007.

ACA Annual Meeting, Salt Lake City, USA, 21-26 July 2007.

International Conference on Neutron and X-ray Scattering, Serpong and Bandung, Indonesia, 23-31 July 2007.

13th International Summer School on Crystal Growth, Park City, USA, 5-11 August 2007.

VIII Latin-American Workshop on Magnetism and Magnetic Materials and Their Applications (LAW3M), Rio de Janeiro, Brazil, 12-16 August 2007.

9th International Biology and Synchrotron Radiation Conference, Manchester, UK, 12-17 August 2007.

ECM-24, Marrakech, Morocco, 22-27 August 2007.

Symposium in Honour of Professor Dame Louise Johnson, FRS, DBE, Oxford, UK, 2-5 September 2007. 
Advanced Methods in X-ray Charge Density Analysis: Extracting Properties from a Multipolar Refinement, Martina Franca, Italy, 3-6 September 2007.

Electron Microscopy and Multiscale Modelling, Moscow, Russia, 3-7 September 2007.

Structure Elucidation by Combining Magnetic Resonance, Computation, Modelling and Diffraction (SMARTER), Aveiro, Portugal, 6-7 September 2007.

Advances in Crystallography at High Pressure at Large-Scale Facilities, Chilton, UK, 6-9 September 2007.

Diffraction Analysis of the Microstructure of Materials, GarmischPartenkirchen, Germany, 7-9 October 2007.

Synchrotron Radiation and Neutrons for Cultural Heritage Studies, Grenoble, France, 8-12 October 2007.

Quasicrystals - the Silver Jubilee, Tel Aviv, Israel, 14-19 October 2007.

MSA-GS-ANL Short Course on 'Amphiboles', Rome, Italy, 29-31 October 2007.

Eighth Asian Crystallographic Association Conference (AsCA '07), Taipei, 4-7 November 2007.

II International Workshop on Layered Materials: 'Structure and Properties', Vercelli, Italy, 28-29 March 2008.

Rietveld Refinement Training School, Durham, UK, 30 March - 3 April 2008.

RapiData 2008, Brookhaven, USA, 6-11 April 2008.

International School on Mathematical and Theoretical Crystallography, Gargnano, Italy, 27 April - 3 May 2008.

12th International Workshop on Protein Crystallization, Quintano Roo, Mexico, 6-9 May 2008.

Fourth Moroccan School of Crystallography, Rabat, Morocco, 2629 May 2008.

From Molecules to Medicines: Integrating Crystallography into Drug Discovery, Erice, Italy, 29 May - 8 June 2008.

ACA Annual Meeting, Knoxville, USA, 31 May - 5 June 2008.

European Charge Density Meeting, Gravedona, Italy, 6-11 June 2008.

10th International Conference on Quasicrystals (ICQ10), Zürich, Switzerland, 9-14 June 2008.

Crystallization: Focus on Membrane Proteins, Brookhaven USA, 10-14 June 2008.

Structure Determination from Powder Diffraction Data: a Handson Workshop on X-rays, Synchrotron Radiation and Neutron Diffraction Techniques Including Experimental and Computational Aspects, Villigen, Switzerland, 18-22 June 2008.

The Zürich School of Crystallography - Bring Your Own Crystals 2008, Zürich, Switzerland, 22 June - 5 July 2008.

First K. H. Kuo Summer School of Electron Microscopy and Crystallography: Cryo-Electron Microscopy of Macromolecular Complexes, Beijing, People's Republic of China, 14-16 July 2008.

\section{A11. Reports of Representatives on Regional and Scientific Associates}

A11.1. American Crystallographic Association (ACA). This triennial report for the activities of the ACA as a Regional Associate contains an overview of the more detailed Annual Reports presented since the Florence Congress as well as an outline of future activities announced by the ACA for 2008. During the period covered by this report, the ACA has continued its local actions working for the advancement of crystallography within the USA and Canada, and also keeping and creating programmes aimed at extending regional cooperation in North and South America. The Annual Meetings, which reflect the intense activity of the ACA Officers, Standing Committees and Special Interest Groups (SIGs), as well as the more than 2500 members, are very special events. This has been so for many years, and here I briefly report on the last two meetings and that to take place in 2008.

The 2006 Annual Meeting took place in Honolulu, Hawaii (22-27 July 2006). The site of the event was chosen with the expectation of attracting crystallographers from other Pacific Rim countries. The meeting had one of the largest attendances of all times (963 participants) and 688 scientific contributions. The meeting was preceded by three one-day workshops on Methods in Neutron Protein Crystallography, Management of Synchrotron Image Data and Introduction to Grazing Incidence Small-Angle Scattering with X-rays and Neutrons. The Martin Buerger Award was granted to H. M. Berman (Rutgers University) for her pioneering work in the establishment of the Protein Data Bank and the creation of the Nucleic Acid Database. The recipient of the B. E. Warren Award was C. Majkrzak (NIST) for his contributions to neutron reflectivity and development of related methods. The Margaret C. Etter Early Career Award was presented to C. Wilmot (University of Minnesota), for her outstanding work on the study of fundamental enzymatic processes. The subject of the Transactions Symposium was Smaller Crystals and Larger Molecules with Neutron Diffraction.

The 2007 Annual Meeting was held in Salt Lake City, Utah (22-26 July 2007). Two workshops took place one day prior to the meeting, on 21 July, and were dedicated to: SHELX - Refinements of Twins/ Disorder and Phasing with $S H E L X C / D / E$ and Standards for Publication of Macromolecular NMR Structures. The total number of participants was more than 800 . The morning and afternoon sessions covered the most important topics of crystallography. Poster sessions served as discussion points around the more than 250 presentations.

The highlights of the 2007 meeting programme were:

A Plenary Lecture on 26 July by Nobel Prize Laureate R. D. Kornberg on the Structural Basis of Transcription.

The Transactions Symposium on Diffuse Scattering for the Masses - Local Structural Correlation in Molecular, Macromolecular and Inorganic Crystals.

The Kenneth N. Trueblood Award Symposium Award presented to A. Gavezzotti (Award Lecture: Forty Years of Struggle with Computers over Crystallography and Intermolecular Interactions).

Isidor Fankuchen Award Symposium with presentation of the Award to F. H. Herbstein [Award Lecture: What Can We Learn from the Crystal Structures Reported for Pentacene and for the Anthracene and Tetracyanoquinodimethane (TCNQ) Molecules in their Various Guises?].

The Elizabeth Wood Science Writing Award was presented to L. Randall and the M. C. Etter Early Career Award was received by C. Lind.

The 2008 Annual Meeting will be organized in Knoxville, 31 May 5 June 2008. The site, chosen for its proximity to the new ultra-highintensity Spallation Neutron Source (SNS), will give the participants the chance to visit this facility. The programme includes four workshops, one on neutron macromolecular crystallography and another on small-angle scattering. The Transactions Symposium will be on Complementary Methods to Crystallographic Techniques for Structure/Function Studies of Biological Macromolecules. The Patterson Award will be presented to Bi-Cheng Wang.

The ACA Summer School on Macromolecular Crystallography was held at the Illinois Institute of Technology (Chicago) and the Advanced Photon Source (Argonne), 10-22 July 2006. In 2007, the Summer School took place at Duquesne University, Pittsburgh, 9-18 July. This is an already traditional eight-day course that provides 
extensive coverage of single crystal and powder diffraction theory and techniques for a group of around 20-25 students from the USA, Latin America and other countries. The success of this course is well known among students. The lectures, covering a wide range of topics, are carefully prepared by the very dedicated Professors, many of them members of IUCr Commissions. The students are provided with a CD-ROM containing all notes, presentations and tutorials. C. H. Lake, J. Aitken and B. M Craven, who are in charge of the organization, mention the direct financial support of the ACA, the USNCCr and several commercial firms. Participation in this course is a lasting memory for many of the students, who, according to the organizers, provide feedback for future growth and development. For 2008, the course will take place at the Indiana University of Pennsylvania, Indiana, and follow the same (very successful) programme. The organizers anticipate a total of 24 attendees from the USA and abroad. Twelve experienced teachers will be involved.

It should also be mentioned that the ACA Publications now include the online versions of the Transactions (Volume 39) and the Etter Award Symposium Lectures since 2005. The Newsletter $A C A$ RefleXions continues to be an excellent source of information on all the ACA activities.

\section{Torriani, Representative}

A11.2. Asian Crystallographic Association (AsCA). The Executive Committee notes that AsCA has grown in strength and outreach over the three-year period 2005-2007 and is rapidly establishing itself as a viable, and even vibrant, forum for crystallographers in the AsiaPacific region to meet, discuss their results and deliberate upon matters with a particularly regional focus.

Asia is a vast continent. Along with the Pacific country members, the member countries of AsCA are geographically very widely distributed. Travel between the various countries in the region is not easy (or inexpensive) in many cases. This makes regional-level coordination of scientific activities particularly challenging, and also the movement of young scientists.

The triennial activities of AsCA are mainly centred on the annual meetings. According to present practice, during a triennium one of the meetings is conducted by AsCA, and this took place in Taipei in 2007 with the hospitality and valuable local support and organization of the local hosts. The second meeting is a joint meeting of AsCA held along with the annual meeting of the crystallographic society of one of the member countries. This meeting took place in Tsukuba, Japan, in 2006 when the AsCA meeting was held along with the annual meeting of the Crystallographic Society of Japan (CrSJ). Normally, in the year of the IUCr Congress (third year), there is no meeting of AsCA. Accordingly, no meeting was held in 2005 and the AsCA council met in Florence.

In the meeting in Florence, the arrangements for the meetings in Tsukuba and Taipei were reviewed. A functional web site for AsCA was also constructed during 2005 (http://www.asiancrysassn.org).

The meeting in Tsukuba was very successful with Keynote Lectures by S. Kitagawa, Z. Rao, S. Iwata and C. Howard. A total of 18 Microsymposia in 21 sessions were presented in three parallel sessions. Including the Keynote Lectures, 115 speakers gave oral presentations at the conference and 331 posters were displayed and presented. Approximately 450 registered participants were involved in the academic programme. In the AsCA council meeting in 2006, it was noted that the financial position of AsCA had improved to just over AUD 100 000. However, support is still required from the $\mathrm{IUCr}$ for young scientists.
The AsCA meeting in 2007 was also very successful. The Keynote speakers were Z. L. Wang, J. Trewhella, K. Lal, O. Nureki, K.-H. Lii and Y. Shi. Eighteen Microsymposia on various topics were also arranged. Funding from the IUCr for young scientists was obtained and 41 applications for support were received from around the region with 19 awards being made following careful academic review. The hosting of the AsCA '07 meeting in November by the Taiwan delegation was very successful. A total of 337 abstracts were received: 6 plenary, 96 oral and 235 posters. Of the 412 conference delegates, 295 were international from 20 countries. Importantly, 19 sponsors supported the hosting of the conference. The consensus was that the meeting continued the trend of increasingly higher standards found for the past several conferences.

Reports on the current status and activities of AsCA were presented at a council meeting held during the AsCA '07 conference in Taipei. The financial status of the society continued to improve and there were JPY 634800 held in Japan and AUD 107061 held in Australia, the total thus amounting to $c a$ USD 150000.

Since 2008 is the year of the Osaka Congress no meeting of AsCA will be held. Future meetings of AsCA will be held in 2009 in Beijing, People's Republic of China, jointly with the Chinese societies, and in 2010 in South Korea.

The election of AsCA office bearers took place in Taipei, by unanimous consent: President: J. M. Guss, University of Sydney, Australia; Vice-President: S. W. Suh, Seoul National University, Korea; Secretary/Treasurer: K. Haller, Suranaree University of Technology, Thailand. Their terms were to commence forthwith and run until the AsCA '10 conference in Korea. M. A. Spackman and C. Bond, both of the University of Western Australia, will be the new Trustee and new Associate Trustee.

In summary, AsCA has continued to progress; activities in 2008 will look to formalize the group membership of the IUCr of smaller regional countries. Further details and finalized venues and dates for the AsCA '09 and AsCA '10 conferences in the People's Republic of China and Korea should be presented at the upcoming Osaka Congress. Assignment of an International Programme Committee Chair for AsCA '09 should also take place and be ratified by council members at the Congress. The meeting in Beijing in 2009 is anticipated to strengthen substantially the involvement of crystallographic scientists from the People's Republic of China, which should be an important spur to further growth of the society and furtherance of its aims in the next few years.

AsCA has continued to prosper and strives to foster international links between crystallographers in the region. AsCA welcomes increased participation by crystallographers from the People's Republic of China, Korea and Malaysia, countries where significant scientific activity is now seen. The increasing prosperity through much of Asia, especially the People's Republic of China and India, as well as improved communication conduits through available web sites and e-mail, should help maintain prospects for continued growth and success. Economic disparities and geographical challenges in the region are unique problems and mean that $\mathrm{IUCr}$ assistance to AsCA will remain an important foundation in its efforts to further the crystallographic sciences throughout the Asian region.

\section{G. R. Desiraju, Representative}

A11.3. European Crystallographic Association (ECA). The present membership of the ECA Executive Committee is: President: J. R. Helliwell (UK); Vice-President: S. Larsen (Denmark); Secretary: P. Bombicz (Hungary); Treasurer: R. Kuzel (Czech Republic); 
Members: S. Garcia-Granda (Spain), L. van Meervelt (Belgium), A. Roodt (South Africa); and ECA webmaster M. Nespolo (France, ex officio).

The ECA has acted on the proposal of Y. Ohashi, the IUCr President, that a new IUCr group membership for the ECA region should be introduced at the Osaka General Assembly. The ECA has identified countries that are ECA members but not yet IUCr-member countries: Latvia, Turkey, Ukraine, Algeria, Morocco and Tunisia. These have been invited and have agreed to join as an ECAsupported group.

The ECA is grateful to the IUCr for providing column space on a regular basis in its Newsletter in which the ECA Officers write on topics of policy and community interest within the ECA, and thereby encourage wider debate within the IUCr as a whole. In a recent Newsletter the ECA championed the need for the effort on the education of future generations of crystallographers to be increased at postgraduate, graduate and schools levels. Strong support has been given to a Spanish initiative, which it is hoped will serve as preparation for the establishment of a European Undergraduate/ Graduate School of Crystallography. The ECA Executive Committee has assigned M. Nespolo to act as its Crystallography Education Coordinator.

A11.3.1. Activities 2005/2006. ECA-supported meetings. The Regional Heart of Europe Bio-Crystallography Meeting (HEC-8), the eighth in the series, took place in Karlovy Vary, Czech Republic, 29 September - 1 October 2005. The Meeting was funded in part by the ECA, and also supported by the Czech and Slovak Crystallographic Association. The organizer was the Institute of Molecular Genetics, The Czech Academy of Sciences, Prague, Czech Republic. The meeting was attended by about 100 participants and provided a forum for 32 presentations by young biocrystallographers from Germany, Poland, Austria and the hosting Czech Republic.

The IX International Conference on Crystal Chemistry of Intermetallic Compounds was held in Lviv, Ukraine, 20-24 September 2005. This series of all-Union conferences was initiated in 1971 in context with the creation of the School on Crystal Chemistry at Lviv University, and, since then, a meeting takes place approximately every third year.

The XVII International School on Physics and Chemistry of Condensed Matter and the V International Symposium on Physics in Materials Science was held in Białowieża, Poland, 21-29 June 2005. The topic was Materials in Transition and the organizer was The Institute of Experimental Physics, University of Bialystok, Poland. The School and Symposium gathered 65 participants from ten countries. The programme was a natural continuation of the previous (2004) School on the Structural Aspects of Matter.

The International School on Mathematical and Theoretical Crystallography was held in Nancy, France, 20-24 June 2005. The School was attended by 61 registered participants from 20 countries with different backgrounds (chemistry, physics, mineralogy, mathematics, biology, etc.). The delegates were introduced to several aspects of modern theoretical crystallography by nine invited lecturers. The School also included a poster session, with 23 posters presented. A Special Issue of Acta Crystallographica Section A was published with articles from the lecturers and manuscripts submitted by the participants.

The 2006 ECM was in Leuven, Belgium, 6-11 August, with a satellite meeting on Mathematical and Theoretical Crystallography, a joint school on Structure Determination by X-ray Powder Diffraction and Electron Crystallography (in Antwerp), a Cambridge Crystallographic Data Centre (CCDC) workshop on Making Better Use of the Cambridge Structural Database and a satellite workshop on Rational Protein Crystallization.

Prizes. A new prize for young scientists named after Erwin Lewy Bertaut was established. The winner of the Perutz Prize for 2006 was E. Dodson.

A11.3.2. Activities 2006/2007. ECA-supported meetings. The ECA supported the following meetings between August 2006 and August 2007:

HEC-9 (Bio-Crystallography, Göttingen, Germany).

The first joint Italian-Spanish Meeting of Crystallography MISCA2007 (Calabria, Italy).

The Zürich Crystallography School 2007 (Zürich, Switzerland).

ECM-24 + satellite (Marrakech, Morocco).

ECM-24 was in Marrakech, Morocco, 22-27 August 2007, and was preceded by satellite meetings on (i) Mathematical and Theoretical Crystallography: The Enchanting Crystallography of Moroccan Ornaments and (ii) Science Meets Industry and by an Advanced Training Workshop on Development Training in Computational Methods and Synchrotron Facilities for Crystallography.

Prizes. The first prize awardee for the new ENSA/ECA Prize for young scientists, named after Erwin Lewy Bertaut, was H. M. Rønnow of the Laboratory of Quantum Magnetism, Ecole Polytechnique Fédérale de Lausanne, Switzerland, whose work has concentrated on experimental and theoretical aspects of quantum magnetism; he has also been involved in development of neutron instrumentation as well as simulation and data-analysis software.

The ECA Perutz Prize awardee for 2007 was D. Stuart of The Wellcome Trust Centre for Human Genetics, Oxford, UK, who is one of the pioneers of virus crystallography. His award is in recognition of his impact in this field and his contributions to the structural chemistry of disease at the atomic level.

A11.3.3. Future ECA meetings. The organization of the programme of ECA meetings has been reviewed, and in future they will more closely follow focus areas as pioneered at ECM-21. The ECA, ECM25 and ECM-26 will advertize their activities at a booth at the Osaka Congress.

Future ECA meetings will be held as follows: ECM-25 Istanbul, Turkey, August 2009; ECM-26 Darmstadt, Germany, August 2010 (this will be held along with EPDIC-22); ECM-27 Bergen, Norway, 2012.

\section{J. Gilmore, Representative}

A11.4. International Centre for Diffraction Data (ICDD). J. A. Kaduk has played a full role as the ICDD representative to the Commission on Powder Diffraction (CPD). The CPD maintains close links with the ICCD and also with IXAS; IXAS information is available via the ICDD web site at http://www.icdd.com/ and the IXAS web site at http://www.i-X-s.org/.

W. I. F. David, Representative

A11.5. International Organization of Crystal Growth (IOCG). After the very successful 14th International Conference of Crystal Growth (ICCG-14), Grenoble, France, August 2004 [see J. Crystal Growth (2007), Volume 275] and - preceding it - the 12th International Summer School of Crystal Growth (ISSCG-12), in Germany, the main activity of IOCG was preparation for the next event, which was scheduled for August 2007. 
In the meantime there were many conferences and meetings devoted to crystal growth around the world organized and attended by members and consultants of the Commission on Crystal Growth and Characterization of Materials. These meetings and conferences are listed in the Annual Reports.

In August 2007 two very important meetings organized by the IOCG took place in Utah, USA. The first was the 13th International Summer School on Crystal Growth, in Park City, http://www. crystalgrowth.us/isscg13/index.php. The school was attended by 159 post-graduate and post-doctoral students as well as researchers from industry and academia from 24 countries. The school's objective was to provide a series of lectures on theoretical and experimental aspects of growth and characterization of semiconducting, oxide, metallic, organic and biological crystals. Lectures by leading researchers (including E. Vlieg, P. Rudolph and K. Kakimoto) concentrated on crystal growth and epitaxial processes, nanocrystallization, in situ and ex situ characterization, crystal properties, and applications, with a focus on fundamental discussion of the chemical and physical processes that control the assembly of atoms and molecules from the melt, solution or vapour.

The level of the school was intended for young researchers interested in gaining a fundamental knowledge of crystal growth and epitaxy. The Co-Chairs of ISSCG-13 were J. De Yoreo and C. Wang. D. Bliss was a member of the Organizing Committee. The financial support from the IUCr for this school was greatly appreciated.

The other important meeting was the 15th International Conference on Crystal Growth (in conjunction with the 13th Conference on Vapour Growth and Epitaxy and the US Biennial Workshop on Organometallic Vapour Phase Epitaxy) held in Salt Lake City, USA (Co-Chairs R. Feigelson and G. Stringfellow). D. Bliss, T. Duffar, T. Ohachi and E. Vlieg were among the session organizers and P. Rudolph presented a Plenary Lecture. The venue was attended by 751 scholars from around the world and more than 640 papers were submitted. Topics covered a wide selection of subjects related to crystal growth - from fundamentals of crystal growth and correlated electron crystals to growth of laser hosts, magnetic semiconductors, epitaxial layers and biological crystals. Details of the programme may be found at http://www.crystalgrowth.us/iccg15/index.php.

The prestigious Frank Prize was awarded to V. Voronkov for 'theoretical contribution to the understanding of defect formation in melt grown crystals, especially in $\mathrm{Si}$, interface structure and shape formation'. The Laudise Prize went to B. Mullin 'for creating the high-pressure LEC process, the development of MOVPE growth of $\mathrm{HgCdTe}$ alloy and the discovery of non-equilibrium segregation of facets'. V. Bermudez-Benito received the IOCG Schieber (Young Author) Award, and the rarely bestowed Distinguished Service Award went to I. Sunagawa. These Prizes, awarded by IOCG, help to promote crystal growth science in different countries as well as collaboration between national crystal growth organizations.

The new President and Officers of IOCG were confirmed during this meeting following the election in early 2007. A. A. Chernov became the new President and R. Fornari and T. Ohachi were elected Co-Vice-Presidents. V. Fratello became Treasurer, T. Kuech Secretary and H. A. Dabkowska, J. Derby, T. Duffar, K. Kakimoto, S. Krukowski, K. Roberts, P. Rudolph and E. Vlieg were elected to serve as Executive Committee Members.

The next (16th) ICCG will be organized in Beijing, People's Republic of China, in August 2010, preceded by ISSCG-14 in Dalian, People's Republic of China. J. Wang is a Co-Chair of the Local Organizing Committee.

H. A. Dabkowska, Representative

\section{A12. Reports of Representatives on bodies not belonging to the} Union

A12.1. Interdivisional Committee on Terminology, Nomenclature and Symbols of the International Union of Pure and Applied Chemistry (IUPAC ICTNS). During the triennium, ICTNS continued its activities on behalf of IUPAC in reviewing and approving Technical Reports and Recommendations submitted to IUPAC. Most of these Technical Reports and Recommendations were, or are about to be, published in Pure and Applied Chemistry. A few comprise what are essentially research papers containing new results but emanating from IUPAC projects, and these have been reviewed with publication recommended in research journals. A few others emanated from publications in preparation or prepared by international bodies of which IUPAC is a member; these were reviewed in the usual way.

The following Technical Reports and Recommendations have been reviewed by referees chosen among IUCr members:

Graphical Representation Standards for Chemical Structure Diagrams.

International Vocabulary of Metrology - General Concepts and Associated Terms.

Guide to the Expression of Uncertainty in Measurements.

Finally, several of the 'colour' books have undergone revision, and these have been reviewed by ICTNS. These include:

Nomenclature of Inorganic Chemistry (Red Book), 2005.

Compendium of Chemical Terminology, online XML version (Gold Book), 2006.

Quantities, Units and Symbols in Physical Chemistry (Green Book), 3rd edition, 2007.

Terminology and Nomenclature in Polymer Chemistry (Purple Book), 2nd edition, 2008.

A. Authier, Representative

A12.2. International Council for Science (ICSU). The IUCr Representative attended ICSU's 28th General Assembly in Suzhou, People's Republic of China, in 2005 and reported on the work of the IUCr and its Regional Associates.

W. L. Duax, Representative

A12.2.1. ICSU Committee on Data for Science and Technology (CODATA). CODATA is the interdisciplinary Committee on Data for Science and Technology of the International Council for Science (ICSU). It is currently a worldwide network of 23 national data committees, two Associate National Members, 16 international scientific unions, 4 co-opted delegates, and 20 supporting organizations from industry, government and academia, which define and lead its scientific programme. It is concerned with collection, management, manipulation, access to and exploitation of quantitative data in science and technology. Specific projects are addressed by Task Groups answerable to the CODATA General Assembly, by Working Groups, by themed workshops or conferences, and by publications on specific aspects of data handling or data compilation, including conference proceedings.

The major activities of CODATA in the past triennium were as follows.

The 20th International CODATA Conference took place in Beijing, People's Republic of China, October 2006. Its theme was Scientific Data and Knowledge within the Information Society. Over 600 delegates attended. Several sessions celebrated CODATA's first 40 years of existence, and many other sessions focused on continuing developments in data collection, management, interpretation and 
curation. The IUCr representative presented a paper on the impact of publishing policy on data quality. A full meeting report is available at http://www.iucr.org/iucr-top/data/docs/.

In response to the ICSU Priority Area Assessment review on Scientific Data and Information presented in 2004, a draft Strategic Plan was developed to guide the future activities of CODATA. This Plan will be presented to the next General Assembly in 2008. The draft recommends that CODATA pursue three major initiatives during the period 2006-2012: the Global Information Commons for Science Initiative (GICSI); the Scientific Data Across the Digital Divide Programme; and Advanced Data Methods and Information Technologies for Research and Education. The IUCr delivered a response to the initial GICSI prospectus (http://www.iucr.org/iucrtop/iucr/gicsi/response.html) and has taken note of its principles in its evolving approach to understanding the application of intellectual property rights to scientific data.

The new Mission Statement for CODATA, arising from the development of its Strategic Plan and adopted at the 25th General Assembly, emphasizes the social responsibility of scientists in their approach to handling data: 'The mission of CODATA is to strengthen international science for the benefit of society by promoting improved scientific and technical data management and use'.

Details of CODATA's involvement in other meetings and projects can be found in the Annual Reports of the undersigned. Although many activities are of global scope, or fall well outside the areas of scientific interest of the IUCr, engagement with CODATA remains important for following developments in general aspects of data management, access, interoperability, intellectual property rights and archiving. I believe that we also have an important role to play in continuing to emphasize the importance of applying the highest achievable quality criteria to the handling of physical science data, as a model for good practice in other disciplines.

The CODATA web site is at http://www.codata.org.

\section{B. McMahon, Representative}

A12.2.2. ICSU Committee on Space Research (COSPAR). The Committee on Space Research (COSPAR) was established during an international meeting in London in 1958, following the launch of Sputnik I in 1957. To mark this date, a 50th Anniversary Celebration will take place during the COSPAR Assembly in July 2008 in Montreal, Canada.

As COSPAR acts mainly as a body responsible for organizing biennial Scientific Assemblies, the years 2005 and 2007 were devoted respectively to organization of the 36th and 37th Assemblies.

In July 2006 the 36th COSPAR Scientific Assembly was held in Beijing, People's Republic of China. It provided a forum open to all scientists, for the discussion of problems that may affect scientific space research. About two thousand scientists from around the world participated in the Beijing meeting (1499 full participants, 399 students and 27 press representatives). A total of 228 full-day sessions accommodated 80 scientific events.

The COSPAR Awards recognizing outstanding contribution to Space Science were accepted by A. Nishida (Japan) for his pioneering work in nearly every field of space physics and by E. Grun (Germany) for shaping the concept of dust astronomy.

More information about the 2006 Assembly and its Programme may be found at http://cosparhq.cnes.fr/Meetings/sciass.htm.

The next meeting (2008) will be held in Montreal, Canada. During this meeting the plan for the next 50 years of space exploration will be revealed.
The role of space governance, the viability of space tourism, entertainment, colonization and resource mining to solve problems on Earth will be discussed.

Alternative propulsion systems and their availability within the next 50 years will be also assessed.

The questions of extraterrestrial intelligence, the possibility of biological evolutionary paths that may be significantly different from those seen on the Earth and the theological and social implications of such discoveries are fascinating from the point of view of humanity. From the point of view of the IUCr the behaviour of materials in space - in microgravity conditions - is of some interest. Experiments of growing different crystals in microgravity have held the attention of our community for many years now.

Since its formation, the main objective of COSPAR has been to promote international collaboration on various levels in scientific research in space, with an emphasis on the exchange of results, information and opinions. Developing world standards for the space environment and its protection requires the creation of national and international organizations and specialist working groups.

In 2005-2007 the COSPAR President was R.-M. Bonnet (France) and the Vice-Presidents were W. Hermsen (The Netherlands) and E. C. Stone (USA). Members of the Bureau are: M.-H. Jiang (People's Republic of China), T. Kosugi (Japan), M. E. Machado (Argentina), G. G. Shepherd (Canada), R. Sridharan (India), L. Zelenyi (Russia) and J. B. Zielinski (Poland).

The 2010 Assembly will take place in Bremen, Germany - one of most important Europe aerospace centres, where essential parts of the Airbus and Columbus module are being produced.

More information about COSPAR may be found at http:// cosparhq.cnes.fr/.

Lists of COSPAR-sponsored meetings are presented in the Annual Reports.

\section{H. A. Dabkowska, Representative}

A12.3. International Council for Scientific and Technical Information (ICSTI). ICSTI offers a unique forum for interaction among organizations that create, disseminate, and use scientific and technical information. ICSTI is a scientific associate of ICSU, the International Council for Science. ICSTI's mission cuts across scientific and technical disciplines as well as international borders, to give member organizations the benefit of a truly global community.

In February 2006 ICSTI organized a workshop on Information and Data in e-Science - Making Access to Data a Seamless Reality which was held in Paris, France, at the French Ministry of Research, INISTCNRS and INSERM. This was a timely discussion spanning the fields of the physical sciences, the social sciences and the biological sciences. The workshop brought together scientists, publishers, library managers and information scientists. There were 12 talks; a detailed report is available at http://www.icsti.org/winter_mtg_2006/ index.html. On behalf of the IUCr, J. R. Helliwell spoke on The Role of Quality and emphasized that the crystallographic community is energetic in its efforts to uphold quality standards in a diverse scientific environment. The development of a crystallographic information file (CIF) and associated data dictionaries has allowed the seamless transfer of information for deposition and publication. It also allows the definition of formal publication data quality standards, and the deployment of mechanisms for checking compliance with such standards, such as the IUCr checkCIF service. The role of IUCr Journals in maintaining quality, and the possibilities provided by the CIF dictionaries for semantic web applications, were also discussed. 
In June 2006 ICSTI organized a public conference on the theme of Partnering in Science Information: Necessities of Change. This event was held at the National Library of Medicine in Bethesda, Maryland, at the USA NIH. A report can be found at http://www.warr.com/ pisi.html. On behalf of the IUCr, J. R. Helliwell presented a talk on Experience of Global Responsibilities in Science Publishing: Examples from an Editor-in-Chief for ICSU International Union of Crystallography. A key aspect emerged within the ICSTI context, namely concerning the Global Information Commons Initiative (GICSI); http://www.codata.org/wsis/GlobalInfoCommonsInitiative.html. GICSI is sponsored by CODATA, ICSTI, INASP, the World Data Centers (WDC) and ICSU, in collaboration with the InterAcademy Panel on International Issues (IAP), the Academies of Science in Developing Countries (TWAS), the OECD, UNESCO, and Science Commons. It was emphasized by J. R. Helliwell that the IUCr already makes globally available as much of its data and material as possible within the basic constraint of retaining the sustainability of the $\mathrm{IUCr}$ journals. Furthermore, it was stressed that the IUCr is discussing how to enhance further its efforts in the global information supply for the good of science.

The UK-based Research Information Network organized a conference in June 2006 at Imperial College, London, on the theme of Data Webs: New Visions for Research Data on the Web; http:// www.rin.ac.uk/data-webs. On behalf of the IUCr, J. R. Helliwell presented a talk entitled Changing Methods of Data Sharing in Crystallography. In addition, a session was devoted to The Future of Scientific Publications. Within this session two lectures were presented: the first was given by P. Bourne, Editor-in-Chief of Public Library of Science - Computational Biology, and entitled The Convergence Between Scientific Papers and Scientific Databases, and the second was given by A. de Waard of Elsevier Advanced Technology Group, Amsterdam, and Centre for Content and Knowledge Engineering, University of Utrecht, and entitled Separating Fact from Fiction; a Rhetorical Structure for Scientific Publications. Publications as a hot topic also featured in the closing Panel discussion with criticism of peer review being evident from several speakers. Instead, J. R. Helliwell spoke up in defence of the good value and important role of peer review in maintaining the security and quality of research information accessed by readers of all levels of experience.

Within the business meetings of ICSTI, held in Paris, France, in February 2006 and in Washington DC, USA, in June 2006, many topics were discussed. These included a general review of ICSTI's role, including its links with CODATA within the ICSU framework, whereby the rapid changes that are occurring in science publishing and information provision generally obviously mean that such regular review is important. In addition J. R. Helliwell, on behalf of the IUCr, was able to keep close contact with the IUPAC and IUPAP science delegates, namely W. Warr and Sir Roger Elliott FRS, respectively, as well as library managers and information scientists across the world.

A most interesting new initiative coming together in 2006 was the Global Science Gateway Project (http://worldwidescience.org/). This project is now (early 2008) at the point of having Government Agencies' information portals, which total 15, from ten countries, integrated. Its aim is to accelerate global knowledge diffusion and in practice a single query search returns combined results in relevant rank order. It is modelled after http://www.science.gov/. It should be emphasized that this is information that is not penetrated by, for example, Google search engines. The access, however, requires username and password. In the ICSTI Paris February 2008 Committee Meeting the governance and modus operandi of an Executive Committee for this World Wide Science project was agreed; as well as global representation at the meeting of participants, e.g. from Europe, USA, Japan and Korea, there were also teleconference link-ups with input from Brazil and South America. In January 2007 in London the US Under Secretary for Science R. Orbach (a PhD Theoretical Physics student of Sir Roger Elliot) and L. Brindley, Chief Executive of the British Library, signed a statement of intent to create and sustain this international science information gateway.

The sharing of experimental information via telepresence into the teaching classroom was explored under a NATO-funded Advanced Training Workshop (ATW) (Directors J. R. Helliwell and A. Thalal) held immediately prior to ECM-24, and which proved to be very much appreciated by teachers and students alike in adding new dimensions to such a training event. The classroom telepresence methods used built on trials and experiences within a synchrotron facility beam-time experiment between continents (UK and Morocco). The technical details and methodology have been written up in a short communication entitled Science Experiments via Telepresence at a Synchrotron Radiation Source Facility [J. E. Warren, G. Diakun, G. Bushnell-Wye, S. Fisher, A. Thalal, M. Helliwell \& J. R. Helliwell (2008). J. Synchrotron Rad. 15, 191-194]. This technical development and article also form a contribution within the Global Information Commons for Science Initiative (http://www.codata.org/ wsis/GICSI-prospectus.html). Specifically, the GICSI prospectus includes among its goals 'cooperative sharing of research materials and tools among researchers', which should be supported wherever possible.

Interesting issues have surfaced during 2007 in biological crystallography whereby in one case five publications of several related protein structures were withdrawn owing to a problem with the core diffraction images data analyses being treated on the wrong chirality and in another case a publication appeared to have been based on fabricated diffraction data. This has strengthened the widespread suggestion \{for example, see the compelling case presented by Jovine, Morgunova \& Ladenstein, CCP4 2007; see also our IUCr Acta Cryst. Section D and Section F Editors' commendation of the proposal in Baker et al. [Acta Cryst. (2008), D64, 337-338]\} that diffraction data images should be deposited as core supplementary files accompanying any publication of a biological crystal structure study. An alternative is that journal Notes for Authors make clear that authors confirm their compliance to archive such data for at least ten years (i.e. the same as their research funding agency regulations). There is not yet unanimous community support for the need for centralized data archiving of diffraction images. However, the fast evolution of cheaper computer mass storage is in effect removing one of the major technical obstacles to central archiving. Another practical obstacle is to reach agreement on standardized diffraction image data formats but good progress is being made on this too, i.e. with mmCIF image data definitions and work led by H. J. Bernstein and colleagues. There are two very useful and practical outcomes of the debate on this so far. Firstly, that IUCr journals Notes for Authors for 2008 now include a statement that 'Authors are encouraged to make arrangements for the diffraction data images for their structure to be archived'. Secondly, although not necessarily explicitly linked to the diffraction images deposition debate, for PDB depositions from 1 February 2008, structure-factor amplitudes/intensities (for crystal structures) and restraints (for NMR structures) will be a mandatory requirement for PDB deposition (see http://www.pdb.org/pdb/static.do?p=general_ information/news_publications/news/news_2007.html\#20071204). IUCr journals have of course had this policy for a number of years, an important leadership contribution. The advantages of diffraction data images deposition not only extend to making it much more difficult to fabricate data but also allow the building up a diffuse-scattering 
Table 9

Estimated budget for the General Fund.

\begin{tabular}{lrr}
\hline & \multicolumn{1}{c}{ CHF } & CHF \\
\hline Income & & \\
Subscriptions from Adhering Bodies & 456000 & \\
Yield from investments and banking accounts & 450000 & \\
\cline { 2 - 2 } Expenditure & & \\
Administration & 1434500 & \\
Subscriptions to ICSU and bodies of ICSU & 36000 & \\
Administrative meetings & 275000 & \\
Scientific meetings & 54000 & \\
\cline { 2 - 2 } & & -8995000 \\
\hline
\end{tabular}

archive, thus preserving them for the future when we can fully interpret the scattered intensity between Bragg spots in terms of protein dynamics, clearly a very important field for any consideration of biological function based on structure. The core elements of these developments were tabled by the undersigned on 5 February 2008 at the ICSTI Winter Committee meeting held in Paris, France.

An emphasis, which started in earnest in ICSTI's 2007 Public Conference and Workshops, held in June 2007 in Nancy, France, including those planned for 2008, is to understand the possible new practices in knowledge production and knowledge sharing - in particular, considering the emerging alternatives to the traditional publishing model that are becoming available for researchers. A growing emphasis is on the need for readers of science results to have a better connection with the primary data. Indeed the IUCr is widely recognized as a leader in these matters, being awarded a prize for technical innovation from the Association of Learned Society Publishers (ALPSP) in 2007. The planned ICTSI June 2008 Public Conference in Korea includes two Microsymposia on these developments.

J. R. Helliwell acknowledges with gratitude the close collaboration with the IUCr Journals Managing Editor, Peter Strickland, and with IUCr's Representative to CODATA, Brian McMahon. A publication by us on Integrating Research Articles and Supporting Data is in press in Learned Publishing (Volume 21, Issue 1), the journal of the ALPSP in association with the Society for Scholarly Publishing. We also published The Role of Quality in Providing Seamless Access to Information and Data in e-Science; the Experience Gained in Crystallography in the journal Information Services \& Use [(2006), 26, 4555] (Proceedings of the ICSTI Workshop on e-Science held Paris, France, February 2006).

\section{J. R. Helliwell, Representative}

\section{A13. Budget estimates for period to Twenty-Second General} Assembly: determination of unit contribution

A13.1. Budget estimates. The estimated budget for the General Fund is set out in Table 9, for the period until the next General Assembly. Since the budget estimates had to be prepared at a time when the decisions on many activities were still to be made, these estimates should be considered with due reserve. With this proviso, and in accordance with Statute 9.3, the Executive Committee presents to the General Assembly the following estimates for the three-year period 1 January 2008 - 31 December 2010.

A13.2. Unit Contribution. According to Statute $5.10(k)$, the General Assembly has to determine the Unit Contribution to be paid by the Adhering Bodies for the period to the next General Assembly. The Executive Committee recommends to the General Assembly that the Unit Contribution should remain at its present level of CHF 1000 (set at the Beijing Congress in 1993) for the years 20092011.

\section{APPENDIX $B$ \\ Statutes and By-Laws of the International Union of Crystallography}

as Adopted by the Fourth General Assembly in 1957 and Amended by the Fifth General Assembly in 1960, the Sixth General Assembly in 1963, the Seventh General Assembly in 1966, the Eighth General Assembly in 1969, the Ninth General Assembly in 1972, the Tenth General Assembly in 1975, the Eleventh General Assembly in 1978, the Seventeenth General Assembly in 1996, and the Eighteenth General Assembly in 1999

\section{Statutes}

\section{Objects of the Union}

1.1. The objects of the Union are

(a) to promote international cooperation in crystallography;

(b) to contribute to the advancement of crystallography in all its aspects, including related topics concerning the non-crystalline states;

(c) to facilitate international standardization of methods, of units, of nomenclature and of symbols used in crystallography;

(d) to form a focus for the relations of crystallography to other sciences.

1.2. For these purposes the Union shall have the power

(a) to adhere to the International Council for Science;

(b) to organize international meetings and conferences on subjects falling within the purview of the Union;

(c) to promote international publication of crystallographic research and of crystallographic works;

(d) to set up Commissions or other bodies for special objects;

(e) to initiate, promote and coordinate crystallographic research requiring international cooperation;

$(f)$ to organize Special Projects which shall be financed independently of the regular operations of the Union;

( $g$ ) to participate in Joint Commissions with other Unions or other scientific bodies in matters of interest to the Union;

(h) to perform all such other legal acts as are essential for or conducive to the objects of the Union including the constitution or organization of separate or independent bodies having an appropriate legal status;

(i) to receive into association existing regional organizations of crystallographers having substantially the same aims and objects as the Union; these organizations shall be known as Regional Associates of the Union;

$(j)$ to receive into association existing international scientific organizations whose interests overlap with the aims and activities of the Union; these organizations shall be known as Scientific Associates of the Union.

\section{Organization and Legal Domicile}

2.1. Under the name of International Union of Crystallography an Association has been organized and incorporated; it is governed by Articles 60 and following of the Swiss Civil Code and by the present Statutes of Incorporation.

2.2. The duration of the Union is not limited.

2.3. The legal domicile of the Union is in Geneva, Switzerland. 


\section{Membership}

3.1. The members of the Union are its Adhering Bodies.

3.2. There shall be only one member for each country. Only under extraordinary circumstances the General Assembly may admit a suitably designated additional Adhering Body from a country, provided a corresponding Adhering Body of that country has already been admitted as a National Member of the International Council for Science (ICSU). In this case, each Adhering Body will have separate delegates and will be treated separately in questions of voting and finances.

3.3. The Adhering Body can be a National Academy, National Research Council or similar body, or a scientific society or group of such societies. Each Adhering Body shall form a National Committee for Crystallography to represent it in the Union.

3.4. Any number of Countries may agree to form a group in order to name or establish a single Adhering Body. This Body shall form a joint National or Regional Committee for Crystallography. Wherever the terms Country and National Committee for Crystallography are used in these Statutes or in the By-Laws, they shall be taken to include such groups of Countries and joint National or Regional Committees for Crystallography.

3.5. Membership in the Union shall be fully effective when the nature of the Adhering Body and the membership of the National Committee have been reported to and accepted by the General Assembly. Any replacement of an Adhering Body is subject to the approval of the Executive Committee and acceptance by the General Assembly. Any major change in the nature of an Adhering Body shall be considered valid only after it has been reported to and accepted by the General Assembly.

3.6. Adherence to the Union shall be in one of five Categories I-V with corresponding voting powers and contributions as set out in Statutes 5.5 and 9.4. A Body applying for adherence to the Union shall specify in which Category it wishes to adhere; this choice of Category, or any desired change in the Category, is subject to the approval of the Executive Committee and confirmation by the General Assembly.

3.7. Any extension of a joint adherence formed in accordance with Statute 3.4 is subject to the approval of the Executive Committee and acceptance by the General Assembly.

3.8. Participation in Special Projects [Statute 1.2(f)] shall not be obligatory. The extent of financial participation shall be a matter for special negotiation for each such project, except that the relationship between contribution and voting power within the project shall be that of the Category scheme defined in Statutes 5.5 and 9.4 to determine this relationship in the General Assembly.

3.9. Each National Committee has the right to submit to the Union through the General Secretary questions within the competence of the Union.

3.10. Any Adhering Body may withdraw from the Union if it has given notice of withdrawal at least six months before the end of the current financial year; it is required to fulfil its obligations relating to the time period when it was a member of the Union. Its membership and any further obligations shall then be suspended by the Executive Committee at the expiry of the notice of withdrawal. The withdrawal shall take effect when it has been reported to the General Assembly.

3.11. An Adhering Body which withdraws from the Union in accordance with Statute 3.10 , or any Adhering Body whose membership is cancelled in accordance with Statutes 5.12 or 9.6, loses all rights in connexion with the Union.
3.12. If the Countries of a group formed in accordance with Statute 3.4 agree that the group should be dissolved, or if a Country wishes to withdraw from such a group, with or without the agreement of the other Country or Countries of the group, the adherence of the original group shall be suspended by the Executive Committee at the expiry of an appropriate notice, provided that the original group has fulfilled its obligations. The termination of the original adherence shall take effect when the matter has been reported to the General Assembly. Pending this report, the Countries of the group, or any of them, may submit proposals for the continuation of their representation in the Union. In each of such proposals the nature of the Adhering Body, the membership of the National Committee and the desired Category of adherence shall be specified. These proposals are subject to the approval of the Executive Committee, which shall then make ad interim arrangements concerning these adherences. These arrangements are subject to acceptance by the General Assembly.

\section{Administration}

4.1. The work of the Union shall be conducted by

(a) the General Assembly;

(b) the Officers of the Union, constituting the Executive Committee;

(c) the Commissions as defined in Statute 8.1.

The composition and function of these bodies are defined in the following paragraphs, whose application is governed by the By-Laws.

\section{General Assembly}

5.1. The work of the Union shall be directed by the General Assembly which is composed of delegates appointed by the Adhering Bodies.

5.2. The Executive Committee is responsible to the General Assembly and shall participate in its deliberations. Members of the Executive Committee have no voting power in the General Assembly, except for the casting vote of the Chair [Statute 5.8].

5.3. The General Assembly shall, as a rule, hold an ordinary meeting once every three years. The date and the place of the meeting, unless determined by the previous General Assembly, shall be determined by the Executive Committee. The General Secretary shall communicate the date and the place of the meeting to the National Committees and to the Commissions at least twelve months in advance.

5.4. In special cases, the President of the Union, with the consent of the Executive Committee, may call an extraordinary meeting of the General Assembly. This shall be performed at the request of one-fifth of the Adhering Bodies. The routine business of a General Assembly prescribed in Statute 5.10 shall normally be omitted, unless specifically included in the agenda; but an extraordinary General Assembly shall have the same powers, and be subject to the same rules, as an ordinary General Assembly, except where otherwise is stated in the Statutes and By-Laws. The General Secretary shall communicate the date and the place of the extraordinary General Assembly to the National Committees and to the Commissions at least eight months in advance if amendment of the Statutes is contemplated, or at least four months otherwise.

As an alternative, in special cases not requiring an amendment to or a change of the Statutes, the President of the Union with the consent of the Executive Committee may ask for a postal ballot of the Adhering Bodies. This shall be performed at the request of one-fifth of the Adhering Bodies. The voting power of an Adhering Body in a postal ballot is the same as that at General Assemblies. The General Secretary will communicate the matter for determination to the 
National Committees and to the Commissions four months before the deadline for the votes to be received by the General Secretary. In order to facilitate a full discussion between the participants in the postal ballot, the comments and questions of the Adhering Bodies, the responses of the President as well as any amendment to the initial proposal will be circulated among the Adhering Bodies using fast means of communications at the latest one month before the deadline.

5.5. The voting power of an Adhering Body at General Assemblies and in postal ballots shall be in accordance with its Category of adherence, as follows:

\begin{tabular}{llllll}
\hline Category & I & II & III & IV & V \\
Number of votes & 1 & 2 & 3 & 4 & 5 \\
\hline
\end{tabular}

5.6. Each Adhering Body, through its National Committee, shall make known to the General Secretary before the opening of each General Assembly the names of its delegates (and of their alternates, if any), and also the name of the Chair of the national or regional delegation. No Officer of the Union may be a member of any delegation, nor shall any person serve as a member of more than one delegation.

5.7. Normally each of the delegates present at a General Assembly shall have one vote only, but when for special reasons an Adhering Body cannot be fully represented at a General Assembly it may distribute its votes among a number of delegates smaller than the number of votes which that Adhering Body has in accordance with the Category in which it adheres; such a decision has to be made known to the General Secretary before the opening of the General Assembly concerned. Any Adhering Body not represented at a General Assembly may forward its views to the General Secretary by letter, and such views shall be made known to the General Assembly if received before voting takes place.

5.8. Except where otherwise provided in the Statutes and By-Laws, decisions of the General Assembly are taken by a majority of the votes cast. In the event of an equal division of votes the Chair shall take the final decision.

5.9. No question which has not been placed on the agenda of business to be transacted at the General Assembly shall be discussed or put to the vote unless a proposal to that effect be approved by at least two-thirds of the votes there represented.

5.10. The General Assembly shall

(a) take appropriate action on any matters concerning membership in the Union [Statutes 3.5, 3.6, 3.7, 3.10, 3.12 and 5.12];

(b) elect the President, the Vice-President, the General Secretary, the Treasurer and the other Officers of the Union [Statutes 6.1 and $6.3]$

(c) consider, and make decisions regarding, the confirmation of the appointments of Editors of publications of the Union [Statute 7.1];

(d) determine the number of elected members of each Commission set up by the General Assembly [Statutes 5.11(c) and 8.2];

(e) elect the Chairs and members of the Commissions [Statute 8.2];

$(f)$ elect representatives of the Union on Joint Commissions with other Unions, and on other scientific bodies [Statutes 1.2( $\mathrm{g})$ and 8.5];

( $g$ ) receive the reports on the activities of the Union and of its Commissions [Statutes 6.8 and 8.4];

(h) receive the audited accounts for the years elapsed since the previous General Assembly [Statute 9.1];

(i) on receipt of satisfactory reports or accounts, release the Treasurer, or any other Officer, or the Chair or any member of any
Commission or other body, from financial or other liability to the Union;

(j) determine the budget for general expenditure for the period to the next General Assembly, on the basis of the estimate prepared by the Executive Committee [Statutes 9.2 and 9.3];

( $k$ ) determine the unit contribution for the period to the next General Assembly [Statute 9.5];

( $l$ ) determine the general policy and the timetable for the period to the next General Assembly;

( $m$ ) give preliminary consideration to the activities of the Union for the three-year period following the next General Assembly.

5.11. The General Assembly shall have the power

(a) to amend these Statutes in accordance with Statute 13.1;

(b) to formulate and amend By-Laws on any matters not covered by these Statutes;

(c) to set up any Commission or other body it may deem necessary for the administrative and scientific work of the Union, and to determine the terms of reference of such a body [Statute 1.2(d)];

(d) to dissolve any Commission or other body set up in accordance with Statute 5.11(c) when its existence is deemed no longer necessary;

(e) to determine the nature of Special Projects which shall be financed independently of the regular operations of the Union [Statute 1.2( $f)$ ];

$(f)$ to accept Regional Associates, to determine the nature of the association in each case, and to determine any mutual financial commitments;

(g) to accept Scientific Associates, to determine the nature of the association in each case, and to determine any mutual financial commitments;

(h) to decide on all other questions falling within the competence of the Union.

5.12. The General Assembly may cancel the membership of any Adhering Body of the Union for any serious cause; such a decision may only be taken after the member in question has been previously given an opportunity to furnish an explanation to the Executive Committee for forwarding to the General Assembly. At least threefourths of the total number of the votes of all Adhering Bodies are required for cancellation.

\section{Executive Committee}

6.1. The Officers of the Union constituting the Executive Committee are

(a) the President;

(b) the Vice-President;

(c) the General Secretary;

(d) the Treasurer;

(e) the immediate Past President;

(f) six ordinary members.

6.2. The election of Officers of the Union shall be arranged in such a way that there will not be more than two Officers from any one Country. A person is regarded as belonging to the Country in which he or she is normally resident and where the main part of his or her work is conducted. In cases of doubt the General Assembly shall decide to which Country a person is considered to belong.

If during the period between General Assemblies the number of Officers from a Country is increased above two because of any change of Country of residence, the Officer or Officers who changed their Country of residence may continue to serve until the close of the next General Assembly. If at that time the number of Officers from the Country concerned would remain above two, one or more of the 
Officers who changed their Country of residence shall be considered to have resigned.

6.3. The offices of General Secretary and Treasurer may be combined and shall then be considered as a single office. Otherwise no person shall hold more than one office simultaneously. The voting power of the Officer holding the combined office of General Secretary and Treasurer shall not be more than that of either the General Secretary or the Treasurer.

6.4. The President holds office as President until the close of the ordinary General Assembly following his or her election, and continues as a member of the Executive Committee until the close of the ordinary General Assembly next but one following that of his or her election. He or she is not then eligible for immediate re-election to the office of President, nor to any other office in the Executive Committee.

The Vice-President holds office until the close of the ordinary General Assembly following his or her election. He or she is not eligible for immediate re-election to the same office.

The General Secretary and the Treasurer hold office until the close of the ordinary General Assembly following that of their election. They are eligible for immediate re-election to the same office, but shall not serve in that office for more than three full consecutive terms.

Three ordinary members are elected at each ordinary General Assembly and hold office until the close of the ordinary General Assembly next but one following that of their election. They are not eligible for immediate re-election to the same office.

In the event of a vacancy, through resignation, death or other cause, any Officer elected by the General Assembly to fill the unexpired term of office shall serve only to the end of the normal term of the Officer he or she replaces; at the end of this service he or she may be nominated for re-election for a full term to the same office.

6.5. The Executive Committee shall carry out the decisions of the General Assembly and give effect to the general policy of the Union as determined by the General Assembly.

6.6. During the periods between General Assemblies the Executive Committee shall have full power to carry on the business of the Union in all matters not specifically assigned by the Statutes, the ByLaws or the General Assembly to individuals or to Commissions or other bodies. If necessary, it may make ad interim arrangements in all matters assigned by the Statutes and By-Laws to the General Assembly.

6.7. In the event of an individual, a Commission or another body of the Union failing to act in any matter assigned to him or her or it by the Statutes, By-Laws or the General Assembly, the Executive Committee may, after reasonable notice to the individual or body in question, take action on behalf of the Union.

6.8. The Executive Committee shall report on its activities to the General Assembly. The action taken by the Executive Committee in accordance with Statutes 3.5, 3.6, 3.7, 3.10, 3.12, 6.6, 6.7, 7.1, 7.2, 8.2, 9.6 and 9.9 shall be included in this report. The report to the General Assembly shall be dispatched by the General Secretary to the National Committees and to the Commissions at least ten weeks before the meeting.

\section{Publications of the Union}

7.1. The Editors of the publications of the Union are appointed by the Executive Committee for initial terms extending through not more than six years beyond the ordinary General Assembly following the appointment. Each initial appointment is subject to confirmation by that General Assembly. Reappointments may be made by the Executive Committee for terms of not more than three years, and are subject to confirmation by the ordinary General Assembly following the reappointment.

7.2. Co-editors and Assistant Editors are appointed by the Editors for terms of not more than three years, but they may be reappointed immediately for terms of the same length. The appointments and reappointments are subject to the approval of the Executive Committee.

7.3. Editors and Co-editors are members of the Commissions set up for their respective publications.

\section{Commissions and Joint Commissions}

8.1. The term Commission shall be understood to include all Commissions, Committees, and other bodies of the Union with the exception of National Committees for Crystallography, and the Executive Committee and its subcommittees.

8.2. The Chairs and members of the Commissions are elected at each General Assembly. Subject to the approval of the Executive Committee, Commissions may co-opt further members during the periods between General Assemblies, and may fill vacancies arising from resignation, death or other cause. Members (but not Chairs) may be nationals of or residents in a Country not adhering to the Union.

8.3. The Commissions shall be responsible to the General Assembly. They shall generally have full freedom in arranging their internal structure and work. They may formulate their own Rules of Procedure within the framework of the Statutes and By-Laws of the Union, and within their terms of reference.

8.4. The Chairs shall report on the activities of the Commissions to the General Assembly. These reports shall reach the General Secretary at least fourteen weeks before the General Assembly and shall be dispatched by him or her to the National Committees and the Commissions at least ten weeks before the meeting.

8.5. The representatives of the Union on Joint Commissions and on other scientific bodies [Statute 1.2( $\mathrm{g})$ ] are elected at each General Assembly. For each such body one representative shall be designated as the chief representative of the Union. His or her obligations to report are the same as those of the Chairs of the Commissions.

\section{Finance}

9.1. The Executive Committee shall be responsible to the General Assembly for all the financial affairs of the Union.

9.2. The Chair of each Commission (or other member approved by the Executive Committee) shall be responsible to the Executive Committee for any expenditure of funds by this Commission. Five months before each General Assembly he or she shall submit to the Executive Committee an estimate of the budget of the Commission for the period between that General Assembly and the one following it. He or she shall submit annually to the Executive Committee a revised budget for the ensuing year and a statement of accounts for the preceding year. These accounts shall be available for audit by the Executive Committee or its appointees.

9.3. The Executive Committee shall prepare an estimate of the budget for the period between the next General Assembly and that following it. This estimate shall be dispatched by the General Secretary to the National Committees and to the Commissions at least ten weeks before the meeting. 
9.4. Each Adhering Body shall pay an annual subscription in accordance with its Category of adherence, as follows:

\begin{tabular}{llllll}
\hline Category & I & II & III & IV & V \\
Number of unit contributions & 1 & 3 & 6 & 10 & 15 \\
\hline
\end{tabular}

The annual subscriptions are payable during the calendar year to which they apply.

9.5. The unit contribution, stated in terms of a currency to be designated by the Executive Committee, shall be determined by the General Assembly for the period to the next General Assembly.

9.6. Any Adhering Body which is in arrears with its subscription for two years shall be warned and shall be deprived of its voting power. The membership of any Adhering Body which is in arrears for four years shall be automatically suspended and may be cancelled by the General Assembly under Statute 5.12. An Adhering Body whose membership has been suspended shall receive no privileges of the Union and incur no further responsibility for dues; it may be reinstated by action of the Executive Committee.

9.7. The financing and management of publications of the Union shall be kept distinct from general expenditure. Editors and Coeditors shall be responsible to the Executive Committee for any receipts or expenditure of funds by them with respect to their publications.

9.8. The financing and management of Special Projects of the Union shall be kept distinct from the regular operations of the Union.

9.9. No funds may be solicited or accepted on behalf of the Union or any of its Commissions from any international, governmental or other agency or person without the prior approval of the Executive Committee. Any National Committee for Crystallography may however solicit funds within its own Country for the support of its own activities or in its capacity as host for a General Assembly, Congress or other meeting sponsored by the Union. Any funds, in the form of donations, legacies, or grants, accepted by the Executive Committee shall be used so far as is possible in accordance with the wishes of the donors.

\section{Liability}

10.1. The Union is liable only to the extent of its assets, and the Adhering Bodies are not individually liable for its corporate debts and liabilities.

10.2. The liabilities of the Adhering Bodies are limited to the payment of their annual subscriptions and to such contributions to the Special Projects of the Union as they may have pledged.

10.3. No Officer of the Union shall be individually liable for the corporate debts and liabilities of the Union. The Union shall indemnify any Officer or former Officer in respect of any claims laid against him or her in respect to his or her authorized actions on behalf of the Union. At its discretion the Executive Committee may extend this indemnity to other persons in respect of their authorized actions on behalf of the Union.

10.4. The Union shall not accept any liability for any personal loss, damage or accident sustained by an individual, not being an employee of the Union, engaged in any activity, including travel, on behalf of the Union.

\section{Auditor and Representation of the Union}

11.1. The Auditor of the Union shall be a person or corporation authorized to act as a public accountant. The Auditor shall be appointed by the Executive Committee on the recommendation of the Treasurer and maintained thereafter subject to the approval of the General Assembly.

11.2. With the exception of cheques, all contracts and formal agreements involving the Union shall be signed by two Officers of the Union. The Executive Committee may restrict the power to sign a particular document or type of document to specific persons among the Officers; and it shall determine rules for the signing of cheques.

11.3. The President shall be the official representative of the Union on all other civil and legal occasions and in dealing with other organizations. The President may in this respect delegate his or her powers to another Officer of the Union, or, with approval of the Executive Committee, to any other person.

\section{Dissolution of the Union}

12.1. The Union shall not be dissolved except on a motion presented at a General Assembly. If a motion to dissolve is to be presented, the notice for that General Assembly as given under Statute 5.3 or 5.4 shall include a statement of the motion to dissolve and shall refer specifically to this Statute. Such a motion shall be presented to the General Assembly without amendment and at least three-fourths of the votes there represented shall be required for dissolution.

In the event that less than three-fourths of the total number of the votes of all Adhering Bodies are represented at the General Assembly, a postal ballot may be arranged, and in such a postal ballot at least three-fourths of the total number of the votes of all Adhering Bodies shall be required for dissolution.

12.2. In the event of dissolution of the Union in accordance with Statute 12.1, the General Assembly shall appoint a special Committee, reporting to the International Council for Science, for the liquidation of the assets of the Union. The net assets shall be given to one or more, preferably international, organizations or institutions which shall spend the assets for purposes so far as is possible in accordance with the objects of the Union.

\section{Statutes}

13.1. Amendments to the Statutes require action at a General Assembly. An amendment is adopted at such an Assembly only if (i) at least two-thirds of the votes represented at the General Assembly are affirmative and (ii) if these affirmative votes amount to more than half the total number of the votes of all Adhering Bodies. In the event that the vote on a proposed amendment satisfies condition (i) but not condition (ii), the Executive Committee may refer the proposed amendment to a postal ballot of the Adhering Bodies. If the proposed amendment then obtains affirmative votes amounting to more than half the total number of the votes of all Adhering Bodies, the amendment is adopted.

Proposals for amendments may be made by the Executive Committee or by any National Committee. Such proposals made by National Committees shall reach the General Secretary at least six months in advance of the General Assembly. The General Secretary shall dispatch these proposals, and those made by the Executive Committee, to the National Committees and to the Commissions at least four months before the meeting.

13.2. The present English text shall be considered the authoritative text in the interpretation of these Statutes. Where disputes arise concerning this interpretation, the matter shall be decided by the General Assembly, or, during the periods between General Assemblies, by a ruling of the President of the Union. 


\section{By-Laws}

\section{General Assembly}

1.1. The agenda of business to be transacted at a General Assembly shall be determined by the Executive Committee and shall be dispatched by the General Secretary to the National Committees and to the Commissions at least ten weeks before the meeting.

1.2 Any National Committee and any Commission of the Union may propose business to be transacted at a General Assembly. Such proposals shall reach the General Secretary at least four months before the meeting, and shall be included in the agenda of the General Assembly.

1.3. The General Assembly may provisionally determine the date and the place of the next but one ordinary meeting of the General Assembly.

1.4. Chairs of the National Committees and of the Commissions, and representatives of Regional Associates and Scientific Associates may attend the General Assembly and take part in the discussions but shall have no voting power. The President may invite representatives of scientific bodies, or individuals, to attend the General Assembly; such invited guests may take part in the discussions but shall have no voting power. Other interested persons may also attend the General Assembly but they shall not take part in the discussions, unless specifically invited or permitted to do so by the Chair, and they shall have no voting power.

At the discretion of the Chair any or all of the persons attending the General Assembly under this By-Law may be required to withdraw.

1.5. If a delegate to a General Assembly is absent from a session of the Assembly, his or her place may be taken by any of the alternates nominated to the Assembly under Statute 5.6 provided that the Secretary of the Assembly is notified before the beginning of the session of the name of the delegate and of the name of the alternate, either by the delegate or by the Chair of his or her delegation. In general no such substitution may take place during a session of the Assembly, but the Chair of the Assembly may permit substitution to be made under special circumstances.

1.6. The names of the representatives of a Body whose application for adherence to the Union has been received and declared in good order by the Executive Committee under By-Law 2.9(a) shall be made known to the General Secretary as prescribed in Statute 5.6. These representatives shall be seated with the delegates of the Adhering Bodies during the preliminary ceremonies and the initial business of the General Assembly. At the discretion of the Chair or by a vote of the Assembly, the representatives may be required to withdraw during the discussion of and voting on matters concerning adherence to the Union. The delegates of a new member may take their seats among the other delegates as soon as the General Assembly has accepted their Adhering Body as a member of the Union.

1.7. Unless decided otherwise by the General Assembly, matters concerning adherence to the Union shall take precedence over all other business at the first business session of the General Assembly, and shall normally precede the reading of the minutes and the discussions of matters arising therefrom.

1.8. Delegates of an Adhering Body may not vote on any matter concerning its membership in the Union.

1.9. In the event of the General Assembly considering a change in a group of Countries according to Statute 3.12, the delegates from the Countries belonging or previously belonging to the group may not vote on any matters concerning the representation in the Union of any of these Countries. After acceptance of the ad interim arrange- ments made by the Executive Committee under Statute 3.12, these delegates have full voting power.

1.10. The delegates of new members may not vote on any matters concerning adherence to the Union, nor on any matters concerning the adoption of the minutes of the previous General Assembly, during the General Assembly at which they themselves are admitted.

1.11. The General Secretary shall post on the official bulletin board of the General Assembly the names of the Chairs and members (and alternates, if any) of the delegations and the numbers of votes represented by them.

1.12. During the General Assembly any delegate (or alternate) and any Officer of the Union is considered to have been notified of any action of the General Assembly, or of the Executive Committee, or of any Commission, if one of the two following procedures is adopted

(a) a notice is placed in the mail box or other location at which the delegate (or alternate) or the Officer is accustomed to receive mail during the course of the General Assembly, or

(b) a notice is handed to the designated Chair of each delegation with the specific request that he or she communicate its contents to his or her delegation, and to the General Secretary with the specific request that he or she communicate its contents to the Executive Committee, provided that in either case a similar notice is posted on the official bulletin board.

1.13. Minutes of the meetings of the General Assembly shall be made. Copies of the draft minutes shall be communicated by the General Secretary to the National Committees, to the Officers of the Union and to the Chairs of its Commissions. After approval at a subsequent General Assembly, two copies of the definitive minutes shall be signed by the Chair and the Secretary of the session at which they are approved, and shall be kept by the President and the General Secretary.

\section{Executive Committee}

2.1. The Executive Committee shall meet at each General Assembly. There shall be at least two additional meetings during the period between General Assemblies, unless the Executive Committee by a postal vote decides otherwise.

2.2. The Executive Committee shall make nominations to the General Assembly for the Officers of the Union, for the Chairs and members of the Commissions, and for representatives on Joint Commissions and on other scientific bodies. Normally these nominations shall be made after a preceding postal communication with the National Committees. In each case in which an Officer of the Union is nominated for another office, either by the Executive Committee or by delegates to the General Assembly [By-Law 8.2], the Executive Committee shall also include a nomination for the office which would be vacated if the election to the other office occurs. If the election to the other office does not occur and if the Officer's term has not expired, the nomination to the office which would have been vacated shall not be considered.

2.3. In the event of the resignation, death or disability of the President, the Vice-President shall assume the office of President until the close of the next ordinary General Assembly.

In the event of the resignation, death or disability of the VicePresident, the Executive Committee may appoint one of its members to serve as Vice-President until the close of the next ordinary General Assembly.

In the event of such circumstances that the General Secretary or the Treasurer cannot carry out his or her duties, the other shall assume those duties until the Executive Committee has considered the situation. In that event the Executive Committee may, but need 
not, appoint a new General Secretary or Treasurer to serve until the close of the next ordinary General Assembly.

In the event of the resignation, death or disability of an ordinary member of the Executive Committee, the Executive Committee may co-opt a new member to serve until the close of the next ordinary General Assembly.

The accession of an Officer of the Union to a new office under the conditions of this By-Law shall be accompanied by his or her resignation from the office to which he or she was previously elected, but service under this By-Law shall not affect his or her eligibility for immediate re-election to the new office.

2.4. Any Officer unable to attend a meeting of the Executive Committee may designate a deputy to attend that meeting. Such a deputy shall be named in writing to the President or the General Secretary. He or she shall have no voting power and shall not be counted as part of a quorum.

2.5. The President, on his or her own initiative or at the request of the Executive Committee, may invite any individual to be present at a meeting of the Executive Committee; such an invited guest may take part in the discussions but shall have no voting power.

2.6. At a meeting of the Executive Committee two-thirds (fractional parts neglected) of the Officers specified by Statutes 6.1 and 6.3 , excluding any who have resigned or died, shall constitute a quorum; and decisions shall be taken by a simple majority of the Officers present and voting. The Chair of the meeting shall not vote in open ballots; but in the event of an equal division of votes the Chair may take the final decision. In secret ballots required by the Statutes or By-Laws or ordered by the Chair, he or she may vote at his or her discretion. If the Chair does not vote and there is an equal division of votes, he or she may take the final decision. If the Chair has voted in a secret ballot, he or she may not take the final decision, and must leave it to further discussion and ballot.

2.7. During the period between meetings of the Executive Committee, voting may take place by post. Adoption of a proposal shall require affirmative votes from two-thirds (fractional parts neglected) of the Officers specified by Statutes 6.1 and 6.3, excluding any who have resigned or died. No decision on any proposal other than calling or cancelling a meeting of the Executive Committee shall be made by postal vote in the event that at least two Officers express the wish that the matter concerned should first be given more or further consideration, either by correspondence or at a meeting of the Executive Committee.

2.8. Minutes of the meetings of the Executive Committee shall be made. Two copies of the minutes shall be signed by the Chair and the Secretary of the meeting at which they are approved, and shall be kept by the President and the General Secretary. A summary of the draft minutes of meetings of the Executive Committee shall be despatched by the General Secretary to the National Committees within ten weeks of the conclusion of each meeting.

2.9. In addition to the obligations described in the Statutes and elsewhere in these By-Laws, the Executive Committee shall

(a) receive and report on applications for adherence to the Union if the nature of the applying Body and the membership of the National Committee have been duly reported to and considered to be in good order by the Executive Committee; pending the next General Assembly the Executive Committee may in the case of such applications provide such services of the Union as it deems proper;

(b) consider and report on any other questions concerning adherence to the Union;

(c) present an annual report, including an audited statement of receipts and expenditure, to the National Committees; (d) report to the Commercial Registry of Geneva any changes in the registered information concerning the Union;

(e) have the power to appoint representatives on scientific bodies not belonging to the Union.

\section{President}

3.1. The President of the Union is Chair of the General Assembly and of the Executive Committee. In the absence of the President from a session or meeting, the Vice-President, or if he or she is not present another Officer of the Union designated by the Executive Committee, shall act as Chair.

3.2. The President of the Union is an ex officio member, with voting power, of all Commissions of the Union.

\section{General Secretary}

4.1. The General Secretary of the Union is Secretary of the General Assembly and of the Executive Committee. In the absence of the General Secretary from a session or meeting, another Officer of the Union designated by the Executive Committee shall act as Secretary.

4.2. The General Secretary of the Union is an ex officio member, with voting power, of all Commissions of the Union.

4.3. The General Secretary is responsible for conducting the ordinary business of the Union, with the exception of the financial administration, and for keeping its records.

\section{Treasurer}

5.1. The Treasurer of the Union is responsible for the financial administration of the Union and for keeping its accounts.

5.2. The Treasurer is an ex officio member of all Commissions of the Union, with voting power only for those questions which may involve the Union in financial commitments.

\section{Sub-committees of the Executive Committee}

6.1. The Finance Committee is appointed by the Executive Committee to advise on finances, establishment and salaries. The Convener of the Finance Committee should normally be a resident of the same country as the Union Secretariat. If the Convener is not an elected member of the Executive Committee he or she will attend $e x$ officio the meetings of the Executive Committee without voting rights.

6.2. The Sub-committee on the Union Calendar is appointed by the Executive Committee to advise on the sponsorship of the Union for meetings, symposia and schools. The Chair of the Calendar Subcommittee should be a member of the Executive Committee.

6.3. The Executive Committee may establish, modify or abolish any other Sub-committees.

\section{Commissions of the Union}

7.1. The Chairs of the Commissions and the chief representatives on Joint Commissions or other bodies shall forward records of all meetings of the Commissions to the President and the General Secretary. They shall report annually on the activities of these bodies to the Executive Committee.

7.2. If funds are provided for the use of a Commission, it may make its own financial arrangements, with the prior approval of the Executive Committee and subject to the provisions of the Statutes and By-Laws. In cases where the Executive Committee has given prior approval, payments toward travelling expenses of Chairs and 
international union of crystallography

Timetable in preparation for General Assembly

\begin{tabular}{|c|c|c|c|}
\hline & & Statute & By-Law \\
\hline 12 months & $\begin{array}{l}\text { Notice of date and place of ordinary General Assembly to National } \\
\text { Committees and Commissions }\end{array}$ & 5.3 & - \\
\hline 8 months & $\begin{array}{l}\text { Notice of date and place of extraordinary General Assembly to } \\
\text { National Committees and Commissions, if amendment of Statutes is } \\
\text { contemplated }\end{array}$ & 5.4 & - \\
\hline 6 months & Proposals for amendments to Statutes to General Secretary & 13.1 & - \\
\hline 5 months & Estimated budgets from Commissions to Executive Committee & 9.2 & - \\
\hline 4 months & Proposals for agenda of General Assembly to General Secretary & - & 1.2 \\
\hline 4 months & $\begin{array}{l}\text { Notice of date and place of extraordinary General Assembly to } \\
\text { National Committees and Commissions, if amendment of Statutes is } \\
\text { not contemplated }\end{array}$ & 5.4 & - \\
\hline 4 months & $\begin{array}{l}\text { Proposals for amendments to Statutes to National Committees and } \\
\text { Commissions }\end{array}$ & 13.1 & - \\
\hline 14 weeks & Reports of Commissions to General Secretary & 8.4 & - \\
\hline 10 weeks & $\begin{array}{l}\text { Report of Executive Committee to National Committees and } \\
\text { Commissions }\end{array}$ & 6.8 & - \\
\hline 10 weeks & Reports of Commissions to National Committees and Commissions & 8.4 & - \\
\hline 10 weeks & Budget to National Committees and Commissions & 9.3 & - \\
\hline 10 weeks & Agenda to National Committees and Commissions & - & 1.1 \\
\hline
\end{tabular}

Timetable during General Assembly

\begin{tabular}{|c|c|c|c|}
\hline 'Before' & $\begin{array}{l}\text { Notice by National Committees to General Secretary of names of } \\
\text { delegates, alternates and Chairs of delegations, and of distribution } \\
\text { of votes if not one per delegate }\end{array}$ & $5.6,5.7$ & - \\
\hline 96 hours & Nominations by Executive Committee for Officers of Union & _- & 8.1 \\
\hline 72 hours & $\begin{array}{l}\text { Recommendations by Commissions to General Secretary for Chairs } \\
\text { and members of Commissions }\end{array}$ & - & 8.3 \\
\hline 48 hours & $\begin{array}{l}\text { Nominations by Executive Committee for Chairs and members of } \\
\text { Commissions }\end{array}$ & - & 8.3 \\
\hline 48 hours & Notification of motion to amend or suspend By-Laws & _- & 9.1 \\
\hline 36 hours & $\begin{array}{l}\text { Notice to General Secretary of nominations by delegates for Officers } \\
\text { of Union }\end{array}$ & - & 8.2 \\
\hline 24 hours & Posting of nominations by delegates for Officers of Union & - & 8.2 \\
\hline 24 hours & $\begin{array}{l}\text { Notice to General Secretary of nominations by delegates for Chairs } \\
\text { and members of Commissions }\end{array}$ & - & 8.4 \\
\hline 12 hours & $\begin{array}{l}\text { Posting of nominations by delegates for Chairs and members of } \\
\text { Commissions }\end{array}$ & - & 8.4 \\
\hline
\end{tabular}

members of Commissions may be made from the general funds of the Union.

7.3. No person who has served for three consecutive full terms of office on a Commission is eligible for nomination for a fourth consecutive term of service on the same Commission except as Chair. In no case is any person eligible for more than four consecutive full terms of service on the same Commission. These limitations do not apply to Editors [Statute 7.1], Co-editors [Statute 7.2] and ex officio members. Any Commission, in its Rules of Procedure, may reduce the length of service specified here.

7.4. In the event of the resignation, death or disability of the Chair of any Commission, the Executive Committee shall appoint a member of that Commission to serve as Chair until the close of the General Assembly following this appointment.

\section{Nominations and Elections}

8.1. All delegates (and alternates) shall be notified of the nominations presented by the Executive Committee under By-Law 2.2 for the Officers of the Union as early as possible and at least ninety-six hours before the scheduled commencement of the session of the General Assembly at which the vote is to be taken.

8.2. After the delegates have been notified of the nominations by the Executive Committee as prescribed in By-Law 8.1, other nominations for Officers of the Union may be made by any six or more delegates. Such nominations shall be made in writing to the General Secretary not less than thirty-six hours before the voting session and shall be accompanied by a written statement that the consent of the nominees has been obtained. These nominations shall be posted by the General Secretary on the official bulletin board not less than twenty-four hours before that session.

8.3. Recommendations from each Commission for the Chair and members of the Commission shall be made in writing to the General Secretary not less than seventy-two hours before the voting session of the General Assembly. These recommendations shall be approved by a majority of the members of the Commission and shall be accompanied by a written statement that the consent of the persons recommended has been obtained. All delegates (and alternates) shall be notified of the nominations presented by the Executive Committee under By-Law 2.2 for the Chair and members of each Commission at least forty-eight hours before the voting session.

8.4. After the delegates have been notified of the nominations by the Executive Committee as prescribed in By-Law 8.3, other nominations for the Chair and members of each Commission may be made by any six or more delegates. Such nominations shall be made in writing to the General Secretary not less than twenty-four hours before the voting session and shall be accompanied by a written statement that the consent of the nominees has been obtained. These nominations shall be posted by the General Secretary on the official bulletin board not less than twelve hours before that session.

8.5. In voting for the President, Vice-President, General Secretary and Treasurer of the Union, each of these offices shall be taken separately and voting shall be by secret ballot. A simple majority of the votes represented by the delegates present at the voting session shall be required for election.

If there is only one candidate for one of these offices, his or her nomination shall be presented to the General Assembly and the 
candidate concerned shall be considered as elected. If there are two candidates or more, and an election is not achieved after two ballots, the candidate receiving the smallest number of votes in the second ballot shall be removed from the list. If an election is not achieved after a third ballot, this procedure shall be repeated until an election is achieved. Any ballot form showing more than one mark shall be invalid. Any contingency arising during the balloting shall be resolved by a ruling of the Chair of the General Assembly.

8.6. The election of the ordinary members of the Executive Committee shall be by secret ballot, the ballot form showing the nominations presented by the Executive Committee and the nominations made by delegates. A simple majority of the votes represented by delegates present at the voting session shall be required for election. If there are not more candidates than vacancies, the nominations shall be presented to the General Assembly and the candidates shall be considered as elected. If there are more candidates than vacancies and all vacancies are not filled by election at the first ballot, a second ballot shall be arranged containing the names of the candidates not elected. If there are vacancies after the second ballot, the balloting procedure shall be repeated until all vacancies are filled; for each of these subsequent ballots the name of the candidate receiving the smallest number of votes on the preceding ballot shall be removed from the list. Any ballot form showing more marks than the appropriate number of vacancies shall be invalid. Any contingency arising during the balloting shall be resolved by a ruling of the Chair of the General Assembly.

8.7. In the event that an election must be held to fill the unexpired term of an office vacated by an ordinary member [Statute 6.4], the nominations for this office shall be distinct from the nominations for ordinary members for full terms. A person may be nominated for both categories, but can be elected to only one office [Statute 6.3]. If ballots are required in the elections for both categories, the ballots for the full-term offices shall take place first. A person who has been elected to two consecutive non-full terms is not eligible, on completion of his or her second term, for immediate re-election as an ordinary member of the Executive Committee.

8.8. In voting for the Chairs and members of the Commissions each Commission shall be considered separately. For the election of the Chairs the procedure described in By-Law 8.5 shall be followed. For the election of the members of the Commissions the procedure described in By-Law 8.6 shall be followed except that no more than two ballots shall be held. Any vacancies still remaining may be filled as provided in Statute 8.2 .

8.9. The procedure for the nomination and election of representatives of the Union on Joint Commissions and on other scientific bodies is so far as is possible the same as that for the nomination and election of the Chairs and members of the Commissions.

\section{By-Laws}

9.1. These By-Laws may be amended or suspended at any General Assembly and at least two-thirds of the votes there represented are required for an amendment or suspension. A motion to amend or suspend, if not already included in the agenda of business of the General Assembly, may be placed there by the procedure of Statute 5.9. No notice is required for a proposal to suspend the time limits prescribed by By-Laws 8.2 and 8.4. Notification of any other motion to amend or suspend the By-Laws must be given by its originators to all delegates (and alternates) and to all Officers of the Union in accordance with the procedure prescribed in By-Law 1.12, at least forty-eight hours before the session of the General Assembly at which the motion is to be considered.

9.2. The present English text shall be considered the authoritative text in the interpretation of these By-Laws. Where disputes arise concerning this interpretation, the matter shall be decided by the General Assembly, or during the periods between General Assemblies, by a ruling of the President of the Union.

\section{APPENDIX $C$ \\ Committees, Commissions and Representatives}

\author{
C1. Membership of bodies belonging to the \\ Union
}

\section{Executive Committee}

President

S. Larsen (Director of Research, ESRF, BP

220, F-38043 Grenoble Cedex, France)

Vice-President

P. Colman (Australia)

General Secretary and Treasurer

S. Lidin (Inorganic Chemistry, Stockholm

University, 10691 Stockholm, Sweden)

Immediate Past President

Y. Ohashi (Japan)

\section{Ordinary members}

E. Boldyreva (Russia), L. T. J. Delbaere

(Canada), G. R. Desiraju (India), C. J. Gilmore

(UK), C. Lecomte (France), J. M. Perez-Mato (Spain)

[S. Larsen, P. Colman, S. Lidin, Y. Ohashi, G. R. Desiraju and C. Lecomte will hold office until the close of the Twenty-Second General

Assembly (2011). E. Boldyreva, L. T. J.

Delbaere and J. M. Perez-Mato will hold office until the close of the Twenty-Third Assembly (2014).]

Executive Secretary

M. H. Dacombe (International Union of Crystallography, 2 Abbey Square, Chester CH1 2HU, UK)
Commission on Journals

Chair and Editor-in-Chief of IUCr journals G. Kostorz (ETH Zürich, Wolfgang-PauliStrasse 16, CH-8093 Zürich, Switzerland; Acta $A+B+C+D+E+F ; J A C ; J S R)$

\section{Section Editors of Acta Crystallographica} D. Schwarzenbach (Laboratory of Crystallography, Ecole Polytechnique Fédérale, EPFL-FSB-IPMC-LCr, Le Cubotron, CH-1015 Lausanne, Switzerland; Acta A), C. P. Brock (Department of Chemistry, University of Kentucky, Lexington, KY 40506-0055, USA; Acta B), A. Linden (Institute of Organic Chemistry, University of Zürich, Winterhurerstrasse 190, CH-8057 Zürich, Switzerland; Acta C), E. N. Baker (School of Biological 
Sciences, University of Auckland, Private Bag 92-019, Auckland, New Zealand; Acta D), Z. Dauter (National Cancer Institute, Brookhaven National Laboratory, Biology Department, Bldg 463, Upton, NY 11973, USA; Acta $D$ ), W. T. A. Harrison (Department of Chemistry, University of Aberdeen, Aberdeen AB24 3UE, UK; Acta E), J. Simpson (Department of Chemistry, University of Otago, PO Box 56, Dunedin, New Zealand; Acta E), M. Weil (Institute of Chemical Technologies and Analytics, Division of Structural Chemistry, Vienna University of Technology, Getreidemarkt 9/164-SC, Austria; Acta E), H. M. Einspahr (PO Box 6395, Lawrenceville, NJ 08648-0395, USA; Acta F), M. S. Weiss (EMBL Hamburg Outstation, c/o DESY, Notkestrasse 85, D-22603 Hamburg, Germany; Acta F)

Editor of Journal of Applied Crystallography A. Pyzalla (Helmholtz-Zentrum Berlin für Materialien und Energie GmbH, Wissenschaftliche Geschäftsführung, Glienicker Strasse 100, 14109 Berlin, Germany)

\section{Editors of Journal of Synchrotron Radiation} G. E. Ice (Metals and Ceramics Division, Oak Ridge National Laboratory, PO Box 2008, Oak Ridge, TN 37831-6118, USA), A. Kvick (ESRF, BP 220, F-38043 Grenoble Cedex, France), T. Ohta (Ritsumeikan University, 1-1-1 Noji Higashi, Kutsatsu, Shiga 525-8577, Japan)

\section{Co-editors of Acta, JAC and JSR}

K. A. Abboud (USA; Acta E), M. Akkurt (Turkey; Acta E), A. J. Allen (USA; JAC), Y. Amemiya (Japan; Acta A), L. A. Aslanov (Russia; Acta $B+C$ ), A. Authier (France; Acta $A)$, R. F. Baggio (Argentina; Acta $C+E$ ), J. Barbier (Canada; Acta C), L. J. Barbour (South Africa; Acta $C+E$ ), T. M. Bergfors (Sweden; Acta F), L. E. Berman (USA; JSR), S. Bernès (Mexico; Acta E), D. G. Billing (South Africa; Acta B), A. J. Blake (UK; Acta $B+C$ ), E. Boldyreva (Russia; Acta B), N. B. Bolotina (Russia; Acta B), M. Bolte (Germany; Acta E), A. D. Bond (Denmark; Acta E), L. Brammer (UK; Acta B), I. Brito (Chile; Acta E), I. D. Brown (Canada; Acta E), A. M. Brzozowski (UK; Acta $D+F)$, R. J. Butcher (USA; Acta E), O. Büyükgüngör (Turkey; Acta E), C. W. Carter (USA; Acta A), G. Chapuis (Switzerland; Acta B), D. Chateigner (France; $J A C)$, N. Chayen (UK; Acta D), V. V. Chernyshev (Russia; Acta E), K. Chinnakali (India; Acta E), S. Ciccariello (Italy; JAC), P. Coppens (USA; Acta A), M. Czugler (Hungary; Acta E), J.-C. Daran (France; Acta $C+E$ ), W. I. F. David (UK; $J A C$ ), G. R. Desiraju (India; Acta B), V. W. Dmitrienko (Russia; Acta A), E. Dodson (UK; JAC), D. L. Dorset (USA; Acta $A+B$ ), S. E. Ealick (USA; Acta $D+J A C$ ), M. R. J. Elsegood (UK; Acta $C+E$ ),
U. Englert (Germany; Acta $C$ ), J. G. Eon (Brazil; Acta A), L. Eriksson (Sweden; Acta E), C. Esterhuysen (South Africa; Acta E), J. Fabry (Czech Republic; Acta E), L. R. Falvello (Spain; Acta C), P. Fanwick (USA; Acta C), L. J. Farrugia (UK; Acta E), P. F. Fewster (UK; Acta $A+J A C$ ), A. Fischer (Sweden; Acta E), J. L. Flippen-Anderson (USA; Acta E), F. R. Frahm (Germany; $J S R$ ), A. K. Freund (France; $J S R$ ), F. Frolow (Israel; Acta $D+F$ ), G. J. Gainsford (New Zealand; Acta $C+E$ ), J. F. Gallagher (Ireland; Acta $C+E$ ), J. M. Garcia-Ruiz (Spain; Acta F), E. F. Garman (UK; JAC), M. Gdaniec (Poland; Acta E), R. D. Gilardi (USA; Acta E), C. Glidewell (UK; $A c t a C+E$ ), A. Goeta (UK; Acta C), C. H. Görbitz (Norway; Acta B), H. Graafsma (Germany; JSR), T. N. Guru Row (India; Acta B), I. A. Guzei (USA; Acta C), S. S. Hasnain (UK; JSR), B. Hazes (Canada; Acta F), P. C. Healy (Australia; Acta E), J. R. Helliwell (UK; $J A C$ ), M. Helliwell (UK; Acta $C+E$ ), J. L. Hodeau (France; $J A C$ ), T. Hökelek (Turkey; Acta E), H. M. Holden (USA; Acta $D)$, N.-H. Hu (People's Republic of China; Acta E), W. N. Hunter (UK; Acta $D+F)$, A. Iida (Japan; JSR), W. Imhof (Germany; Acta E), H. Ishida (Japan; Acta E), N. Ishizawa (Japan; Acta C), O. Johnson (UK; Acta E), P. G. Jones (Germany; Acta $C$ ), J. A. Kaduk (USA; Acta $B)$, K. A. Kantardjieff (USA; $J A C$ ), H. Kitamura (Japan; JSR), G. J. Kleywegt (Sweden; Acta $D+F)$, B. Kojíc-Prodíc (Croatia; Acta E), H. Kooijman (The Netherlands; Acta E), M. Kubicki (Poland; Acta C), V. Langer (Sweden; Acta C), U. Lee (Korea; Acta E), P. J. Loll (USA; Acta F), A. J. Lough (Canada; Acta $E)$, J. N. Low (UK; Acta E), V. Lunin (Russia; Acta D), A. Mar (Canada; Acta E), L. B. McCusker (Switzerland; Acta B), A. McPherson (USA; Acta F), S. McSweeney (France; JSR), K. Miki (Japan; Acta D), R. P. Millane (New Zealand; Acta $A$ ), A. M. Moore (UK; Acta $A+J A C$ ), P. Mueller (USA; Acta C), M. R. N. Murthy (India; Acta D), L. R. Nassimbeni (South Africa; Acta B), C. Näther (Germany; Acta E), J. M. Newman (Australia; Acta F), S. W. Ng (Malaysia; Acta E), K. Ogawa (Japan; Acta B), S. Ohba (Japan; Acta $C+E$ ), D. H. Ohlendorf (USA; $J A C$ ), K.-I. Ohshima (Japan; JAC), G. Oliva (Brazil; Acta $D+J S R$ ), M. M. Olmstead (USA; Acta E), A. Oskarsson (Sweden; $J A C$ ), H. A. Padmore (USA; JSR), D. Pandey (India; Acta A), S. Parkin (USA; Acta E), D. Parrish (USA; Acta E), S. Parsons (UK; Acta B), M. Parvez (Canada; Acta E), J. M. Perez-Mato (Spain; Acta A), M. L. Pusey (USA; Acta $D+F$ ), J.-P. Renaud (France; Acta F), C. Rizzoli (Italy; Acta E), A. Roodt (South Africa; Acta E), G. M. Rosair (UK; Acta E), V. B. Rybakov (Russia; Acta E), U. Rychlewska (Poland; Acta B), H. W. Schmalle (Switzerland; Acta E), M. L. Scudder (Australia; Acta $C+E$ ),
M. R. M. da Silva (Portugal; Acta E), A. M. Z. Slawin (UK; Acta E), S. van Smaalen (Germany; Acta B), M. A. Spackman (Australia; Acta B), A. L. Spek (The Netherlands; $A c t a C+E$ ), P. J. Squattrito (USA; Acta $C+E$ ), W. C. Stallings (USA; Acta $B+D+F$ ), H. Stoeckli-Evans (Switzerland; Acta $C+E$ ), S. W. Suh (Korea; Acta F), I. Tanaka (Japan; Acta F), K. Tanaka (Japan; Acta A), M. Taniguchi (Japan; JSR), T. C. Terwilliger (USA; Acta F), E. R. T. Tiekink (USA; Acta E), P. A. Timmins (France; Acta D), K. W. Törnroos (Norway; Acta C), M. Tremayne (UK; Acta $C+E$ ), H. Uekusa (Japan; Acta C), S. Wakatsuki (Japan; $J S R$ ), T. R. Welberry (Australia; Acta B+JAC), J. D. Westbrook (USA; Acta F), T. J. White (Singapore; Acta B), S. W. Wilkins (Australia; JSR), C. Wilson (UK; Acta E), C. C. Wilson (UK; Acta B), W.-T. Wong (People's Republic of China; Acta E), A. F. Wrulich (Switzerland; JSR), D. J. Xu (People's Republic of China; Acta E), B. M. Yamin (Malaysia; Acta E), A. I. Yanovsky (Russia; Acta E), Y. O. Yeates (USA; Acta D), M. Zeller (USA; Acta E), H. Zimmermann (Germany; Acta A)

Book-Review Editor

P. Paufler (Germany; Acta, JAC, JSR)

\section{Commission on International Tables}

Chair and Editor of Volume C

H. Fuess (Darmstadt University of Technology, Institute of Materials Science - Structure Research, Petersenstrasse 23, D-64287 Darmstadt, Germany)

Editor of Volume A

M. I. Aroyo (Spain)

Editor of Volume B

U. Shmueli (Israel) (retired; replacement to be appointed)

Editor of Volume D

A. Authier (France)

Editors of Volume $\mathbf{E}$

V. Kopský (Czech Republic), D. B. Litvin (USA)

Editors of Volume $F$

E. Arnold (USA), M. G. Rossmann (USA), D. M. Himmel (USA)

Editors of Volume $\mathbf{G}$

S. R. Hall (Australia), B. McMahon (UK)

Editors of Volume A1

U. Müller (Germany), H. Wondratschek (Germany)

\section{Commission on Aperiodic Crystals \\ Chair}

M. de Boissieu (Laboratoire de Thermo-

dynamique et Physico-Chimie Metallurgiques, BP 75, 38042 St Martin d'Heres, France)

Elected members

M. Baake (Germany), N. Bolotina (Russia), 
J. Hadermann (Belgium), R. Lifshitz (Israel), G. Madariaga (Spain), Y. Michiue (Japan), N. K. Mukhopadhyay (India), V. Petricek (Czech Republic), K. Saitoh (Japan), N. L. Speziali (Brazil)

\section{Commission on Biological Macromolecules}

Chair

E. Arnold (Center for Advanced Biotechnology and Medicine, Rutgers University, Department of Chemistry and Chemical Biology, 679 Hoes Lane, Piscataway, NJ 08854, USA)

Elected members

E. Garman (UK), R. C. Garratt (Brazil), P. L. Howell (Canada), M. Jaskolski (Poland), J. Martin (Australia), M. Martinez Ripoll (Spain), A. D. Podjarny (France), V. Samygina (Russia), Xiao-Dong Su (People's Republic of China), T. C. Terwilliger (USA), D. Turk (Slovenia), A. H.-J. Wang (Taipei) Ex officio member

H. M. Berman (USA; as Director of the PDB)

Commission on Charge, Spin and Momentum Densities

Chair

C. Gatti (CNR-ISTM Istituto di Scienze e

Tecnologie Molecolari, Via Golgi 19, I-20133

Milano, Italy)

\section{Elected members}

L. J. Farrugia (UK), B. Gillon (France),

K. Hämäläinen (Finland), B. Iversen

(Denmark), D. Jayatilaka (Australia),

P. Montano (USA), U. Pietsch (Germany),

Y. Sakurai (Japan), M. Takata (Japan)

Ex officio member

M. T. Fernandez-Diaz (Spain; as Chair of the Commission on Neutron Scattering)

Commission on Crystal Growth and Characterization of Materials

Chair

H. A. Dabkowska (Department of Physics and Astronomy, McMaster University, 1280 Main Street West, Hamilton, Ontario, Canada L8S 4M1)

\section{Elected members}

K. Byrappa (India), J. M. Garcia-Ruiz (Spain),

K. Kakimoto (Japan), Ch. Klemenz (USA),

D. Klimm (Germany), A. Moreno (Mexico),

J. Wang (People's Republic of China),

A. Zappettini (Italy)

Ex officio members

E. Vlieg (The Netherlands; as Representative of the International Organization of Crystal Growth), A. Pyzalla (Germany; as Editor of $J A C$ )

\section{Commission on Crystallographic Computing}

Chair

L. M. D. Cranswick (CNBC, National Research Council, Building 459, Station 18, Chalk River Laboratories, Chalk River, Ontario, Canada K0J 1J0)

\section{Elected members}

B. Carrozzini (Italy), R. W. Grosse-Kunstleve (USA), H. R. Powell (UK), J. Rius (Spain), K. Sekar (India), P. Turner (Australia), B. Winkler (Germany), M. Yao (Japan)

Commission on Crystallographic Nomenclature

Chair

A. Authier (Université Pierre et Marie Curie, Villechenine, 87470 Peyrat-le-Chateau,

France)

\section{Ex officio members}

G. Kostorz (Switzerland; as Editor-in-Chief of IUCr journals), D. Schwarzenbach (Switzerland; as Editor of Acta Cryst. Section A), C. P. Brock (USA; as Editor of Acta Cryst. Section B), A. Linden (Switzerland; as Editor of Acta Cryst. Section C), E. N. Baker (New Zealand; as a Main Editor of Acta Cryst. Section D), Z. Dauter (USA; as a Main Editor of Acta Cryst. Section D), W. T. A. Harrison (UK; as a Main Editor of Acta Cryst. Section E),

J. Simpson (New Zealand; as a Main Editor of Acta Cryst. Section E), M. Weil (Austria; as a Main Editor of Acta Cryst. Section E), H. M. Einspahr (USA; as a Main Editor of Acta Cryst. Section F), M. S. Weiss (Germany; as a Main Editor of Acta Cryst. Section F), G. E. Ice (USA; as a Main Editor of $J S R$ ), A. Kvick (France; as a Main Editor of JSR), T. Ohta (Japan; as a Main Editor of $J S R$ ), M. I. Aroyo (Spain; as Editor of Volume A of International Tables for Crystallography), H. Fuess (Germany; as Editor of Volume C of International Tables for Crystallography), V. Kopský (Czech Republic; as an Editor of Volume E of International Tables for Crystallography), D. B. Litvin (USA; as an Editor of Volume E of International Tables for Crystallography), M. G. Rossmann (USA; as an Editor of Volume F of International Tables for Crystallography), E. Arnold (USA; as an Editor of Volume F of International Tables for Crystallography), D. M. Himmel (USA; as an Editor of Volume F of International Tables for Crystallography), S. R. Hall (Australia; as an Editor of Volume G of International Tables for Crystallography), B. McMahon (UK; as an Editor of Volume G of International Tables for Crystallography), H. Wondratschek (Germany; as an Editor of Volume A1 of International Tables for Crystallography), U. Müller (Germany; as an Editor of Volume A1 of International Tables for Crystallography), D. Viterbo (Italy; as Chair of the IUCr/OUP Book Series Selection Committee), P. Spadon (Italy; as Chair of the Commission on Crystallographic Teaching), J. Hester (Australia; as Chair of the Committee for the Maintenance of the CIF Standard)

\section{Commission on Crystallographic Teaching}

\section{Chair}

P. Spadon (Dip. Scienze Chimiche, Via Marzolo 1, I-35131 Padova, Italy)

Elected members

R. F. Baggio (Argentina), E. Boldyreva (Russia), G. Chapuis (Switzerland), L. M. D. Cranswick (Canada), K. Kantardjieff (USA), M. Rademeyer (South Africa), M. Rossi (USA), S. Schmid (Australia), H. Uekusa (Japan)

Commission on Crystallography in Art and Cultural Heritage

Chair

E. Dooryheé (CNRS - Laboratoire de Cristallographie, 25 av. des Martyrs, BP 166, 38042 Grenoble Cedex, France)

Elected members

C. Abad-Zapatero (USA), G. R. Desiraju (India), E. Makovicky (Denmark), S. Quartieri (Italy), A. Rafalska-Lasocha (Poland), A. Thalal (Morocco), A. Zürn (Switzerland)

\section{Commission on Electron Crystallography}

\section{Chair}

L. D. Marks (Department of Materials Science and Engineering, 2220 N Campus Drive, Northwestern University, Evanston, IL 60201, USA)

\section{Elected members}

A. Avilov (Russia), J. Etheridge (Australia), J. Hadermann (Belgium), U. Kolb (Germany), L. M. Peng (People's Republic of China), N. Tanaka (Japan), X.-D. Zou (Sweden), J. M. Zuo (USA)

\section{Commission on High Pressure \\ Chair}

P. Dera (Geophysical Laboratory, Carnegie Institution of Washington, 5251 Broad Branch Road NW, Washington, DC 20015, USA) Elected members

R. Angel (USA), E. Boldyreva (Russia), F. Fabbiani (Germany), Y. Katayama (Japan), A. Katrusiak (Poland), Haozhe Liu (People's Republic of China), I. Loa (UK), S. A. T. Redfern (UK), V. Solozhenko (France)

\section{Commission on Inorganic and Mineral Structures \\ Chair \\ W. Depmeier (Institut für Geowissenschaften der Universität Kiel, Olshausenstr. 40, Kiel, D-24098, Germany)}


Elected members

T. M. L. Armbruster (Switzerland), H. Effenburger (Austria), P. Mercier (Canada), T. Nagai (Japan), D. Pandey (India), J. Rocha (Portugal), P. A. Thomas (UK), T. J. White (Singapore), O. V. Yakubovich (Russia)

Commission on Mathematical and Theoretical Crystallography

\section{Chair}

M. Nespolo (LCM3B, UMR - CNRS 7036, Université Henri Poincaré Nancy 1, Faculté des Sciences et Techniques, BP 239, Boulevard des Aiguillettes, F-54506 Vandoeuvre-lès-Nancy Cedex, France)

Elected members

M. I. Aroyo (Spain), J. G. Eon (Brazil), R. P. Felix (The Philippines), J. Fuksa (Czech Republic), S. Hyde (Australia), D. B. Litvin (USA), P. Paufler (Germany), D. M. Proserpio (Italy), E. E. Rams (Cuba), B. Souvignier (The Netherlands)

\section{Commission on Neutron Scattering}

Chair

M. T. Fernandex-Diaz (Institut LaueLangevin, av. des Martyrs, BP 156, 38042 Grenoble Cedex 9, France)

Elected members

V. L. Aksenov (Russia), R. Bau (USA), A. Harrison (France), T. Kamiyama (Japan), S. J. Kennedy (Australia), P. S. R. Krishna (India), P. Langan (USA), K. Lefmann (Denmark), W. W. Schmahl (Germany)

\section{Commission on Powder Diffraction}

\section{Chair}

P. Whitfield (Institute for Chemical Process and Environmental Technology, National Research Council Canada, Building M12, 1200 Montreal Road, Ottawa, Ontario, Canada K1A 0R6)

Elected members

S. Billinge (USA), E. Granado (Brazil), I. Madsen (Australia), D. Rafaja (Germany), R. Rizzi (Italy), K. Shankland (UK), L. Smrcok (Slovakia), B. H. Toby (USA), M. Yashima (Japan)

\section{Ex officio member}

J. A. Kaduk (USA; as Representative of the International Centre for Diffraction Data)

\section{Commission on Small-Angle Scattering}

\section{Chair}

J. S. Pedersen (Department of Chemistry, University of Aarhus, Langelandsgade 140, DK-8000 Aarhus C, Denmark)
Elected members

A. Allen (USA), A. Benedetti (Italy), P. R. Jemian (USA), R. Serimaa (Finland), J. Trewhella (USA), V. V. Volkov (Russia), N. Yagi (Japan)

\section{Commission on Structural Chemistry}

Chair

A. Bacchi (Dipartimento di Chimica Generale, University of Parma, Parco Area delle Scienze, 17A, I-43100 Parma, Italy)

Elected members

S. R. Batten (Australia), A. Beatty (USA), P. Bombicz (Hungary), S. A. Bourne (South Africa), M. T. L. Duarte (Portugal), F. Lahoz (Spain), A. Nangia (India), K. Ogawa (Japan), P. R. Raithby (UK)

\section{Commission on Synchrotron Radiation}

Chair

S. Wakatsuki (Photon Factory, Institute of Materials Structure Science (IMSS), High Energy Accelerator Research Organization (KEK), 1-1 Oho, Tsukuba, Ibaraki, Japan) Elected members

S.-L. Chang (Taiwan), R. Garrett (Australia), H. Graafsma (Germany), P. Grochulski (Canada), J. L. Hodeau (France), G. N. Kulipanov (Russia), P. N. Lee (USA), C. Nave (UK)

\section{Commission on XAFS}

Chair

I. Ascone (Division expériences, SynchrotronSoleil, L'Orme des Merisiers Saint-Aubin, BP 48, Gif-sur-Yvette Cedex, France) Elected members

K. Asakura (Japan), F. Boscherini (Italy), C. T. Chantler (Australia), P. Glatzel (France), B. Hedman (USA), F. Jalilehvand (Canada), Y.-L. Soo (Taipei)

\section{C2. Regional Associates}

American Crystallographic Association Representative

L. T. J. Delbaere (Department of Biochemistry, University of Saskatchewan, 107 Wiggins Road, Saskatoon, Saskatchewan, Canada S7N 5E5)

\author{
Asian Crystallographic Association \\ Representative \\ G. R. Desiraju (Indian Institute of Science, \\ Bangalore 560012, India)
}

\section{European Crystallographic Association}

Representative

C. J. Gilmore (Department of Chemistry, University of Glasgow, Glasgow G12 8QQ, UK)

\section{C3. Scientific Associates}

International Centre for Diffraction Data

\section{Representative}

P. Whitfield (Canada; ex officio as Chair of the Commission on Powder Diffraction)

International Organization of Crystal Growth Representative

H. A. Dabkowska (Canada; ex officio as Chair of the Commission on Crystal Growth and Characterization of Materials)

C4. Representatives on bodies not belonging to the Union

Interdivisional Committee on Terminology, Nomenclature and Symbols of the International Union of Pure and Applied Chemistry

\section{Representative}

A. Authier (Université Pierre et Marie Curie, Villechenine, 87470 Peyrat-le-Chateau, France)

\section{International Council for Scientific and} Technical Information

Representative

J. R. Helliwell (Department of Chemistry, University of Manchester, Oxford Road, Manchester M13 9PL, UK)

International Council for Science (ICSU)

Representative

Y. Ohashi (Japan; ex officio as Immediate Past President of the IUCr)

ICSU Committee on Data for Science and Technology

Representative

B. McMahon (International Union of Crystallography, 5 Abbey Square, Chester CH1 2HU, UK)

ICSU Committee on Space Research

\section{Representative}

H. A. Dabkowska (Canada; ex officio as Chair of the Commission on Crystal Growth and Characterization of Materials) 
Table 10

Adhering Bodies.

Adherence to the Union is in one of five Categories I-V, with corresponding voting powers and contributions as set out in Statutes 3.6, 5.5 and 9.4.

\begin{tabular}{|c|c|c|c|}
\hline Country & Category & Adhering Body & Secretary of National Committee \\
\hline Argentina & I & $\begin{array}{l}\text { Consejo Nacional de Investigaciones } \\
\text { Científicas y Técnicas }\end{array}$ & $\begin{array}{l}\text { D. G. Lamas, CINSO-CITEFA, J. B. de La Salle } 4397 \text { (B } 1603 \text { ALO), V. } \\
\text { Martelli, Prov. de Buenos Aires, Argentina }\end{array}$ \\
\hline Australia & III & Australian Academy of Science & $\begin{array}{l}\text { J. Mill, National Relations Officer, Australian Academy of Science, GPO } \\
\text { Box 783, Canberra, ACT 2601, Australia }\end{array}$ \\
\hline Austria & I & $\begin{array}{l}\text { Österreichische Akademie der } \\
\text { Wissenschaften }\end{array}$ & $\begin{array}{l}\text { E. Tillmanns, Institut für Mineralogie und Kristallographie, Universität } \\
\text { Wien - Geozentrum, Althanstrasse 14, Wien, Austria }\end{array}$ \\
\hline Belgium & II & $\begin{array}{l}\text { The Royal Academies for Science } \\
\text { and the Arts of Belgium }\end{array}$ & $\begin{array}{l}\text { L. Van Meervelt, Biomolecular Architecture, Chemistry Department, K. U. } \\
\text { Leuven, Celestijnenlaan 200F, B-3001 Leuven (Heverlee), Belgium }\end{array}$ \\
\hline Brazil & I & Brazilian Crystallographic Association & $\begin{array}{l}\text { I. Torriani, Institut de Física, Universidade Estadual de Campinas, } \\
\text { CP } 6165,13083-970 \text { Campinas SP, Brazil }\end{array}$ \\
\hline Canada & III & National Research Council & $\begin{array}{l}\text { J. D. Schrag, Biotechnology Research Institute, National Research } \\
\text { Council, } 6100 \text { Royalmount Avenue, Montréal, Quebec, Canada } \\
\text { H4P 2R2 }\end{array}$ \\
\hline Chile & I & $\begin{array}{l}\text { Comision Nacional de Investigación } \\
\text { Cientifica y Tecnologia }\end{array}$ & $\begin{array}{l}\text { A. Vega, Departamento de Ciencias Quimicas, Universidad Andres Bello, } \\
\text { Republica 275, Santiago, Chile }\end{array}$ \\
\hline China, People's Republic of & IV & Academia Sinica & $\begin{array}{l}\text { Xiao-Dong Su, Lifes Science College, Peking University, Beijing 100871, } \\
\text { People's Republic of China }\end{array}$ \\
\hline China, Taipei & II & $\begin{array}{l}\text { The Academy of Sciences Located in } \\
\text { Taipei }\end{array}$ & $\begin{array}{l}\text { S. M. Peng, Department of Chemistry, National Taiwan University, } \\
\text { Taipei }\end{array}$ \\
\hline Croatia & I & $\begin{array}{l}\text { Croatian Crystallographic Association } \\
\text { (under the auspices of the Croatian } \\
\text { Academy of Science and Arts) }\end{array}$ & $\begin{array}{l}\text { M. Luic, Ruder Boskovic Institute, Bijenicka cesta 54, POB 180, } 1002 \\
\text { Zagreb, Croatia }\end{array}$ \\
\hline Czech and Slovak Republics & II & $\begin{array}{l}\text { Regional Committee of Czech and } \\
\text { Slovak Crystallographers }\end{array}$ & $\begin{array}{l}\text { R. Kuzel, Faculty of Mathematics and Physics, Charles University, Ke } \\
\text { Karlovu 3, } 121 \text { 16 Praha 2, Czech Republic }\end{array}$ \\
\hline Denmark & I & $\begin{array}{l}\text { Royal Danish Academy of Sciences } \\
\text { and Letters }\end{array}$ & $\begin{array}{l}\text { J.-E. Jorgensen, Department of Chemistry, University of Aarhus, DK-8000 } \\
\text { Aarhus C, Denmark }\end{array}$ \\
\hline Egypt, Arab Republic of & I & $\begin{array}{l}\text { Academy of Scientific Research and } \\
\text { Technology }\end{array}$ & M. M. Radwan, Faculty of Engineering in Fayoum, Fayoum, Egypt \\
\hline Finland & I & $\begin{array}{l}\text { Suomen Tiedeakatemiain } \\
\text { Valtuuskunta }\end{array}$ & $\begin{array}{l}\text { M. Blomberg, Department of Physical Sciences, PO Box 64, University of } \\
\text { Helsinki, FIN-00014 Helsinki, Finland }\end{array}$ \\
\hline France & IV & $\begin{array}{l}\text { Académie des Sciences (Institut de } \\
\text { France) }\end{array}$ & $\begin{array}{l}\text { V. Etgens, Association Française de Cristallographie, Tour 16, } 4 \text { place } \\
\text { Jussieu, F-75252 Paris Cedex 05, France }\end{array}$ \\
\hline Germany & IV & $\begin{array}{l}\text { Deutsche Gesellschaft für } \\
\text { Kristallographie }\end{array}$ & $\begin{array}{l}\text { W. Neumann, Institut für Physik (Kristallographie), Invalidenstrasse 110, } \\
\text { D-10115 Berlin, Germany }\end{array}$ \\
\hline Greece & I & Hellenic Crystallographic Association & $\begin{array}{l}\text { D. Mentzafos, Physics Laboratory, Agricultural University of Athens, } \\
\text { Athens, Greece }\end{array}$ \\
\hline Hungary & I & Magyar Tudományos Akadémia & $\begin{array}{l}\text { P. Bombicz, Institute of Chemistry, Chemical Research Center, } \\
\text { Hungarian Academy of Sciences, H-1525 Budapest, POB 17, Hungary }\end{array}$ \\
\hline India & III & Indian National Science Academy & $\begin{array}{l}\text { P. Chakrabarti, Department of Biochemistry, Bose Institute, P-1/12 CIT } \\
\text { Scheme VII M, Kolkata-700 054, India }\end{array}$ \\
\hline Israel & I & $\begin{array}{l}\text { Israel Academy of Sciences and } \\
\text { Humanities }\end{array}$ & $\begin{array}{l}\text { M. Harel, Department of Structural Biology, The Weizmann Institute of } \\
\text { Science, Rehovot } 76100 \text {, Israel }\end{array}$ \\
\hline Italy & III & Consiglio Nazionale delle Ricerche & $\begin{array}{l}\text { C. Mealli, Istituto di Chimica dei Composti OrganoMetallici - ICCOM } \\
\text { CNR, Area di Ricerca CNR di Firenze, Via Madonna del Piano 10, } \\
50019 \text { Sesto Fiorentino (Firenze), Italy }\end{array}$ \\
\hline Japan & IV & Science Council of Japan & $\begin{array}{l}\text { Y. Kai, Department of Environmental and Biotechnological Frontier } \\
\text { Engineering, Fukui University of Technology, Gakuen 3-6-1, Fukui 910- } \\
\text { 8505, Japan }\end{array}$ \\
\hline Korea, Republic of & I & Korean Crystallographic Association & $\begin{array}{l}\text { S. W. Suh, Department of Chemistry, College of Natural Sciences, Seoul } \\
\text { National University, Seoul, 151-747, Republic of Korea }\end{array}$ \\
\hline Mexico & I & $\begin{array}{l}\text { Consejo Nacional de Ciencia y } \\
\text { Tecnologia }\end{array}$ & $\begin{array}{l}\text { L. Bucio Galindo, Instituto de Fisica, UNAM, Departamento de Estado } \\
\text { Solido, Circuito de la Investigacion Cientifica s/n, Cd. Universitaria, } \\
\text { Mexico, DF, PO Box 20-364, CP 01000, Mexico }\end{array}$ \\
\hline Netherlands & II & $\begin{array}{l}\text { The Dutch Association for } \\
\text { Crystallography (NVK) }\end{array}$ & $\begin{array}{l}\text { R. Peschar, Laboratory for Crystallography, Van't Hoff Institute for } \\
\text { Molecular Sciences (HIMS), Faculty of Science (FNWI), Universiteit } \\
\text { van Amsterdam, Valckenierstraat 65, Kr. 1.43, 1018 XE Amsterdam, The } \\
\text { Netherlands }\end{array}$ \\
\hline New Zealand & I & The Royal Society of New Zealand & $\begin{array}{l}\text { J. Weston, The Royal Society of New Zealand, PO Box 598, Wellington, } \\
\text { New Zealand }\end{array}$ \\
\hline Norway & I & Det Norske Videnskaps-Akademi & $\begin{array}{l}\text { B. Fjaertoft, Institute of Pharmacy, University of Oslo, PO Box 1068, } \\
\text { Blindern, } 0316 \text { Oslo, Norway }\end{array}$ \\
\hline Poland & I & Polska Akademia Nauk & $\begin{array}{l}\text { M. Wolcyrz, Institute of Low Temperature and Structure Research, Polish } \\
\text { Academy of Sciences, PO Box 1410, 50-950 Wroclaw 2, Poland }\end{array}$ \\
\hline Portugal & I & Sociedade Portuguesa de Fisica & $\begin{array}{l}\text { A. M. Damas, Instituto de Biologia Molecular e Celular, R. do Campo } \\
\text { Alegre, } 823,4150 \text { Porto, Portugal }\end{array}$ \\
\hline Regional Committee - AsCA & I & $\begin{array}{l}\text { Regional Committee of Crystallogra- } \\
\text { phers from Bangladesh, Malaysia, } \\
\text { Singapore, Thailand and Vietnam }\end{array}$ & $\begin{array}{l}\text { H. K. Fun, X-ray Crystallography Unit, School of Physics, Universiti Sains } \\
\text { Malaysia, } 11800 \text { USM, Penang, Malaysia }\end{array}$ \\
\hline Regional Committee - ECA & I & $\begin{array}{l}\text { Regional Committee of Crystallogra- } \\
\text { phers from Algeria, Latvia, Morocco, } \\
\text { Tunisia, Turkey and Ukraine }\end{array}$ & $\begin{array}{l}\text { E. Kendi, Department of Physics Engineering, Hacettepe University, } 06532 \\
\text { Beytepe, Ankara, Turkey }\end{array}$ \\
\hline Russia & $\mathrm{V}$ & Russian Academy of Sciences & $\begin{array}{l}\text { N. I. Sorokina, Institute of Crystallography, Russian Academy of Sciences, } \\
\text { Leninsky pr. 59, Moscow 119333, Russia }\end{array}$ \\
\hline Serbia & I & $\begin{array}{l}\text { Serbian Ministry for Science and } \\
\text { Technology }\end{array}$ & $\begin{array}{l}\text { A. Rosic, Belgrade University Computing Center, Kumanovska bb, } \\
\text { Belgrade, Serbia }\end{array}$ \\
\hline Slovenia & I & $\begin{array}{l}\text { Slovenian Ministry of Science and } \\
\text { Technology }\end{array}$ & $\begin{array}{l}\text { I. Leban, Department of Chemistry and Chemical Technology, } \\
\text { University of Ljubljana, PO Box 537, SI-1001 Ljubljana, Slovenia }\end{array}$ \\
\hline
\end{tabular}


Table 10 (continued)

\begin{tabular}{|c|c|c|c|}
\hline Country & Category & Adhering Body & Secretary of National Committee \\
\hline South Africa & II & National Research Foundation & $\begin{array}{l}\text { B. Mnyatheli, South African ICSU Secretariat, National Research } \\
\text { Foundation, PO Box 2600, Pretoria 0001, South Africa }\end{array}$ \\
\hline Spain & III & $\begin{array}{l}\text { Subdirección General de Organismos y } \\
\text { Programas Internacionales, Minis- } \\
\text { terio de Ciencia y Tecnologia }\end{array}$ & $\begin{array}{l}\text { E. Gutierrez Puebla, Instituto de Ciencia de Materiales de Madrid, CSIC, } \\
\text { Cantoblanco, E-28049 Madrid, Spain }\end{array}$ \\
\hline Sweden & II & Kungliga Vetenskapsakademien & $\begin{array}{l}\text { A. Sjögren, Svenska Kemistsamfundet, Wallingatan 24, } 11123 \text { Stockholm, } \\
\text { Sweden }\end{array}$ \\
\hline Switzerland & II & $\begin{array}{l}\text { Schweizerische Gesellschaft für } \\
\text { Kristallographie }\end{array}$ & $\begin{array}{l}\text { M. Hennig, F. Hoffmann - La Roche, Pharma Research 65/319, CH-4070 } \\
\text { Basel, Switzerland }\end{array}$ \\
\hline UK & $\mathrm{V}$ & $\begin{array}{l}\text { The British Crystallographic } \\
\text { Association }\end{array}$ & $\begin{array}{l}\text { G. M. Rosair, School of EPS - Chemistry, Perkin Building, Heriot-Watt } \\
\text { University, Edinburgh EH14 4AS, UK }\end{array}$ \\
\hline USA & V & $\begin{array}{l}\text { National Academy of Sciences } \\
\text { - National Research Council }\end{array}$ & $\begin{array}{l}\text { D. Ohlendorf, Department of Biochemistry, Molecular Biology and } \\
\text { Biophysics, 6-155 Jackson Hall, University of Minnesota, Minneapolis, } \\
\text { MN 55455, USA }\end{array}$ \\
\hline
\end{tabular}

\section{APPENDIX $D$ \\ Adhering Bodies and National Committees for Crystallography}

\section{D1. Adhering Bodies}

Details of the Adhering Bodies are given in Table 10

\section{D2. National Committees for Crystallo- graphy}

\section{Argentina}

R. Baggio (Chair), D. G. Lamas, G. Punte Australia

J. Martin (Chair), B. J. Kennedy, K. Nugent, R. Robinson, M. Spackman, J. Varghese, S. Wilkins, R. Withers

Austria

E. Tillmanns (Chair), P. Fratzl, H. Heritsch, P. Laggner, A. Preisinger, K.-H. Schwarz, J. Zemann

\section{Belgium}

P. Thiry (Chair), K. H. Michel (Vice-Chair), J.-P. Declercq, L. Dupont, G. H. Evrard, L. V. A. Fiermans, D. Maes, J. Naud, H. Reynaers, B. G. A. F. Tinant, J. Van Beeumen, G. G. R. Van Den Bossche, J. F. Van Landuyt, L. Van Meervelt, V. Villeret

Brazil

N. L. Speziali (Chair), Y. P. Mascarenhas, I. Torriani

\section{Canada}

L. T. J. Delbaere (Chair), J. F. Britten (ViceChair), T. S. Cameron, L. M. D. Cranswick, M. Fraser, L. A. Groat, J. D. Schrag, P. Whitfield

Chile

M. T. Garland (Chair), J. A. Costamagna, J. Garin, M. Suwalsky, A. Vega

\section{China, People's Republic of}

Min Nai-ben (Chair), Bai Chun-li, Chang

Wen-rui, Chen Xiao-long, Fan Hai-fu, Jin Xiang-lin, Lin Shao-fan, Mai Zhen-hong, Miao Fang-ming, Niu Li-wen, Peng Lian-mao, Rao Zi-he, Tao Kun, Wang Ji-yang, Wu Xin-tao, Xian Ding-chang, Zhang Ze, Zheng Qi-tai
China, Taipei

Yu Wang (Chair), S.-L. Chang, C.-H. Lee, Y.-C. Liaw, K.-H. Lii, L.-K. Liu, C.-P. Tang, S.-C. Yu, H.-S. Yuan

Croatia

S. Popović (Chair), D. Matković-Calogović (Vice-Chair), M. Luić, D. Tibljas, A. Tonejc,

A. Visnjevac, K. Vlahovicek

Czech and Slovak Republics

M. Koman (Chair), R. Kuzel (Vice-Chair and Secretary), L. Caplovic, J. Cernak, J. Hrdy, I. Kuta-Smatanova, D. Miklos, P. Mikulik Denmark

G. R. Andersen (Chair), R. Feidenhans'l, K. Frydenvang, A. Horsewell, J. E. Joergensen, S. Larsen, C. McKenzie, J. S. Pedersen, H. B. Rasmussen, K. Ståhl, T. B. Zumic Egypt, Arab Republic of M. S. Ahmed (Chair), Y. M. Abbas, A. M. Abdel-Rahman, N. A. Ahmed, S. A. A. Arafa, F. A. Deif, K. El-Sayed, I. S. A. Farag, M. A. Gaffar, F. M. Helmi, K. H. A. Mady, M. M. Radwan, A. A. Ramadan, A. H. Rasmy Finland

K. Hämäläinen (Chair), T. Glumoff, O. Ikkala, I. Mutikainen, J. Rouvinen, J. U. Valkonen France

J.-C. Daran (Chair), V. Etgens, D. Grebille, J.-L. Hodeau, J. Navaza

\section{Germany}

W. Neumann (Chair), H.-D. Bartunik,

U. Bismayer, W. Depmeier, P. Luger, T. Schleid,

E. Weckert

Greece

M. Calamiotou (Chair), I. M. Mavridis (ViceChair), C. A. Kavounis, F. D. Leonidas,

D. Mentzafos

Hungary

G. Faigel (Chair), A. Benyei, P. Bombicz,

A. Kálmán, L. Koszegi, L. Kovacs, J. Labar,

G. Naray-Szabo, G. Radnóczi, K. Simon,

E. Svab, T. Ungár, T. Weiszburg
India

P. Chakrabarti (Chair), K. Byrappa, G. R. Desiraju, S. K. Halder, A. Nangia, C. G. Suresh Israel

N. Adir (Chair), M. Harel, M. Kapon

Italy

R. Oberti (Chair), G. Artioli, M. Bolognesi,

E. Chiancone, V. Martorana, C. Mealli,

C. Paorici, R. Spagna

Japan

S. Sasaki (Chair), J. Akimitsu, S. Iijima, M. Irie, Y. Kai, K. Kurihara, K. Nishikawa, T. Ohachi,

Y. Ohashi, T. Sugawara, J. Takahara,

K. Takayanagi, Y. Waseda

Korea, Republic of

S. W. Suh (Chair), J. T. Ahn, U. U. Chi, S. I. Cho, Y. K. Cho, S. J. Chung, H. J. Kim, H. S. Kim, Y. H. Kim, Y. J. Park

Mexico

J. L. Bucio Galindo (Chair), J. L. Aragon Vera, L. Banos Lopez, S. Bernes Flouriot, J. L. L.

Boldu Olaizola, G. Cabanas Moreno, O. Cano Corona, M. A. Castellanos Roman, A. E. Cordero Borboa, N. E. Garcia Calderon, M. Hesiquio Garduno, E. Horjales Reboredo, V. M. Malpica Cruz, E. A. Munoz Picone, J. Ornelas Tabares, J. Palacios Gomez, A. Reyes Arellano, J. Reyes Gasga, J. Rickards Campbell, D. Rios Jara, R. Rodriguez Mijangos, D. Romeo Casajuana, H. Terrones Maldonado, R. Alfredo Toscano, E. Villafuerte Castrejon

Netherlands

E. Vlieg (Chair), R. de Gelder, H. Kooijman,

R. Peschar, C. Reiss, L. Woning

New Zealand

E. N. Baker (Chair), G. J. Gainsford,

G. Jameson, B. K. Nicholson, W. T. Robinson, J. Simpson

Norway

C. H. Görbitz (Chair), B. Fjaertoft, J. K.

Gjønnes, K. W. Törnroos 


\section{international union of crystallography}

\section{Poland}

A. Pietraszko (Chair), G. D. Bujacz,

S. Hodorowicz, E. Lagiewka, J. Lipkowski,

K. Łukaszewicz, A. Szytula, M. Wolcyrz,

J. Żmija

Portugal

M. M. R. Da Costa (Chair), A. M. Damas, M. T. Duarte

Regional Committee - AsCA

W. Klooster (Chair), H. K. Fun, A. Hussain,

Thammarat Aree, N. Van Tri

Regional Committee - ECA

A. Thalal (Chair), A. Bekka, E. Kendi,

A. Mishnev, N. Bouhmaida, M. Debbabi,

A. Haddad, S. Özbey, R. Gladyshevskii,

M. Bulanova

Russia

Yu. A. Ossipyan (Chair), M. V. Kovalchuk

(Vice-Chair), S. M. Aldoshin, K. S.

Aleksandrov, M. Yu. Antipin, L. A.

Aslanov, L. O. Atovmyan, E. V.

Chuprunov, G. N. Kulipanov, V. V.

Kvardakov, D. Yu. Pushcharovsky,
V. Sh. Shekhtman, R. P. Shibaeva,

V. I. Simonov, Yu. I. Smolin, N. I.

Sorokina, S. M. Stishov, V. S. Urusov,

S. I. Zheludeva

Serbia

A. Kremenović (Chair), A. Kapor (Vice-

Chair), B. Antic, B. Bogdanović, A. Rosic,

S. Stanković, S. Trifunović

Slovenia

L. Golic (Chair), V. Kaučič, I. Leban,

A. Prodan

South Africa

D. C. Levendis (Chair), L. J. Barbour,

J. C. A. Boeyens, S. A. Bourne,

J. P. R. De Villiers, C. Esterhuysen (observer),

A. Jacobs (observer), G. J. Kruger, L. R.

Nassimbeni, A. Roodt, A. Venter

Spain

C. Miravitlles Torras (Chair), M. I.

Arriortua Marcaida, S. Garcia Granda,

J. M. Garcia Ruiz, P. Gomez Sal,

E. Gutierrez Puebla, F. J. Lahoz Diaz,

J. Rius Palleiro
Sweden

S. Nordholm (Chair), L. I. Elding,

A. Hartmanis, K. Holmberg, Y. Lindqvist, J.-E. Nyström, E. Sauer-Eriksson, A. Sjögren

Switzerland

W. Steurer (Chair), M. Hennig, H. J. Scheel,

J. Schefer, M. Schiltz, K. Yvon

UK

E. F. Garman (Chair), D. Beveridge, A. J. Blake, J. Charmant, W. Clegg, R. Cooper, P. Fewster, A. Goeta, A. Griffin, S. Huth, A. Kavanagh, H. R. Powell, M. R. Probert, P. R. Raithby, G. M. Rosair, C. H. Schwalbe, D. Thompson, M. G. Tucker USA

K. A. Kantardjieff (Chair), C. Cahill, G. Calabrese, J. Y. Chan, M. Clegg, F. F. Crimm, A. Ferreras, P. Gamble, A. Joachimiak, J. Kelly, C. Lind, K. B. Mathae, S. Misture, J. Ng, D. Ohlendorf, C. J. Rawn, M. Rossi, B. Rupp, B. D. Santarsiero, S. Sheriff, J. Swift, B. Toby, P. Vekilov, R. Von Dreele, P. Voyles, A. P. Wilkinson, V. G. Young Jr 